Cristiane Andretta Francisco

\title{
A produção do conhecimento sobre o Ensino de Química no Brasil: um olhar a partir das Reuniões Anuais da Sociedade Brasileira de Química
}

Dissertação apresentada ao Instituto de Química de São Carlos, da Universidade de São Paulo para obtenção do título de Mestre em Ciências (Química Analítica)

Orientadora: Profa. Dra. Salete Linhares Queiroz 
Dedico este trabalho a minha grande mestra, amiga e mãe Jandyra (in memorian), que dedicou grande parte de sua vida a alfabetizar inúmeras pessoas que um dia cruzaram em seu caminho. 


\section{AGRADECIMENTOS}

* A Deus pela minha vida, inspiração e iluminação em todos os momentos e em especial neste trabalho.

* Ao Instituto de Química de São Carlos/USP pela oportunidade do desenvolvimento e conclusão do presente trabalho.

* À Profa. Dra. Salete Linhares Queiroz pela paciência, segura orientação e autonomia durante o transcurso da pesquisa.

* À Secretaria da Pós-Graduação e à Biblioteca do IQSC pelo pronto atendimento e auxílio durante o desenvolvimento deste trabalho.

* À Pró-Reitoria de Pós-Graduação da USP, pela bolsa PAE concedida no segundo semestre de 2005 e pelo apoio financeiro na participação em eventos.

* A CAPES pelo auxílio financeiro.

* Aos colegas de grupo Luciana (Lu), Jane, Luciana Massi, Daniel e aos que já passaram pelo grupo (Fábio, Flávio, Ribeiro e Gelson) pela amizade e companheirismo durante o período que passamos juntos na salinha.

* Aos meus pais, Jandyra (in memorian) e Ilídio (in memorian) por terem me gerado, terem me dado a oportunidade de continuar meus estudos e assim, permitindo que eu chegasse até esta etapa de minha formação.

* Aos meus avós, Gioconda (in memorian) e Carlos João (in memorian) que ajudaram meus pais na minha educação durante a infância.

* As minhas amigas: Ana Paula pelo incentivo a retomar meus estudos; Virgínia pela suas orações e por estar ao meu lado não só nas horas alegres, mas também de sempre oferecer seu ombro amigo nos momentos de angústia e tristeza; Fátima, Cléo, Ritinha, Benê e Zeti por suas orações, nas quais ajudaram a fortalecer a minha fé e esperança na superação dos obstáculos que encontrei em minha caminhada até aqui.

* Ao Rafael e ao Adauto, que me ensinou a utilizar algumas das facilidades do Excel para proceder com a análise dos dados coletados durante a pesquisa.

* E não poderia deixar de agradecer a todos que direta ou indiretamente contribuíram de alguma maneira para a concretização deste trabalho. 
“ Há pessoas que desejam saber só por saber, e isso é curiosidade; outras para alcançarem fama, e isso é vaidade; outras para enriquecerem com a sua ciência, e isso é um negócio torpe; outras para serem edificadas, e isso é prudência; e outras para edificarem a outros, e isso é caridade."

S. Tomás de Aquino 


\section{RESUMO}

Este trabalho discute a produção acadêmica brasileira na área de Educação em Química. A principal fonte de informação utilizada foi a Reunião Anual da Sociedade Brasileira de Química (RASBQ), no período de 1999 a 2005. Todos os resumos apresentados na seção de Ensino de Química das RASBQs foram investigados com o intuito de se promover uma discussão sobre o desenvolvimento da área no Brasil. Os resumos foram estudados em função dos seguintes aspectos: ano de apresentação, região brasileira de produção, instituição e unidade responsável pela pesquisa, nível escolar abrangido no estudo e foco temático do estudo.

Os resultados sugerem que a Educação em Química no Brasil é uma área bem estabelecida entre as demais áreas clássicas da Química, com um grande número de grupos de pesquisa. A área vem se consolidando continuamente, em especial nos últimos 5 anos.

As análises realizadas indicaram: (a) um aumento no número absoluto de resumos apresentados na seção de Ensino de Química de 1999 a 2005; (b) uma alta concentração da produção na região Sudeste; (c) uma alta concentração da produção em algumas universidades; (d) uma elevada incidência de estudos sobre o Ensino Básico; (e) uma irregularidade da produção no que diz respeito aos focos temáticos. Existem alguns tópicos que necessitam de uma atenção especial para que sejam satisfatoriamente estudados.

Finalmente, a partir dos resultados provenientes do trabalho, algumas considerações são feitas com relação ao presente e ao futuro da área em foco. 


\section{ABSTRACT}

This work discusses the Brazilian academic production on Chemical Education. The main source of information was the annual meeting of the Brazilian Chemical Society (RASBQ) covering the period 1999-2005. All the papers presented at Teaching of Chemistry Division of the RASBQ were investigated to permit a discussion about the development of the area in Brazil. About such papers, it develops a bibliographical revision research, whose parameters comprise the following aspects: year of presentation, Brazilian region of production, institution and academic unit responsible for the research, scholastic level encompassed in the study and thematic focus of the study.

The results suggest that the Chemical Education in Brazil is now a well established area of research within the classical areas of the Chemistry, with a large number of research groups. The area is continuously improving, particularly during the last 5 years

The relevant findings concern: (a) an increase in the absolute number of papers from 1999 to 2005; (b) a high concentration of research in the southeast region; (c) a high concentration of works from some universities; (d) a great incidence of studies about basic school; (e) a dispersion and irregularity of the production in the thematic focus. There are some topics that require a focused attention for proper evolution.

Finally, taking into account the outcomes of this study, some considerations are made on the present and the future of this field. 


\section{LISTA DE ILUSTRAÇÕES}

Figura 1. Evolução da representatividade da seção de ED nas RASBQs no período de 1999 a 2005.

Figura 2. Distribuição dos trabalhos de acordo com a região geográfica brasileira apresentados na seção de ED nas RASBQs no período de 1999 a 2005.....

Figura 3. Gráfico de distribuição de IES com maior número de trabalhos apresentados na seção de ED nas RASBQs no período de 1999 a 2005.

Figura 4. Distribuição dos trabalhos de acordo com o nível de escolaridade brasileira apresentados na seção de ED nas RASBQs no período de 1999 a 2005.......

Figura 5. Distribuição dos trabalhos de acordo com o foco temático apresentado na seção de ED nas RASBQS no período de 1999 a 2005. 


\section{LISTA DE TABELAS}

Tabela 1. Distribuição absoluta e percentual dos resumos na seção de ED no período de 1999 a 2005

Tabela 2. Número (absoluto e relativo) de resumos apresentados por seção nas RASBQs no período de 1999 a 2005.

Tabela 3. Distribuição dos resumos apresentados na seção de ED nas RASBQs de acordo com as regiões geográficas brasileira no período de 1999 a 2005.

Tabela 4. Número de IES distribuídos de acordo com as regiões geográficas brasileiras e setores administrativos.

Tabela 5. Distribuição dos trabalhos resultantes de interações entre pesquisadores de diferentes regiões geográficas brasileiras apresentados na seção de ED nas RASBQs no período de 1999 a 2005.

Tabela 6. Distribuição dos trabalhos da seção de ED que não mencionam a instituição de produção, no período de 1999 a 2005.

Tabela 7. Distribuição de parte dos trabalhos da seção de ED de acordo com a Instituição de Ensino Superior de origem de produção no período de 1999 a 2005

Tabela 8. Distribuição dos trabalhos apresentados na seção de ED nas RASBQs de acordo com interações entre áreas de Ciências Humanas e Ciências Exatas no período de 1999 a 2005

Tabela 9. Distribuição dos trabalhos na seção de ED nas RASBQs de acordo com o nível escolar abrangido no período de 1999 a 2005

Tabela 10. Distribuição dos trabalhos com mais de um nível de escolaridade apresentados na seção de ED das RASBQs no período de 1999 a 2005......

Tabela 11. Distribuição dos trabalhos da seção de ED das RASBQs de acordo com os focos temáticos no período de 1999 a 2005. 


\section{LISTA DE ABREVIATURAS OU SIGLAS}

\begin{tabular}{|c|c|}
\hline ABRAPEC & Associação Brasileira de Pesquisa em Educação em Ciências \\
\hline Anped & Associação Nacional de Pós-Graduação e Pesquisa em Educação \\
\hline CAPES & Coordenação de Aperfeiçoamento de Pessoal de Nível Superior \\
\hline CBQ & Congresso Brasileiro de Química \\
\hline CEFETQ-Nilópolis & Centro Federal de Educação Tecnológica de Química de Nilópolis \\
\hline CEFET-RJ & Centro Federal de Educação Tecnológica do Rio de Janeiro \\
\hline CTS & Ciência, Tecnologia e Sociedade \\
\hline DCE & Diretório Central de Estudantes \\
\hline EAD & Educação à Distância \\
\hline ECODEQ & Encontro Centro-Oeste de Debates sobre o Ensino de Química \\
\hline ED & Ensino de Química \\
\hline EDEQ & Encontro de Debates sobre o Ensino de Química \\
\hline ENEQ & Encontro Nacional de Ensino de Química \\
\hline ENNEQ & Encontro Norte-Nordeste de Ensino de Química \\
\hline ENPEC & Encontro Nacional de Pesquisa em Educação em Ciências \\
\hline EPPEQ & Encontro Paulista de Pesquisa em Ensino de Química \\
\hline ESEQ & Encontro Sudeste de Ensino de Química \\
\hline FIOCRUZ & Fundação Oswaldo Cruz \\
\hline FoCo & Programa de Formação Continuada de Professores \\
\hline GT & Grupo de Trabalho \\
\hline IES & Instituição de Ensino Superior \\
\hline INEP & Instituto Nacional de Estudos e Pesquisas Educacionais \\
\hline Intercom & Sociedade Brasileira de Estudos Interdisciplinares da Comunicação \\
\hline MEC & Ministério da Educação \\
\hline ONG & Organização Não-Governamental \\
\hline PCN & Parâmetros Curriculares Nacionais \\
\hline PCNEM & Parâmetros Curriculares Nacionais para o Ensino Médio \\
\hline PUC-RS & Pontifícia Universidade Católica do Rio Grande do Sul \\
\hline RASBQ & Reunião Anual da Sociedade Brasileira de Química \\
\hline SBQ & Sociedade Brasileira de Química \\
\hline UCB & Universidade Católica de Brasília \\
\hline UEL & Universidade Estadual de Londrina \\
\hline UEM & Universidade Estadual de Maringá \\
\hline UESB & Universidade Estadual do Sudoeste da Bahia \\
\hline UFBA & Universidade Federal da Bahia \\
\hline UFC & Universidade Federal do Ceará \\
\hline UFF & Universidade Federal Fluminense \\
\hline UFG & Universidade Federal de Goiás \\
\hline UFMG & Universidade Federal de Minas Gerais \\
\hline UFMS & Universidade Federal de Mato Grosso do Sul \\
\hline UFPA & Universidade Federal do Pará \\
\hline UFPE & Universidade Federal de Pernambuco \\
\hline UFRGS & Universidade Federal do Rio Grande do Sul \\
\hline UFRJ & Universidade Federal do Rio de Janeiro \\
\hline UFRPE & Universidade Federal Rural de Pernambuco \\
\hline UFRR & Universidade Federal de Roraima \\
\hline UFS & Universidade Federal de Sergipe \\
\hline
\end{tabular}


UFSC

UFV

ULBRA

UnB

UNESP

UNICAMP

UNICENTRO

UNICSUL

UNIJUI

UNISC

USP
Universidade Federal de Santa Catarina

Universidade Federal de Viçosa

Universidade Luterana do Brasil

Universidade de Brasília

Universidade Estadual Paulista Júlio de Mesquita

Universidade Estadual de Campinas

Universidade Estadual do Centro-Oeste do Paraná

Universidade Cruzeiro do Sul

Universidade do Noroeste do Estado do Rio Grande do Sul

Universidade de Santa Cruz do Sul

Universidade de São Paulo 


\section{SUMÁRIO}

RESUMO

ABSTRACT

LISTA DE ILUSTRAÇÕES

LISTA DE TABELAS

LISTA DE ABREVIATURAS OU SIGLAS

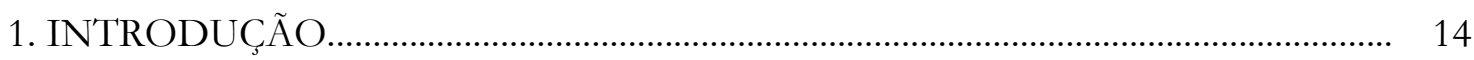

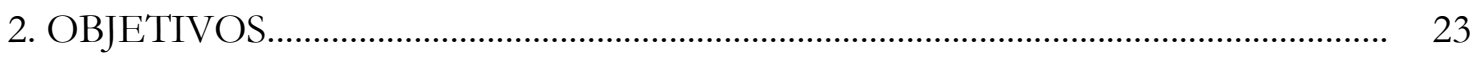

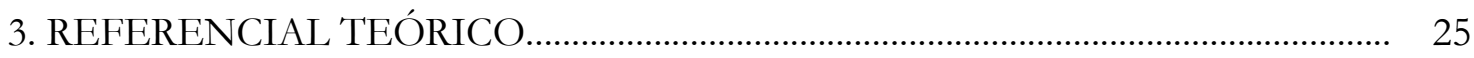

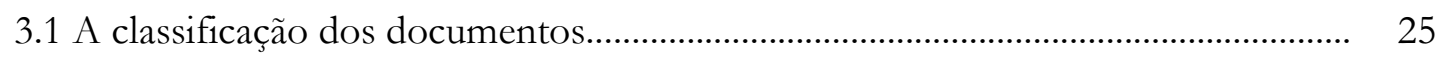

3.1.1 Classificação do nível escolar..................................................................... 26

3.1.2 Classificação por foco temático de investigação............................................... 27

4. METODOLOGIA DE PESQUISA............................................................................. 33

4.1 Identificação dos trabalhos pertencentes à seção de Ensino de Química..... 34

4.2 Configuração dos aspectos de classificação e descrição dos trabalhos..................... 35

4.3 Organização dos dados bibliográficos em fichas de classificação............................ 36

4.4 Organização dos resultados.................................................................................... 39

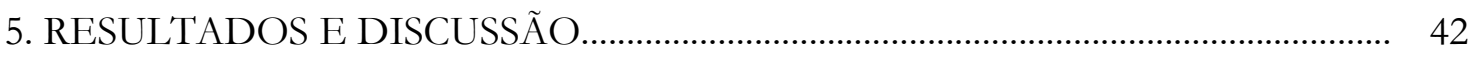

5.1 A produção e sua distribuição no tempo e representatividade de acordo com o número de trabalhos apresentados nas seções das RASBQs................................... 42

5.2 A produção e sua distribuição de acordo com as regiões brasileiras....................... 45

5.3 A produção e sua distribuição por instituições acadêmicas....................................... 51

5.4 A produção e sua distribuição de acordo com o nível escolar abrangido no estudo...

5.5 A produção e sua distribuição de acordo com o foco temático............................... 64

5.5.1 Trabalhos sobre Currículos e Programas....................................................... 66

5.5.2 Trabalhos sobre Conteúdo-Método............................................................ 69

5.5.3 Trabalhos sobre Recursos Didáticos.......................................................... 72 
5.5.4 Trabalhos sobre Características do Professor................................................ 75

5.5.5 Trabalhos sobre Características do Aluno..................................................... 77

5.5.6 Trabalhos sobre Formação de Conceitos........................................................ 79

5.5.7 Trabalhos sobre Formação Continuada de Professores............................... 81

5.5.8 Trabalhos sobre Formação Inicial de Professores.......................................... 82

5.5.9 Trabalhos sobre Políticas Públicas......................................................................... 84

5.5.10 Trabalhos sobre Organização da Escola...................................................... 85

5.5.11 Trabalhos sobre Programa de Ensino Não Escolar....................................... 87

5.5.12 Trabalhos sobre Filosofia da Ciência......................................................... 88

5.5.13 Trabalhos sobre História da Ciência............................................................... 89

5.5.14 Trabalhos sobre História do Ensino de Ciências............................................ 90

5.5.15 Trabalhos sobre Foco Temático Outro.......................................................... 90

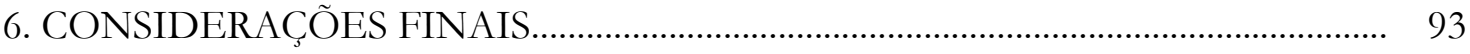

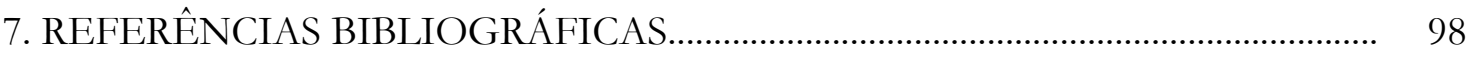

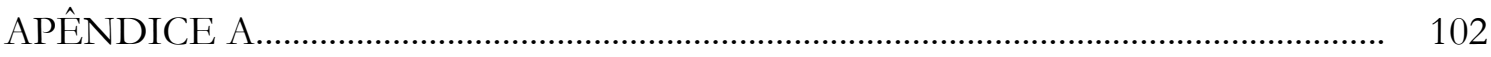

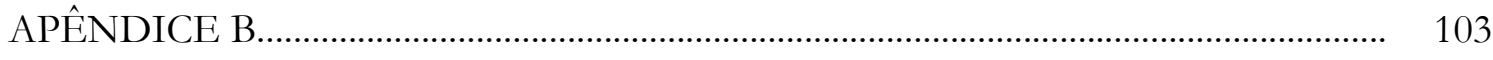

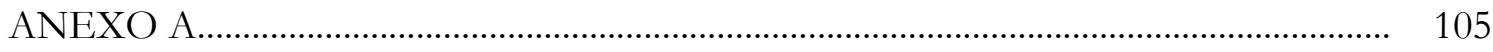

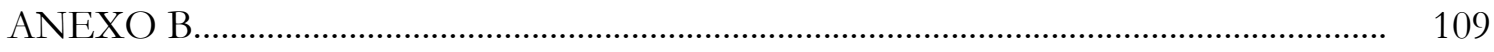

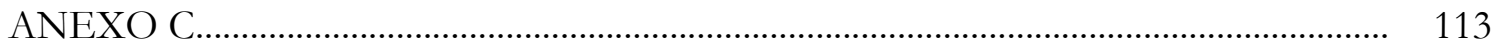

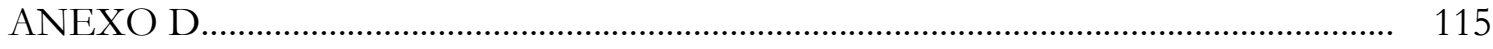

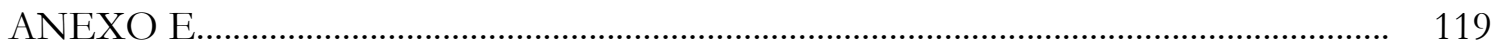

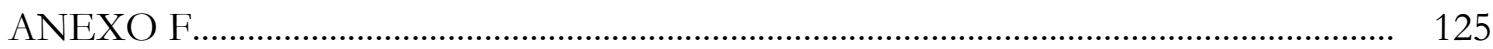

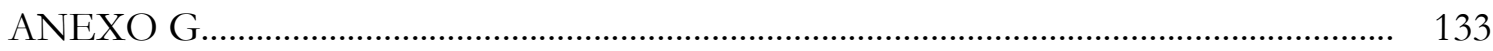

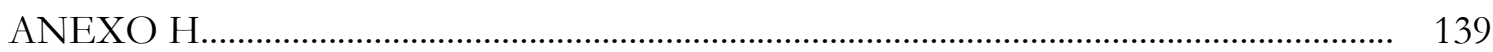




\section{INTRODUÇÃO}

A partir dos anos oitenta, um novo campo de pesquisa vem se destacando no Brasil: a área de pesquisa em Ensino de Química. Podemos citar como marcos iniciais para o seu estabelecimento a realização do Primeiro Encontro de Debates sobre o Ensino de Química (EDEQ), organizado em 1980 por Ático Chassot no Rio Grande do Sul e, em 1982, o Primeiro Encontro Nacional de Ensino de Química (ENEQ), realizado no Instituto de Química da Universidade Estadual de Campinas (UNICAMP) ${ }^{1}$. Neste último, discussões sobre a atuação do pesquisador da área, conduziram ao levantamento de várias questões e ao delineamento das diferenças entre a pesquisa em Química e a pesquisa em Ensino de Química, que foram sintetizadas por Malcolm J. Frazer ${ }^{2}$, professor da Universidade de East Anglia na Inglaterra, convidado para o evento, da seguinte forma:

[...] a pesquisa em educação em química: i) consiste no aperfeiçoamento do ensino e aprendizagem de química; ii) utiliza conceitos químicos; iii) utiliza teorias da Psicologia, Sociologia, Filosofia etc; iii) utiliza técnicas tais como: testes, observações, entrevistas, questionários. Nesse sentido, as diferenças entre pesquisas em educação química e química são: i) investiga-se sobre pessoas e não sobre elétrons; ii) os resultados de pesquisa variam com o tempo e o local; iii) não existe ainda uma metodologia de pesquisa bem estabelecida e aceita; iv) não existe ainda um sistema de publicação bem estabelecido.

Um outro marco importante para o desenvolvimento da área foi a constituição da Divisão de Ensino na Sociedade Brasileira de Química (SBQ), criada em julho de 1988, durante a XI Reunião Anual da Sociedade Brasileira de Química (RASBQ). Seu embrião provém, segundo Schnetzler ${ }^{1}$, da Primeira RASBQ, realizada em 1978 e sediada em São Paulo, na qual ocorreu também a primeira Seção Coordenada de trabalhos de pesquisa em Ensino de Química, sendo que esta se prolongou por um tempo maior que o previsto, sugerindo um grande entusiasmo entre os participantes do evento em discutir e trocar idéias sobre a situação do Ensino Médio de 
Química da época, além da proposição de abertura de um espaço na comunidade Química para estudos e pesquisas nesta área, com o intuito de melhorar não somente o Ensino de Química, mas também a formação do docente.

Durante estes anos, desde a organização do primeiro EDEQ, tem se verificado um crescente interesse pela área, evidenciado principalmente, pela realização de vários encontros nacionais como: Encontro Centro-Oeste de Debates sobre Ensino de Química (ECODEQ), Encontro Norte-Nordeste de Ensino de Química (ENNEQ), Encontro Sudeste de Ensino de Química (ESEQ). Mais recentemente, em 2004, foi organizado o Primeiro Encontro Paulista de Pesquisa em Ensino de Química (EPPEQ), que reuniu vários pesquisadores no Instituto de Química da UNICAMP, e a sua promoção foi uma iniciativa do Grupo de Trabalho Químicas Integradas, conhecido como G-6, do qual fazem parte alguns docentes da área vinculados às universidades públicas paulista. Cabe ainda destacar a existência de outro encontro de caráter mais geral, o Encontro Nacional de Pesquisa em Educação em Ciências (ENPEC), organizado pela Associação Brasileira de Pesquisa em Educação em Ciências (ABRAPEC), que acontece a cada dois anos no Estado de São Paulo, desde 1997. Este visa promover, divulgar e socializar a pesquisa em Educação em Ciências e não somente no Ensino de Química.

Considerando a recente produção científica na área de pesquisa em Ensino de Química em nosso país, proveniente tanto dos encontros acima mencionados como de outras fontes, julgamos pertinente a realização de um trabalho de caráter bibliográfico a seu respeito. Segundo Ferreira ${ }^{3}$, nos últimos quinze anos em nosso país, pesquisas de caráter bibliográfico foram realizadas em várias áreas do conhecimento buscando mapear e discutir uma certa produção acadêmica em diferentes campos do conhecimento. Estas tentam responder quais aspectos e dimensões vêm sendo destacadas e privilegiadas em diferentes épocas e lugares, de que formas e em que condições têm sido produzidas certas dissertações de Mestrado, teses de Doutorado, publicações em periódicos além de comunicações em anais de congressos, encontros e seminários. Logo, possuem 
um caráter inventariante e descritivo da produção acadêmica e científica sobre os temas que buscam investigar.

Os pesquisadores que realizam pesquisas de caráter bibliográfico tomam como fonte básica de referência para realizar o levantamento de dados de suas análises, catálogos de faculdades, institutos, universidades, associações nacionais e órgãos de fomento de pesquisa, livros de resumos dos trabalhos apresentados em encontros e anais de congressos da área de interesse, entre outros. Esse material anteriormente era impresso, podendo hoje ser encontrado na forma de CD-ROM e até mesmo em sites da rede mundial de comunicação, a Internet. De posse do material necessário para a pesquisa, começa então o inventário de seus dados por meio de leitura dos resumos dos trabalhos e análise dos mesmos, fazendo um mapeamento da produção num período delimitado pelo pesquisador (os anos, locais e áreas de produção), sendo que estes dados devem ser objetivos e concretos. Uma segunda parte da pesquisa é inventariar as tendências, ênfases, escolhas metodológicas e teóricas que aproximam ou não os trabalhos entre si. A partir daí, o pesquisador começa a enfrentar dificuldades inúmeras e de diferentes ordens, pois já não terá de responder apenas "quando", “onde” e "quem” produz pesquisas, mas “o quê", e "como" foram produzidas.

O que move os pesquisadores que desenvolvem os trabalhos desta natureza pode ser entendido conforme a reflexão que Ferreira ${ }^{3}$ faz:

[...] é o interesse em conhecer a totalidade de estudos e pesquisas em determinada área do conhecimento, que apresenta crescimento tanto quantitativo quanto qualitativo, ou seja, é o desafio de conhecer o já construído e produzido para depois buscar o que ainda não foi feito dedicar cada vez mais a atenção a um número considerável de pesquisas realizadas de difícil acesso, e dar conta de determinado saber que aumenta cada vez mais rapidamente e de divulgá-lo para a sociedade.

Movidos também por esta percepção buscamos conhecer as características e tendências da pesquisa acadêmica brasileira sobre o Ensino de Química a partir da análise dos trabalhos 
apresentados na seção de Ensino de Química, no período de 1999 a 2005, nas Reuniões Anuais da Sociedade Brasileira de Química (RASBQ).

O papel fundamental desempenhado pela Sociedade Brasileira de Química (SBQ) para o desenvolvimento das pesquisas na área de Ensino de Química é digno de nota e foi responsável entre outros fatores pela escolha dos trabalhos que seriam alvo da nossa atenção e estes fatores estão apresentados no Capitulo 4 - Metodologia de Pesquisa desta dissertação. De fato, a Divisão de Ensino da SBQ é a mais antiga das divisões científicas da entidade. A Divisão vem participando, desde sua criação, do esforço para consolidar e ampliar a área de Educação em Química no país. Entre estes esforços estão: a publicação da revista Química Nova na Escola, desde 1995 e esta é, possivelmente, a produção mais significativa da Divisão de Ensino e o maior esforço da SBQ para aproximar a Química dos cidadãos comuns, em especial os professores e os estudantes do Ensino Médio; a promoção da Olimpíada Científica da SBQ, iniciativa que tenta acrescentar ao ensino tradicional (que ainda utiliza o livro texto), a divulgação da Química através do uso da revista Química Nova na Escola por professores e estudantes do Ensino Médio; a participação na organização e na promoção de encontros da área ${ }^{4}$.

Dentre os vários trabalhos de caráter bibliográfico produzidos no nosso país, citamos alguns deles que foram realizados nestes últimos anos como: “Alfabetização no Brasil - o estado do conhecimento",5; "Rumos da pesquisa brasileira em educação matemática: o caso da produção científica em cursos de Pós-Graduação"; "Pesquisa em leitura: um estudo dos resumos de dissertações de Mestrado e teses de Doutorado defendidas no Brasil de 1980 a 1995"; "Estado da arte da formação de professores no Brasil”; "A produção científica da Anped e da Intercom no GT da educação e comunicação"; "A produção do conhecimento sobre a política educacional no Brasil: um olhar a partir da Anped"10; "Ensino supletivo no Brasil: o estado da arte" ${ }^{\text {}}$.Cabe destacar que alguns trabalhos de caráter bibliográfico foram recentemente reunidos no livro intitulado "A Química no Brasil Através da Química Nova"12 Neste livro, são apresentados artigos sobre a evolução das áreas que compõem as doze divisões científicas da 
SBQ: Catálise; Eletroquímica/Eletroanalítica; Ensino de Química; Química Medicinal; FísicoQuímica; Fotoquímica; Produtos Naturais; Química Ambiental; Química Analítica; Química de Materiais; Química Inorgânica e Química Orgânica.

Considerando apenas as pesquisas de caráter bibliográfico relacionadas mais estreitamente à temática que pretendemos desenvolver, destacamos na literatura nacional os trabalhos de Fracalanza ${ }^{13}$ e Megid $\mathrm{Neto}^{14}$, Duarte $^{15}$, e Nardi ${ }^{16}$, intitulados respectivamente: “O que sabemos sobre os livros didáticos para o ensino de Ciências"; "Tendências da pesquisa acadêmica sobre o ensino de Ciências no nível fundamental"; "O estado da arte na pesquisa em educação em Ciências em Portugal”; "Memórias da Educação em Ciências No Brasil: A Pesquisa em Ensino de Física".

O trabalho de Fracalanza ${ }^{13}$ descreve os principais aspectos e resultados do Projeto Livro Didático e do Serviço de Informação sobre Livro Didático da Biblioteca Central da Universidade Estadual de Campinas, classificando e descrevendo a produção acadêmica e científica do livro didático no Brasil.

O trabalho de Megid Neto ${ }^{14}$ descreve a produção acadêmica sobre o Ensino de Ciências no Brasil, enfocando particularmente 212 trabalhos voltados para o Ensino Fundamental e relata que a produção acadêmica, na época da conclusão da pesquisa (1999), sobre o Ensino de Ciências no nível fundamental estava centrada em questões mais internas do processo de ensinoaprendizagem escolar. Poucas pesquisas investiam na abordagem das relações entre ciência e sociedade e não havia uma preocupação em tratar a realidade e o cotidiano dos alunos.

O trabalho de Duarte ${ }^{15}$ descreve uma investigação sobre o Ensino de Ciências em Portugal, realizado a partir da análise de teses de Mestrado e Doutorado defendidas em universidades portuguesas, de trabalhos apresentados em congressos e em revistas nacionais e estrangeiras. São tratados os seguintes aspectos: início das investigações e fatores que contribuíram para o seu incremento, principais instituições que financiam a investigação, 
principais problemáticas investigadas e exemplos de investigações realizadas, níveis de ensino mais investigados e metodologias de investigação privilegiadas.

O trabalho de $\operatorname{Nardi}^{16}$ recupera, através de registros elaborados nas últimas décadas, como artigos, atas de eventos, relatórios de grupos de pesquisa e entrevistas realizadas recentemente com pesquisadores em exercício, alguns detalhes dos caminhos traçados pela pesquisa em Ensino de Física no Brasil. A interpretação de certos efeitos de sentido atribuídos pelos entrevistados e outros contidos nos registros analisados, permitem ao autor perceber a pluralidade dessa área de estudos, a diversidade de fatores considerados importantes para sua constituição e as características da pesquisa nessa área.

Um trabalho de caráter bibliográfico que merece a nossa particular atenção, especialmente por estar intimamente relacionado à pesquisa que desenvolvemos, se intitula "A pesquisa em Ensino de Química no Brasil: conquistas e perspectivas"1. De autoria de Roseli Pacheco Schnetzler, o trabalho foi publicado na Revista Química Nova, em 2002, e segundo a autora, apresentou um possível "estado da arte” da pesquisa em Ensino de Química no Brasil, a partir de levantamento bibliográfico realizado em artigos da revista Química Nova na Escola, em artigos publicados na seção de educação da revista Química Nova, em comunicações publicadas nos resumos das Reuniões Anuais da Sociedade Brasileira de Química e com base em resumos de teses e dissertações produzidas na área, no intervalo de 1977 a 2001.

Destacamos a seguir as observações feitas por Schnetzler ${ }^{1}$ no referido artigo e que se relacionam aos trabalhos apresentados nas RASBQs, uma vez que estes trabalhos são também alvo da nossa atenção. A autora aponta inicialmente para uma acentuada evolução no número de trabalhos apresentados nas RASBQs de 1977 a 2001, passando de 5 para 108 resumos neste intervalo. No entanto, chama atenção para o fato de que grande parte dos resumos apresentados (51\%) não se relacionarem a investigações na área de Ensino de Química. Tratam, na verdade, de relatos de experiência e de descrições de inovações tecnológicas, que incluem propostas de ensino 
ou de atividades práticas de laboratório. Os demais trabalhos $(59 \%)$ se relacionam a investigações na área em foco.

Considerando apenas os trabalhos relacionados a investigações, Schnetzler ${ }^{1}$ afirma que as temáticas mais freqüentemente exploradas dizem respeito à aprendizagem, dificuldades e concepções dos alunos (57\%) e a concepções e dificuldades dos professores $(20 \%)$, sendo que estas passam a ser investigadas a partir da década de 80, com um significativo aumento na década de 90. O mesmo ocorre com relação aos trabalhos sobre novas tecnologias de informação. O livro didático e a experimentação são tratados com constância. Com relação ao nível de escolaridade a que são direcionados os trabalhos, Schnetzler ${ }^{1}$ observa que os percentuais relacionados ao Ensino Fundamental, são extremamente baixos (4\%). Trabalhos direcionados a abordagens interdisciplinares são também muito escassos, representando apenas 3\% do total analisado.

Embora a metodologia de análise e de coleta de dados adotada no trabalho de Schnetzler ${ }^{1}$ seja distinta da que estabelecemos para o nosso trabalho, muitas das observações aí presentes foram de grande valia para o nosso entendimento sobre a pesquisa em Ensino de Química e muitos dos dados por nós coletados e analisados serviram para complementar e atualizar aqueles referenciados no artigo, conforme discutiremos no Capitulo 5 - Resultados e Discussão desta dissertação.

Os seguintes trabalhos de caráter bibliográfico realizados anteriormente por membros do nosso Grupo de Pesquisas também serviram de subsídio para a realização desta dissertação: “Análise dos trabalhos apresentados nas Reuniões Anuais da Sociedade Brasileira de Química na seção de Ensino de Química de 1999 a 2003”17 apresentado IV ENPEC, “A abordagem de temas concernentes à Educação Ambiental por pesquisadores da área de Educação em Ciências" apresentado no XLIV Congresso Brasileiro de Química, “A pesquisa acadêmica brasileira sobre as temáticas das concepções alternativas dos alunos e da abordagem CTS de ensino"19 apresentado na 28 RASBQ, “Análise dos trabalhos apresentados nos Encontros de Debates sobre o Ensino de Química de 1999 a 2003”20 apresentado no V ENPEC, “ Aprendizagem Significativa e Ensino de 
Química: Uma análise dos trabalhos em eventos da área de Educação em Química no Brasil”21 aceito para apresentação no V Encontro Internacional de Aprendizagem Significativa, a ser realizado em Madrid - Espanha e "Análise dos trabalhos apresentados nos Encontros Nacionais de Ensino de Química no período de 2000 a 2002"22 aceito para apresentação no XIII ENEQ que será sediado em Campinas. 


\section{OBJETIVOS}

Considerando a escassa produção de trabalhos do tipo estado da arte sobre a pesquisa acadêmica brasileira na área de Ensino de Química e acreditando na relevância de trabalhos desta natureza, decidimos nos juntar ao rol de pesquisadores que procuram de maneira exaustiva inventariar a produção acadêmica numa determinada área do conhecimento.

Assim, este trabalho visa à identificação, análise e descrição das principais características e tendências dos trabalhos produzidos na área de Ensino de Química no Brasil, compreendendo o período de 1999 a 2005. Este período foi escolhido porque abarca um número considerável de trabalhos, a partir dos quais indícios sobre tendências e regularidades existentes na pesquisa acadêmica podem ser encontrados.

Para concretizamos nossos objetivos, escolhemos como fonte de dados os trabalhos presentes nos Livros de Resumos das Reuniões Anuais da Sociedade Brasileira de Química (RASBQs), ocorridas no período anteriormente mencionado. A escolha de tal fonte se deve à ampla divulgação das RASBQs que conta com a presença de diversos pesquisadores de várias regiões de nosso país e a credibilidade que inspiram entre os membros da comunidade acadêmica da área de Química e Ensino de Química. Ademais, nas RASBQs estão representadas várias áreas de pesquisa em Química.

Serão objetos do nosso estudo os resumos dos trabalhos apresentados em tais reuniões, especificamente na seção de Ensino de Química, os quais serão classificados de acordo com o ano de apresentação, a instituição de origem (e conseqüentemente a região geográfica de origem), o nível de escolaridade a que a pesquisa se destina e o foco temático de estudo abrangido no trabalho. 


\section{REFERENCIAL TEÓRICO}

Para o desenvolvimento desta pesquisa do tipo estado da arte, que mescla dados quantitativos e qualitativos Ferreira ${ }^{3}$, buscamos um referencial que pudesse satisfazer os nossos objetivos iniciais do estudo. Dentre os vários trabalhos encontrados e analisados para apoiar as metas propostas inicialmente nesta pesquisa, encontramos um trabalho que nos guiou em todo o percurso de desenvolvimento de análise dos dados coletados.

O trabalho intitulado "Tendências da Pesquisa Acadêmica Sobre o Ensino de Ciências no Nível Fundamental", produzido por Megid $\mathrm{Neto}^{14}$, que trata da produção acadêmica sobre o Ensino de Ciências no nível fundamental, apresenta uma abordagem consistente quanto aos descritores necessários para classificação dos trabalhos que analisamos tanto no diz respeito à reunião dos documentos, quanto ao nível de escolaridade como também ao foco temático de estudo que a pesquisa pretende desenvolver. Um diferencial da nossa pesquisa em relação à pesquisa realizada por Megid Neto ${ }^{14}$ relaciona-se em determinados aspectos com o conteúdo abrangido no levantamento dos dados, pois aqui tratamos do Ensino de Química no Brasil e não distinguimos um nível de escolaridade específico para estudo. Analisamos os resumos apresentados nas Reuniões Anuais da Sociedade Brasileira de Química (RASBQ) e Megid Neto reuniu como fonte de análise para a sua pesquisa dissertações e teses defendidas até o ano de 1995 relativas ao Ensino de Ciências, dedicadas ao Ensino Fundamental ${ }^{14}$.

\subsection{A CLASSIFICAÇÃO DOS DOCUMENTOS}

Os procedimentos para o desenvolvimento da pesquisa seguiram as linhas gerais estabelecidas por Megid $\mathrm{Neto}^{14}$ quanto à fundamentação dos critérios detalhados utilizados para a classificação dos descritores dos documentos investigados. Primeiramente organizamos os dados bibliográficos dos resumos em ficha de classificação para facilitar a análise dos documentos. Esta 
ficha possui campos para ano de produção, a Instituição, o nível de escolaridade, foco temático de estudo para cada documento. No que se refere à Instituição de origem dos autores do trabalho, na maioria das vezes são indicadas no resumo e costumam ser Instituições de Ensino Superior (IES) ou centros tecnológicos de ensino e escolas da rede de ensino pública e privada.

\subsubsection{CLASSIFICAÇÃO DO NÍVEL ESCOLAR}

O nível escolar abrangido pelo trabalho acadêmico foi identificado por meio de elementos apresentados nos resumos que configurem um direcionamento do trabalho ou preocupação do autor do trabalho quanto a sua aplicação em um ou mais níveis de escolaridade. Logo, os sujeitos participantes da pesquisa (professores, alunos etc.), os materiais didáticos avaliados, os programas de ensino propostos, a discussão e avaliação do currículo escolar, a legislação educacional referenciada, são elementos presentes nas investigações que permitiram caracterizar a qual/quais níveis escolares estão direcionados tais trabalhos.

Pelas diretrizes educacionais existentes no Brasil, as denominações dos níveis escolares sofreram algumas mudanças. Tínhamos até meados dos anos 90 as seguintes designações: Ensino Pré-escolar, Ensino de $1^{\circ}$ Grau, Ensino de $2^{\circ}$ Grau e Ensino de $3^{\circ}$ Grau que se baseavam nas Leis Federais n $.4 .024 / 68$ e n ${ }^{\circ}$ 5.692/71. A partir de 1996/97, com a implantação da nova Lei de Diretrizes e Bases da Educação Nacional (Lei Federal n.9.394/96) a nomenclatura dos níveis escolares sofreu uma atualização ${ }^{14}$. Neste trabalho, utilizamos os níveis escolares estabelecidos pela nova nomenclatura e que se encontram descritos a seguir.

- Educação Infantil: trabalhos que tratam do ensino de 0 a 6 anos.

- Ensino Fundamental: trabalhos direcionados ao Ensino Fundamental correspondente ao antigo Ensino de $1^{\circ}$ Grau. Incluem-se os eventuais estudos sobre o Ensino Supletivo ou educação formal de adultos equivalentes a esta faixa escolar.

- Ensino Médio: estudos que tratam do Ensino Médio, correspondente ao antigo Ensino de $2^{\circ}$ Grau, incluindo-se estudos sobre o Magistério de $2^{\circ}$ Grau, estudos sobre o Ensino 
Técnico integrado ao $2^{\circ}$ Grau, bem como trabalhos direcionados ao Ensino Supletivo equivalente a esta faixa escolar.

- Ensino Superior: trabalhos voltados para a educação superior, antigo $3^{\circ}$ Grau, que englobam o Ensino de Graduação, Licenciaturas e Pós-Graduação.

- Geral: pesquisas que discutem o Ensino no âmbito escolar de forma genérica quanto ao nível de escolaridade, sem uma abordagem específica ou preferencial para alguma etapa de escolarização.

\subsubsection{CLASSIFICAÇÃO POR FOCO TEMÁTICO DE INVESTIGAÇÃO}

O conjunto de descritores específicos com respeito ao foco temático de investigação estabelecido por Megid $\mathrm{Neto}^{14}$ foi detalhado para guiar o processo de classificação dos documentos. Este conjunto de descritores tem como base três estudos sobre pesquisas acadêmicas na área de Ensino de Ciências ${ }^{13,23,24}$. Este conjunto de aspectos formadores dos descritores dos temas que abrangem os documentos exprime, de forma geral, o assunto tratado no trabalho científico, reunidos em quatorze temas distintos. São eles: Currículos e Programas, Conteúdo-Método, Recursos Didáticos, Características do Professor, Características do Aluno, Formação de Conceitos, Formação de Professores, Políticas Públicas, Organização da Escola, Programa de Ensino Não Escolar, Filosofia da Ciência, História da Ciência, História do Ensino de Ciências e Outro. Para a classificação dos trabalhos por nós estudados, consideramos as seguintes definições para cada um dos temas:

- Currículos e Programas - estudos dos princípios, parâmetros, diretrizes e fundamentos teórico-metodológicos para o Ensino de Química, contemplando as diversas etapas atribuídas à grade curricular (objetivos educacionais, conteúdos, estratégias, avaliações etc.). Discussão do papel da escola, das relações entre ciência e sociedade e outros aspectos do sistema educacional. Avaliação de propostas curriculares ou projetos 
educacionais. Proposição e desenvolvimento de programas ou propostas alternativas de ensino para uma série, disciplina, semestre letivo ou ciclo escolar completo.

- Conteúdo-Método - pesquisas que analisam a relação Conteúdo-Método no Ensino de Química, com foco de atenção no conhecimento científico veiculado na escola, na forma como este conhecimento é difundido por meio de métodos e técnicas de ensinoaprendizagem, ou ainda na perspectiva de indissociação entre forma e conteúdo. Estudos a respeito da aplicação de métodos e técnicas de Ensino de Química, como instrução programada, courseware, módulos de ensino, experimentação, dramatização, entre outros, de forma isolada ou comparativa. Trabalhos que propõem método alternativo para o Ensino de Química ou que descrevem e avaliam práticas pedagógicas e a metodologia de ensino neles presente.

- Recursos Didáticos - estudos de avaliação de matérias ou recursos didáticos no Ensino de Química, como textos de leitura, livros didáticos, matérias de laboratório, filmes, computador, jogos, mapas conceituais entre outros. Trabalhos que propõem e/ou aplicam e avaliam novos materiais, kits experimentais, softwares ou outros recursos e meios instrucionais em situações de ensino formal ou extracurricular.

- Características do Professor - diagnóstico das condições profissionais do professor da área de Química. Identificação do perfil sociográfico do professor, de sua estrutura intelectual, de seu conhecimento 'espontâneo', de suas concepções sobre Ciência, métodos de produção científica, educação, ambiente, saúde, sexualidade etc. Diagnóstico da prática pedagógica de um professor ou grupo de professores, explicitando suas idiossincrasias e concepções do processo educacional.

- Características do Aluno - diagnóstico das condições sócio-econômicas e culturais dos alunos e suas implicações no rendimento escolar ou aprendizagem em Química. Identificação ou constatação do conhecimento prévio do aluno, de sua estrutura intelectual, modelos de pensamento ou de suas idéias sobre ciência, métodos de produção 
científica, ambiente, saúde, sexualidade etc. Estudos das atitudes e características de um aluno ou grupo de alunos no contexto do processo de ensino-aprendizagem.

- Formação de Conceitos - pesquisas que descrevem e analisam o desenvolvimento de conceitos científicos no pensamento dos alunos e/ou professores, implicando em processos de mudança ou evolução conceitual. Comparação de modelos de pensamento com modelos conceituais presentes na História da Ciência. Estudos sobre a relação entre estrutura cognitiva de estudantes e o processo ensino-aprendizagem de conceitos científicos em processos formais ou não-formais de ensino. Relação entre modelos de pensamento ou faixa etária ou nível de escolaridade dos indivíduos.

- Formação de Professores - investigações relacionadas com a formação inicial de professores para o ensino na área de Ciências Naturais, no âmbito da Licenciatura, da Pedagogia ou do Ensino Médio - modalidade normal (antigo Magistério). Estudos de avaliação ou propostas de reformulação de cursos de formação inicial de professores. Estudos voltados para a formação continuada ou permanente dos professores da área de Química envolvendo propostas e/ou avaliação de programas de aperfeiçoamento, atualização, capacitação, treinamento ou especialização de professores. Descrição e avaliação da prática pedagógica em processos de formação em serviço.

- Políticas Públicas - programas, diretrizes ações, objetivos e interesses de um indivíduo ou grupo, governamental ou não, voltados para o público em geral e relacionados com um único conjunto de problemas da coletividade, desde que explicitadas suas repercussões ou ligações com a educação científica.

- Organização da Escola - diagnóstico das características de instituições escolares da educação básica ou superior, abrangendo aspectos relativos à gestão escolar, nos seus aspectos político-administrativos, pedagógico, funcional, físico entre outros. Estudos das relações entre os diversos segmentos escolares e da escola com a comunidade. 
- Programa de Ensino Não-Escolar - pesquisas com foco de atenção na organização de instituições não-escolares ou não-formais de ensino, como organizações nãogovernamentais (ONGs); secretarias de meio-ambiente, de saúde, de cultura; museus, clubes ou Centros de Ciências, mostras, feiras ou exposições científicas. Programas de educação ambiental, de higiene e saúde ou de educação sexual realizado junto à comunidade. Programas de formação continuada de professores executados por instituições educacionais não-escolares (por exemplo, Centro de Ciências). Programas de atividades extracurriculares para alunos efetuados em espaços não-formais de ensino, como exemplo, em Museus de Ciências.

- Filosofia da Ciência - aspectos relativos à filosofia ou epistemologia da Ciência, tais como concepção de Ciência, de cientista, de método científico, formulação e desenvolvimento de teorias científicas, paradigmas e modelos científicos e suas implicações no ensino quanto à formulação de currículos, à formação de professores, ao desenvolvimento de programas de ensino-aprendizagem entre outros.

- História da Ciência - estudos de revisão bibliográfica em fontes primárias e secundárias que resgatam acontecimentos, fatos debates, conflitos e circunstâncias da produção científica em determinada época do passado próximo ou remoto, e as articulações entre eles. Necessariamente, esses estudos devem explicitar alguma relação com o ensino na área de Química, como: fundamentação de currículos, programas de formação de professores, concepções 'espontâneas' dos estudantes e outras implicações para o processo de ensino-aprendizagem.

- História do Ensino de Ciências - pesquisas de caráter histórico sobre a evolução de Ensino de Química no Brasil ou sobre características isoladas desse ensino (materiais didáticos, currículos, legislação, formação de professores etc.), abrangendo determinada época do passado remoto ou distante. 
- Outro - foco particular que não encontra correspondência com os demais, cuja incidência de casos no conjunto dos documentos classificados é bastante pequena. Incluem-se estudos sobre exames vestibulares, pesquisas do tipo estado da arte sobre a produção acadêmica e científica, entre outros temas presentes nos documentos em estudo sobre o Ensino de Química.

Estabelecido o referencial teórico para cumprimento do nosso objetivo de estudo, organizamos de forma consistente a metodologia de pesquisa e procedimentos para análise dos dados obtidos durante o desenvolvimento do trabalho. 


\section{METODOLOGIA DE PESQUISA}

Esta pesquisa refere-se à análise de resumos apresentados na seção de Ensino de Química (ED), nas RASBQs. Desde a sua criação, em 1977, até o ano de 2005, ocorreram vinte e oito reuniões ${ }^{4}$. Para nós, a análise de todos os resumos apresentados neste intervalo de tempo mostrou-se inviável devido à própria natureza do trabalho que nos propusemos a realizar: a preparação de uma dissertação de Mestrado em um período de tempo relativamente restrito. Deste modo, optamos por analisar os resumos apresentados nos últimos sete anos das RASBQs, acreditando que conseguiríamos indícios sobre tendências e regularidades existentes na pesquisa acadêmica na área de Ensino de Química, no nosso país, nos últimos anos.

Assim, a primeira etapa da pesquisa foi a escolha do evento promovido na área de Ensino de Química que seria investigado. Em seguida, reunimos todos os resumos para o levantamento dos dados necessários ao estudo. A partir daí, podemos relacionar as etapas posteriores da pesquisa da seguinte maneira:

1. Identificação dos trabalhos pertencentes à seção de ED nos Livros de Resumos das RASBQs .

2. Configuração dos aspectos a serem considerados na classificação e descrição dos trabalhos em estudo.

3. Organização dos dados bibliográficos e de informações complementares em uma ficha de classificação.

4. Leitura e classificação dos documentos com relação aos aspectos definidos na etapa 2.

5. Organização dos resultados da classificação dos documentos com relação aos vários aspectos analisados em forma de tabelas e gráficos. 
6. Análise dos resultados e elaboração das principais tendências verificadas nos documentos, com o intuito de observar as possíveis contribuições desta produção acadêmica e apontar possíveis lacunas existentes em tal produção.

\subsection{IDENTIFICAÇÃO DOS TRABALHOS PERTENCENTES À SEÇÃO DE ENSINO DE QUÍMICA}

Faz-se necessário o esclarecimento sobre alguns aspectos pertinentes à elaboração e forma de divulgação dos resumos que serão analisados:

a) condição imprescindível para apresentação de resumos nas RASBQ é o ineditismo do trabalho;

b) nos anos de 1999 e 2000 os resumos foram dispostos em duas colunas por página do Livro de Resumos. Neles deveriam constar: título do trabalho, nome dos autores, a categoria de cada autor (pesquisador, professor do ensino fundamental/médio, pós-graduando ou graduando), instituição a que cada autor se vincula e três palavras-chave. O texto do resumo deveria conter introdução, objetivos, métodos, resultados, conclusões e bibliografia. Estes resumos encontramse impressos nos Livros de Resumos da $22^{\mathrm{a}}$ e $23^{\mathrm{a}}$ Reunião Anual da Sociedade Brasileira de Química.

c) nos anos de 2001 a 2005 dois modelos de resumo foram adotados. No primeiro deles, um "Template do Resumo" deveria ser seguido, no qual deveriam ser inseridos: o título do trabalho, os nomes dos autores, endereço dos autores, máximo de três palavras-chave e um pequeno resumo, representando um espaço de aproximadamente $18 \mathrm{~cm} \times 5,5 \mathrm{~cm}$ ou, aproximadamente $1 / 5$ de uma folha de papel A4. Estes resumos encontram-se impressos em Livros de Resumos da 24a $25^{a}$ e $26^{a} 27^{a}$ e $28^{a}$ Reunião Anual da Sociedade Brasileira da Química. O modelo deste tipo de resumo está representado no Apêndice A desta dissertação. No segundo modelo, o texto do resumo, em uma página, deveria também seguir um "Template do Trabalho", no qual deveriam ser inseridos: o título do trabalho, os nomes dos autores, a categoria 
de cada autor (pesquisador, professor do ensino fundamental/médio, pós-graduando ou graduando), instituição a que cada autor se vincula e máximo de três palavras-chave. O texto do trabalho, em uma página, deveria apresentar introdução, resultados e discussão, conclusões, agradecimentos e referências bibliográficas. Estes resumos encontram-se disponibilizados na página da Internet da Sociedade Brasileira de Química (www.sbq.org.br) em arquivo do tipo PDF, e não estão impressos em Livros de Resumos. O modelo deste tipo de resumo está representado no Apêndice B desta dissertação.

Ao iniciarmos a separação e impressão dos trabalhos da seção de Ensino de Química, encontramos um obstáculo no ano de 2001. Apesar de conseguirmos acessar a página do site da SBQ onde estão disponibilizados os trabalhos da $24^{a}$ RASBQ, não era possível fazer o download de nenhum dos trabalhos. Diante desta situação, entramos em contato com os responsáveis pela manutenção da página de Internet da SBQ que nos deram ciência acerca de um problema no sistema onde estavam armazenados os arquivos dos trabalhos referentes a esta reunião, que impedia a sua recuperação. Assim, analisamos apenas os resumos que constavam do Livro de Resumos da reunião ocorrida em 2001. Uma vez que as informações aí apresentadas são extremamente restritas, a análise dos resumos apresentados no ano de 2001 foi realizada de maneira diferenciada das demais, conforme explicaremos a seguir. Com relação às reuniões subseqüentes, não tivemos problemas para separar e imprimir todos os trabalhos existentes na seção de ED.

\subsection{CONFIGURAÇÃO DOS ASPECTOS DE CLASSIFICAÇÃO E DESCRIÇÃO DOS TRABALHOS}

Tendo em mãos os trabalhos das reuniões em estudo, configuramos os aspectos de classificação e descrição dos conteúdos presentes no conjunto de resumos que reunimos no período compreendido entre 1999 a 2005. Com base no trabalho de Megid Neto ${ }^{14}$, decidimos 
classificar os documentos de acordo com os dados que eram fornecidos em cada trabalho a ser analisado. Assim, determinamos a classificação e descrição dos trabalhos da seguinte maneira:

- Ano de apresentação.

- Número do trabalho pertencente à seção de ED.

- Instituição ou Instituições de vínculo dos autores.

- Região geográfica brasileira a que pertence a Instituição.

- Interações entre departamentos ou faculdades da área de Ciências Humanas e de Ciências Exatas. Ou seja, se os pesquisadores envolvidos no trabalho pertenciam, por exemplo, tanto a Institutos de Química, como a Faculdades de Educação, ou somente as áreas de Ciências Humanas ou Ciências Exatas.

- O nível de escolaridade ao qual o trabalho se refere. Neste caso adotamos como referencial para análise os níveis caracterizados por Megid Neto ${ }^{14}$ e descritos no Capitulo 3: Referencial Teórico desta dissertação.

- O foco temático ao qual o trabalho se refere. Neste caso também adotamos como referencial para análise os focos caracterizados por Megid Neto $^{14}$ e descritos no Capitulo 3: Referencial Teórico desta dissertação.

\subsection{ORGANIZAÇÃO DOS DADOS BIBLIOGRÁFICOS EM FICHAS DE CLASSIFICAÇÃO}

Para facilitar o processo de classificação dos trabalhos criamos uma ficha de classificação geral de todos os dados bibliográficos que teríamos ao longo da leitura do conjunto de resumos que separamos para análise. Esta ficha possui campos de preenchimento de acordo com os aspectos definidos no item anterior, disponibilizada em uma folha do tamanho A4, impressa no formato retrato. Além dos aspectos pré-estabelecidos, acrescentamos uma coluna para comentários gerais sobre cada um dos trabalhos em estudo. Posteriormente, esses dados foram transferidos em planilhas do programa Excel, para a construção de tabelas e gráficos que 
auxiliaram na análise dos dados que obtivemos durante a pesquisa. Estas planilhas de encontra-se apresentadas nos Anexos desta dissertação.

Definidos todos os aspectos a serem classificados, a ficha de classificação e o conjunto de trabalhos a serem analisados, iniciamos a leitura dos resumos pelo ano de 1999. Com o decorrer do processo de leitura, classificação dos trabalhos e preenchimento da ficha classificatória, deparamos-nos com alguns problemas quanto à classificação do foco temático e nível de escolaridade.

Quanto ao foco temático, tivemos algumas dúvidas em relação aos focos ConteúdoMétodo e Recursos Didáticos. A descrição apresentada por Megid Neto ${ }^{14}$ para cada um deles não parecia estabelecer uma diferença clara entre os dois. Assim, para que pudéssemos distinguir entre o foco Recursos Didáticos e o foco Conteúdo-Método, desenvolvemos um parâmetro próprio de classificação: quando o trabalho apresentava a descrição de um recurso didático ou de uma proposta de experimento e se restringia a apresentação do material em si ou das etapas para a execução do experimento, era classificado no foco Recursos Didáticos. Quando o trabalho apresentava além do próprio recurso ou procedimento experimental, algum tipo de comentário/avaliação a respeito do papel por eles desempenhado no processo de ensinoaprendizagem, era classificado no foco Conteúdo-Método.

Outro foco temático digno de nota foi o foco Formação de Professores. No que diz respeito a trabalhos classificados neste foco, tivemos dificuldades em fazer a classificação quanto ao nível de escolaridade ao qual se destinavam. Após uma análise cuidadosa destes trabalhos, optamos por adotar o parâmetro de classificação descrito a seguir. Dividimos o foco temático Formação de Professores em dois outros focos. Os focos temáticos seriam distintos entre Formação Continuada de Professores e Formação Inicial de Professores. Conseqüentemente, também distinguimos o nível escolar para cada foco temático reformulado. Quando o tema tratava da Formação Continuada de Professores o trabalho em estudo era classificado quanto ao nível de escolaridade em Ensino Fundamental ou Médio, uma vez que os professores 
participantes da pesquisa atuavam nestes níveis de escolaridade (professores de Ciências do Ensino Fundamental e professores de Química no Ensino Médio em serviço na rede pública ou privada de ensino). No caso do trabalho tratar da Formação Inicial de Professores, a sua classificação quanto ao nível escolar foi sempre tomada como Ensino Superior, uma vez que estes trabalhos versavam sobre os alunos dos cursos de Licenciatura.

Um foco temático que merece um comentário a parte é o foco Outro. Segundo Megid Neto $^{14}$ esta classificação era destinada aos trabalhos cujo foco em estudo não encontrava correspondência com os demais, e sua incidência de casos no conjunto dos documentos classificados havia sido pequena, principalmente trabalhos que discutiam questões envolvendo vestibulares e pesquisas do tipo estado da arte.

$\mathrm{Na}$ pesquisa por nós realizada, verificamos que alguns dos trabalhos que seriam classificados como Outro (de acordo com Megid Neto ${ }^{14}$ ) mereciam pertencer a um foco temático próprio, uma vez que o número de trabalhos referentes ao assunto era elevada. Este é o caso dos trabalhos relacionados com os vestibulares, pois apareceram com uma certa freqüência nos resumos das RASBQs. Mesmo assim, decidimos por adotar os focos propostos por Megid Neto $^{14}$, e discutir com detalhes os trabalhos que foram classificamos no foco Outro.

Após a leitura e classificação dos resumos contidos nos Livros de Resumos das $22^{\mathrm{a}}$ e $23^{\mathrm{a}}$ RASBQs, passamos a leitura e classificação dos resumos da $24^{a}$ RASBQ. Cabe lembrar que para esta reunião tivemos acesso aos resumos impressos no Livro de Resumo. Conforme mencionamos anteriormente, devido ao reduzido tamanho deste tipo resumo, os trabalhos foram classificados apenas nos aspectos referentes à Instituição a que o pesquisador está vinculado e a região geográfica brasileira de origem do trabalho. As demais reuniões, $25^{\mathrm{a}}, 26^{\mathrm{a}} 27^{\mathrm{a}}$ e $28^{\mathrm{a}}$ RASBQs, seguiram os critérios anteriormente estabelecidos com exceção da reunião ocorrida em 2004.

Uma característica peculiar deve ser ressaltada quanto à 27 RASBQ, realizada em 2004. Esta reunião englobou outro congresso - XXVI Congreso Latinoamericano de Química. Quando 
iniciamos a leitura destes trabalhos, encontramos vários trabalhos de origem estrangeira e que também classificamos como os demais. No entanto, no aspecto relacionado à região geográfica do Brasil, introduzimos o descritor exterior, e o país de origem do trabalho apresentado.

\subsection{ORGANIZAÇÃO DOS RESULTADOS}

Feitas todas as classificações, passamos para a organização dos dados da pesquisa. Organizamos os dados obtidos quanto aos aspectos analisados, na forma de tabelas e gráficos, para uma melhor visualização dos mesmos os subdividimos em tópicos distintos. Estes tópicos são:

1. Distribuição no tempo e a representatividade dos trabalhos em relação as demais seções das RASBQs.

2. Distribuição de acordo com as regiões geográficas.

3. Distribuição de acordo com as Instituições acadêmicas e interações diagnosticadas entre as áreas de Ciências Humanas e Ciências Exatas.

4. Distribuição de acordo com o nível escolar.

5. Distribuição de acordo com o foco temático

Após cada distribuição dos aspectos analisados, verificamos as tendências, as características de toda produção e ao final especulamos sobre as contribuições que a comunidade acadêmica tem oferecido ao Ensino de Química praticado no Brasil.

Temos ciência de que os resumos analisados neste trabalho não representam a totalidade dos trabalhos acadêmicos que vêm sendo desenvolvidos na área de Ensino de Química. Ocorreram em nosso país, no intervalo de tempo em estudo (1999 a 2005) outros congressos que também permitiriam uma discussão deste tipo de produção. Podemos mencionar os Encontros Nacionais de Ensino de Química (ENEQs), os Encontros de Debates sobre o Ensino de Química (EDEQs), que acontecem todos os anos na região Sul do nosso país, os Encontros Nacionais de Pesquisa em Ensino de Ciências (ENPECs) que englobam também trabalhos 
dentro do Ensino de Química, os Congressos Nacionais da Associação Brasileira de Química (CBQ) que possui também uma seção de trabalhos dedicados a pesquisa na área de Ensino de Química e outros tantos encontros regionais que ocorrem em nosso território nacional.

Em conseqüência disso, uma análise aprofundada sobre os vários fatores que colaboram para delinear o perfil do Ensino de Química no Brasil torna-se inviável; ainda assim, muitas considerações, que julgamos úteis para a comunidade interessada no aperfeiçoamento deste Ensino, podem ser tecidas a partir do trabalho que aqui apresentamos. 


\section{RESULTADOS E DISCUSSÃO}

\subsection{A PRODUÇÃO E SUA DISTRIBUIÇÃO NO TEMPO E REPRESENTATIVIDADE DE ACORDO COM O NÚMERO DE TRABALHOS APRESENTADOS NAS SEÇÕES DAS RASBQs}

No conjunto de resumos pertencentes à seção de ED das sete últimas RASBQs, encontramos oitocentos e setenta e nove trabalhos. A distribuição dos mesmos no decorrer das reuniões pode ser verificada na Tabela 1.

Tabela 1 - Distribuição absoluta e percentual dos resumos na seção de ED no período de 1999 a 2005.

\begin{tabular}{|c|c|c|c|c|c|c|c|}
\hline & $\begin{array}{c}\mathbf{2 2}^{\mathbf{a}} \\
\mathbf{( 1 9 9 9 )}\end{array}$ & $\begin{array}{c}\mathbf{2 3}^{\mathbf{a}} \\
\mathbf{( 2 0 0 0 )}^{2}\end{array}$ & $\begin{array}{c}\mathbf{2 4}^{\mathbf{a}} \\
\mathbf{( 2 0 0 1 )}^{\mathbf{2 0 0}}\end{array}$ & $\begin{array}{c}\mathbf{2 5}^{\mathbf{a}} \\
\mathbf{( 2 0 2 )}^{\mathbf{2 0 0 2}}\end{array}$ & $\begin{array}{c}\mathbf{2 6}^{\mathbf{a}} \\
\mathbf{( 2 0 0 3 )}\end{array}$ & $\begin{array}{c}\mathbf{2 7}^{\mathbf{a}} \\
\mathbf{( 2 0 0 4 )}\end{array}$ & $\begin{array}{c}\mathbf{2 8}^{\mathbf{a}} \\
\mathbf{( 2 0 0 5 )}\end{array}$ \\
\hline $\begin{array}{c}\text { Número de resumos na } \\
\text { seção de ED }\end{array}$ & 85 & 90 & 108 & 106 & 135 & 194 & 161 \\
\hline $\begin{array}{c}\text { Percentual dos resumos da } \\
\text { seção de ED em relação às } \\
\text { demais seções }\end{array}$ & $5,99 \%$ & $5,69 \%$ & $7,35 \%$ & $6,00 \%$ & $7,49 \%$ & $7,41 \%$ & $7,15 \%$ \\
\hline
\end{tabular}

Observando o levantamento numérico dos resumos, verificamos um indicativo de amadurecimento da área em estudo: o número de trabalhos apresentados é crescente no período de 1999 a 2005 e um acréscimo considerável se verifica no número de trabalhos apresentados em 2004, com relação aos demais anos investigados. Este acréscimo se deve ao fato da $27^{\mathrm{a}} \mathrm{RASBQ}$, realizada neste ano em Salvador (Bahia), ter ocorrido juntamente com o XXVI Congreso Latinoamericano de Quimica. Assim, cinqüenta e três trabalhos foram apresentados em outro idioma, que não o português. No entanto, um dos trabalhos apresentados em outro idioma, ED-038, foi produzido em parceria com pesquisadores brasileiros, e assim, a produção nacional ficou então restrita a cento e quarenta e dois trabalhos (cento e noventa e quatro trabalhos apresentados na RASBQ - cinqüenta e dois trabalhos apresentados em espanhol ou inglês e produzidos exclusivamente por pesquisadores estrangeiros), o que nos permite concluir que 2005 destaca-se 
como o ano em que o maior número de trabalhos produzidos no Brasil foi apresentado. Ou seja, embora o número de trabalhos apresentados em 2004 seja maior que em 2005 em relação ao valor absoluto, temos em 2004, na realidade, apenas cento e quarenta e dois trabalhos que procedem do nosso país, enquanto que em 2005 temos cento e sessenta e um trabalhos.

Uma análise sobre a representatividade dos trabalhos da seção de ED nas RASBQs, nestes sete anos, indica que, com relação às outras seções, o ano que teve maior representatividade de trabalhos foi 2003 (7,49\%), mantendo uma certa linearidade (na casa dos 7,3\%) nos anos seguintes e o de menor foi 2000 (5,69\%), conforme mostra a Figura 1.

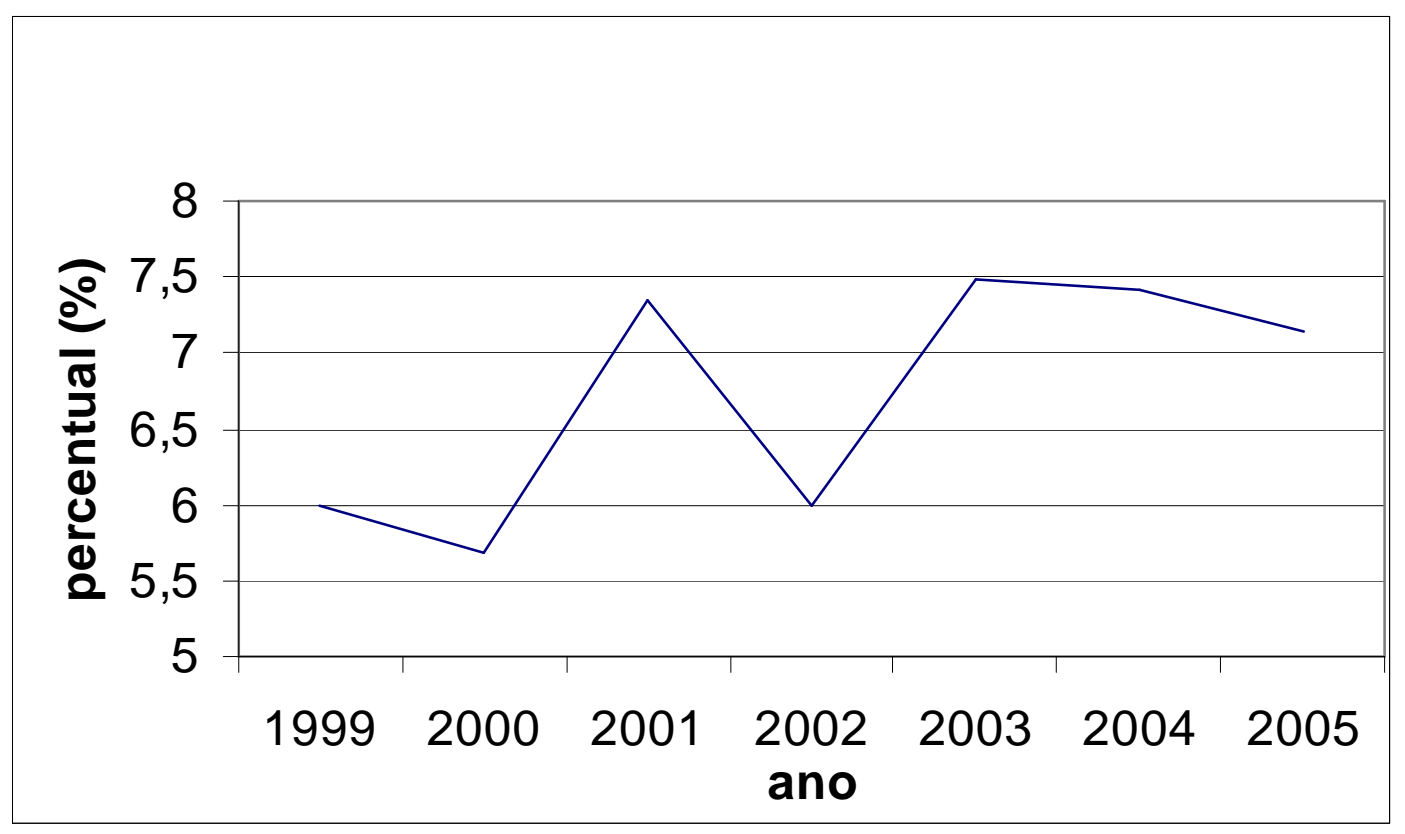

Figura 1 - Evolução da representatividade da seção de ED nas RASBQs no período de 1999 a 2005.

Uma visão geral sobre a representatividade de todas as seções integrantes das RASBQs nos últimos sete anos pode ser obtida a partir da observação da Tabela 2. Verificamos que os trabalhos em Ensino de Química representaram em média 6,83\% dos resumos apresentados nos encontros, o que demonstra uma demanda razoável para esta área, que se equipara à maioria das demais, sendo acentuadamente superada apenas por áreas clássicas da Química (Química Analítica, Química Orgânica e Química Inorgânica) e pelas áreas de Produtos Naturais, Química 
de Materiais, Eletroquímica e Eletroanalítica e Química Ambiental de forte tradição em pesquisas no país.

Tabela 2 - Número (absoluto e relativo) de resumos apresentados por seção nas RASBQs no período de 1999 a 2005.

\begin{tabular}{|c|c|c|}
\hline Área / Seção & Número de resumos & Representatividade (\%) \\
\hline Química Ambiental & 947 & 7,35 \\
\hline Catálise & 383 & 2,97 \\
\hline Ensino de Química & 879 & 6,83 \\
\hline Eletroquímica e Eletroanalítica & 985 & 7,65 \\
\hline Físico-Química & 612 & 4,75 \\
\hline Fotoquímica & 195 & 1,51 \\
\hline História da Química & 54 & 0,42 \\
\hline Química Medicinal & 521 & 4,05 \\
\hline Produtos Naturais & 1700 & 13,20 \\
\hline Química Analítica & 1565 & 12,15 \\
\hline Química Biológica & 363 & 2,82 \\
\hline Química de Superfícies e Colóides & 119 & 0,92 \\
\hline Química Inorgânica & 1241 & 9,64 \\
\hline Química de Materiais & 1224 & 9,50 \\
\hline Química Orgânica & 1408 & 10,93 \\
\hline Química Teórica & 368 & 2,86 \\
\hline Química Tecnológica & 314 & 2,44 \\
\hline
\end{tabular}

De acordo com os dados apresentados verifica-se o fortalecimento de uma comunidade nacional, disposta a eleger como assunto de seus estudos o tema "Ensino de Química". Provavelmente, o aumento da produção na área pode ser articulado com a consolidação do sistema de Pós-Graduação a nível nacional, em especial na área de Ensino de Ciências. Segundo consta no site da Coordenação de Aperfeiçoamento de Pessoal de Nível Superior (CAPES) ${ }^{25}$. alguns dos cursos de Mestrado e/ou Doutorado abertos nos últimos dez anos são: o Mestrado e Doutorado em Educação Para a Ciência da Universidade Estadual Paulista/Bauru; o Mestrado e Doutorado em Educação Científica e Tecnológica da Universidade Federal de Santa Catarina; o Mestrado e Doutorado em Educação em Ciências, Sociedade e Educação da Universidade Federal Fluminense (1998); o Mestrado em Educação em Ciências da Universidade do Noroeste do Estado do Rio Grande do Sul -UNIJUÍ; o Mestrado Profissionalizante em Ensino de Ciências da Universidade de Brasília; o Mestrado em Ensino das Ciências da Universidade Federal Rural 
de Pernambuco; o Mestrado em Educação em Ciências e Matemática da Universidade Federal do Pará; o Mestrado em Ciências e Matemática da Pontifícia Universidade Católica do Rio Grande do Sul - PUC-RS (2002).

\subsection{A PRODUÇÃO E SUA DISTRIBUIÇÃO DE ACORDO COM AS REGIÕES BRASILEIRAS}

O número de trabalhos apresentados nas RASBQs no período compreendido entre 1999 e 2005 de acordo com a distribuição por regiões geográficas do Brasil, encontra-se na Tabela 3. Cabe esclarecer que dentre os oitocentos e setenta e nove trabalhos mencionados anteriormente, apenas oitocentos e vinte e um foram considerados nesta análise, uma vez que os cinqüenta e dois trabalhos procedentes exclusivamente do exterior (apresentados na $27^{a} \mathrm{RASBQ}$ ) não foram contabilizados. Também foram excluídos desta análise cinco resumos (ED-014 e ED-046 em 2001; ED-047 em 2004; ED-016 e ED-141 em 2005), que não indicavam nem a instituição nem o endereço dos autores, e o trabalho ED-022, apresentado na reunião ocorrida em 1999, uma vez que tudo leva a crer, a partir da análise do conteúdo nele expresso, que foi anexado equivocadamente à seção de ED. Acreditamos que o referido trabalho pertença à seção de Química Biológica ou área afim. Ou seja, os trabalhos mencionados acima não foram contabilizados nos nossos percentuais e o valor total de trabalhos que consideramos foi oitocentos e vinte e um (oitocentos e setenta e nove trabalhos apresentados nas RASBQs (cinqüenta e dois trabalhos procedentes do exterior + cinco trabalhos sem indicação de região geográfica + o trabalho ED-022 apresentado em 1999).

É necessário destacar ainda que na Tabela 3 o número de trabalhos excede os oitocentos e vinte e um mencionados anteriormente, uma vez que cada trabalho apresentado por dois autores provenientes de regiões diferentes foi computado duas vezes, em cada uma das regiões. Considerando que vinte e três trabalhos foram apresentados em parceria por autores de duas 
regiões diferentes, o número de trabalhos computados na Tabela 3 é de oitocentos e quarenta e quatro. Todos os percentuais foram calculados sobre oitocentos e vinte e um trabalhos.

Tabela 3 - Distribuição dos resumos apresentados na seção de ED nas RASBQs de acordo com as regiões geográficas brasileira no período de 1999 a 2005.

\begin{tabular}{|c|c|c|c|c|c|c|c|c|c|}
\hline $\begin{array}{c}\text { Região } \\
\text { geográfica }\end{array}$ & $\mathbf{1 9 9 9}$ & $\mathbf{2 0 0 0}$ & $\mathbf{2 0 0 1}$ & $\mathbf{2 0 0 2}$ & $\mathbf{2 0 0 3}$ & $\mathbf{2 0 0 4}$ & $\mathbf{2 0 0 5}$ & Total & Porcentagem(\%) \\
\hline Sul & 08 & 12 & 13 & 16 & 25 & 19 & 18 & 111 & 13,52 \\
\hline Sudeste & 49 & 61 & 74 & 67 & 79 & 67 & 101 & 498 & 60,65 \\
\hline Centro-oeste & 09 & 07 & 08 & 10 & 14 & 15 & 22 & 85 & 10,35 \\
\hline Nordeste & 21 & 13 & 13 & 19 & 21 & 38 & 19 & 144 & 17,53 \\
\hline Norte & - & - & 01 & - & - & 01 & 03 & 05 & 0,61 \\
\hline
\end{tabular}

Podemos verificar que a quantidade majoritária de trabalhos é proveniente da região Sudeste, representando $60,65 \%$ do total apresentado. O fato desta região abrigar um número elevado de IES e dentre elas se encontrarem algumas das universidades públicas de maior tradição em pesquisa no nosso país, como a Universidade de São Paulo (USP), Universidade Federal do Rio de Janeiro (UFRJ) e Universidade Federal de Minas Gerais (UFMG), justifica, em parte, esta relevante contribuição. A região conta ainda, segundo o portal da $\mathrm{CAPES}^{25}$, com seis programas de Pós-Graduação na área específica: Educação Para a Ciência da Universidade Estadual Paulista/Bauru (UNESP); Ensino de Ciências - modalidade Física e Química (USP); Ensino de Ciências e Matemática do Centro Federal de Educação Tecnológica do Rio de Janeiro (CEFET-RJ) e da Universidade Cruzeiro do Sul - SP (UNICSUL); Educação (Ciências, Sociedade e Educação) da Universidade Federal Fluminense (UFF); Tecnologia Educacional na Ciências e Saúde da Universidade Federal do Rio de Janeiro (UFRJ) e Ensino e História da Ciências da Terra da Universidade Estadual de Campinas (UNICAMP). Estes programas certamente catalisam a produção de trabalhos na área de Ensino de Química. Além disto, ainda existem programas voltados ao Ensino em Ciências de algumas IES que estão aguardando a 
homologação de reconhecimento do programa na área. Outro fator que pode contribuir para essa representatividade que verificamos na região Sudeste seria que nesta região temos um número maior de IES tanto administradas pelo poder público (federal, estadual e municipal) quanto administradas pelo setor privado, segundo dados disponibilizados no pelo Ministério da Educação (MEC), no site do Instituto Nacional de Estudos e Pesquisas Educacionais Anísio Teixeira (INEP) ${ }^{26}$, apresentados de forma sucinta na Tabela 4.

Tabela 4 - Número de IES distribuídos de acordo com as regiões geográficas brasileiras e setores administrativos.

\begin{tabular}{|c|c|c|c|}
\hline Região Geográfica & $\begin{array}{c}\text { Administração } \\
\text { Pública }\end{array}$ & $\begin{array}{c}\text { Administração } \\
\text { Privada }\end{array}$ & Total de IES \\
\hline Sul & 39 & 369 & 408 \\
\hline Sudeste & 105 & 1054 & 1159 \\
\hline Centro-oeste & 18 & 240 & 258 \\
\hline Nordeste & 61 & 364 & 425 \\
\hline Norte & 21 & 122 & 143 \\
\hline
\end{tabular}

Por fim, há ainda um outro aspecto que pode justificar o fato da região Sudeste apresentar a maioria dos trabalhos nas RASBQs no período investigado. Das sete reuniões, seis foram realizadas no Estado de Minas Gerais, na cidade de Poços de Caldas, aspecto que aparentemente favoreceu muito a apresentação de trabalhos por pesquisadores da região Sudeste. De fato, podemos avaliar a relevância deste aspecto quando observamos que na ocasião em que o evento foi sediado na região Nordeste, em 2004, o número de trabalhos apresentados por pesquisadores desta região quase que duplicou em relação aos dois anos anteriores e ao ano posterior.

As regiões Sul e Nordeste colaboraram, respectivamente, com 13,52\% e 17,53\% dos trabalhos apresentados. No Nordeste, um número considerável de resumos foi apresentado por pesquisadores dos Estados de Pernambuco, Bahia e Sergipe, em comparação com os demais que fazem parte da região. Assim como observado anteriormente para a região Sudeste, pode-se especular que os programas de Mestrado em Ensino das Ciências da Universidade Federal de Pernambuco (UFPE) e Ensino, Filosofia e História das Ciências da Universidade Federal da 
Bahia (UFBA) fomentaram a apresentação de trabalhos na área de Ensino de Química. $\mathrm{Na}$ região Sul encontra-se o maior número de programas de Pós-Graduação na área de Ensino de Ciências e Matemática, reconhecidos pela CAPES, sendo eles: Educação Científica e Tecnológica da Universidade Federal de Santa Catarina (UFSC), Educação em Ciências e Matemática da Pontifícia Universidade Católica do Rio Grande do Sul (PUC-RS), Educação em Ciências: Química da Vida e Saúde da Universidade Federal do Rio Grande do Sul (UFRGS), Ensino de Ciências e Educação Matemática da Universidade Estadual de Londrina (UEL), Educação Para a Ciência e o Ensino de Matemática da Universidade Estadual de Maringá (UEM) e Ensino de Ciências e Matemática da Universidade Luterana do Brasil do Rio Grande do Sul (ULBRA). Esta concentração de programas de Pós-Graduação justifica, em conjunto com a existência de alguns centros de pesquisa de destaque na área de Química, a constatação de resumos provenientes de todos os estados da região.

A região Norte, surpreendentemente, compareceu com a apresentação de apenas cinco trabalhos no período investigado: ED-011(2001) da Universidade Federal do Pará (UFPA); ED144 (2004) da Universidade Federal de Roraima (UFRR) e os ED-013, ED-014 e ED-070 (2005) produzidos também pela UFRR. Embora exista um programa de Mestrado em Educação em Ciências e Matemática na UFPA e outro da Universidade Estadual do Amazonas, esperando a homologação ser concedida pelo MEC, quase todos os trabalhos provenientes desta região foram produzidos por pesquisadores do Estado de Roraima. Considerando o isolamento típico do local e o seu distanciamento do Sudeste, estes podem explicar em parte, a quase que total ausência de resumos apresentados pertencentes a esta região. No entanto, pode ser observado que em outras seções das RASBQs são encontrados trabalhos de pesquisadores da região Norte, com especial destaque na seção de Produtos Naturais, sugerindo que o número reduzido de resumos na seção de ED pode ser devido também à pouca atividade de pesquisa na área, nesta região.

A região Centro-oeste, no período investigado, aumentou linearmente a sua representatividade a cada ano. No entanto, apresenta ainda uma produção inferior à das regiões 
Nordeste e Sul. A recente criação, em 2004, do Mestrado Profissionalizante em Ensino de Ciências na Universidade de Brasília (UnB) e a espera da homologação do mesmo programa de Pós-Graduação pela Universidade Federal do Mato Grosso do Sul (UFMS), aliadas ao fato da região contar duzentos e cinqüenta e oito IES (dezoito de administração pública e duzentos e quarenta de administração do setor privado) sugerem a sua potencialidade para a produção de trabalhos na área em questão. A Figura 2 sintetiza a distribuição dos trabalhos na seção de ED por região brasileira.

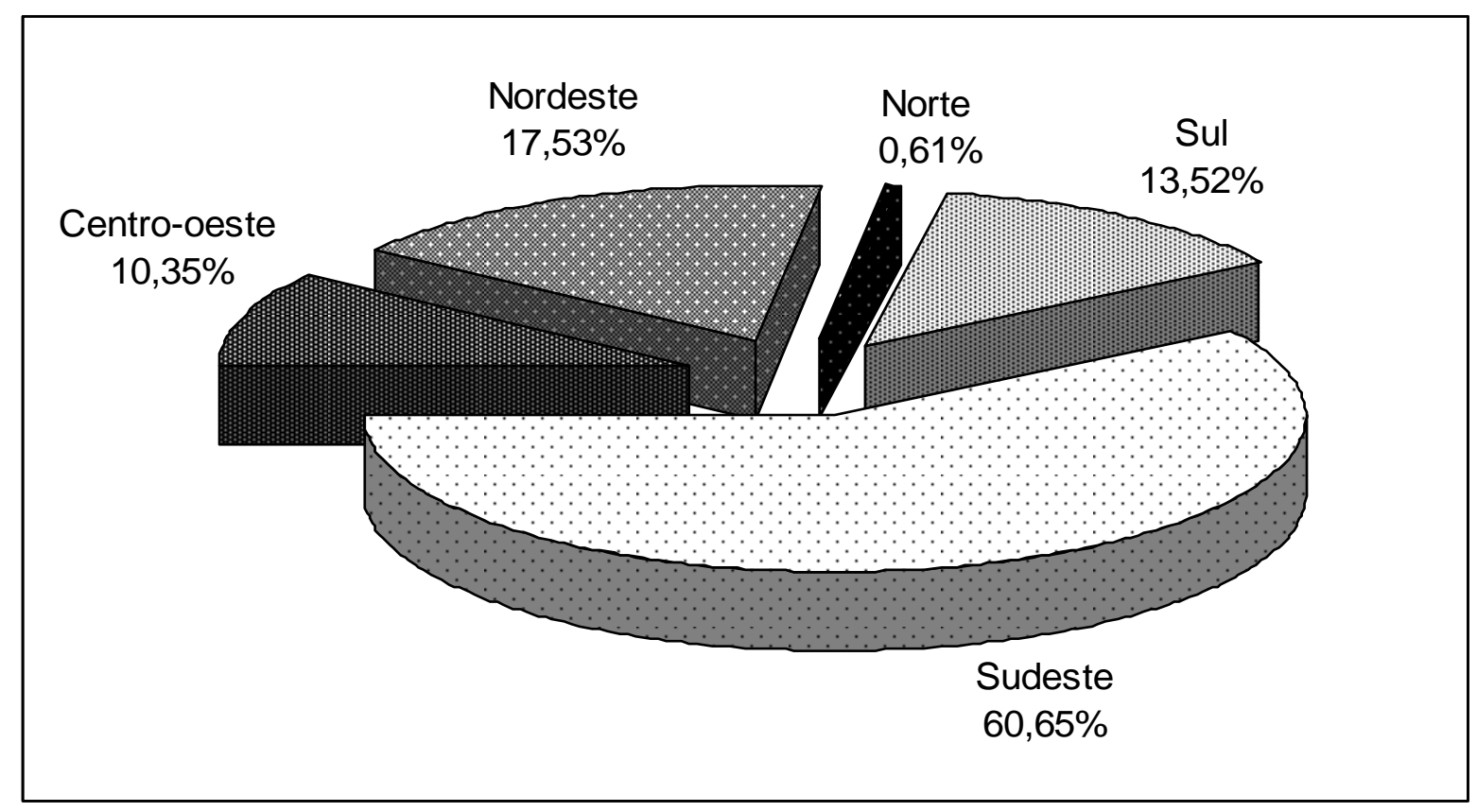

Figura 2 - Distribuição dos trabalhos de acordo com a região geográfica brasileira apresentados na seção de ED nas RASBQs no período de 1999 a 2005.

Mencionamos anteriormente que encontramos vinte e três trabalhos que contaram com a participação de pesquisadores de instituições de regiões diferentes na sua produção. Verificamos que a maioria das parcerias na produção de trabalhos provenientes de diferentes regiões foi estabelecida entre os pesquisadores das regiões Sudeste e Centro-Oeste, Sudeste e Nordeste, Sudeste e Sul. Um único trabalho, proveniente das regiões Sul e Centro-Oeste (Universidade Federal do Mato Grosso do Sul e Universidade Estadual de Maringá) foi encontrado, como mostra a Tabela 5. De acordo com a análise desses trabalhos, as IES que mais se destacaram 
neste tipo de interação foram: a Universidade de Brasília (UnB), a Universidade Católica de Brasília (UCB), a Universidade Federal de Minas Gerais (UFMG), a Universidade Estadual Paulista (UNESP), a Universidade de São Paulo(USP), a Universidade Estadual do Sudoeste da Bahia (UESB), a Universidade Federal do Ceará (UFC), a Universidade do Noroeste do Estado do Rio Grande do Sul (UNJUÍ) e a Universidade Estadual do Centro Oeste do Paraná (UNICENTRO).

Tabela 5 - Distribuição dos trabalhos resultantes de interações entre pesquisadores de diferentes regiões geográficas brasileiras apresentados na seção de ED nas RASBQs no período de 1999 a 2005.

\begin{tabular}{|c|c|c|c|c|}
\hline & Sudeste e Centro-oeste & Sudeste e Nordeste & Sudeste e Sul & Sul e Centro-oeste \\
\hline 1999 & $\begin{array}{l}\text { ED-046 } \\
\text { ED-050 } \\
\text { ED-070 }\end{array}$ & - & - & - \\
\hline 2000 & $\begin{array}{l}\text { ED-007 } \\
\text { ED-049 }\end{array}$ & - & ED-058 & - \\
\hline 2001 & ED-061 & - & $\begin{array}{l}\text { ED-001 } \\
\text { ED-085 }\end{array}$ & - \\
\hline 2002 & $\begin{array}{l}\text { ED-049 } \\
\text { ED-065 }\end{array}$ & $\begin{array}{l}\text { ED-017 } \\
\text { ED-021 } \\
\text { ED-054 }\end{array}$ & ED-046 & - \\
\hline 2003 & $\begin{array}{l}\text { ED-111 } \\
\text { ED-129 } \\
\end{array}$ & ED-080 & ED-113 & - \\
\hline 2004 & - & - & - & - \\
\hline 2005 & - & $\begin{array}{l}\text { ED-072 } \\
\text { ED-139 } \\
\text { ED-142 }\end{array}$ & - & ED-120 \\
\hline Total & 10 & 07 & 05 & 01 \\
\hline
\end{tabular}

As interações entre as IES das regiões Sudeste e Centro-Oeste ocorreram, principalmente, entre os grupos liderados pelos pesquisadores Gerson de Souza Mol (que até a reunião de 2000, este era pesquisador da UFMG e a partir de 2001 passa a ser pesquisador da UnB) e Eduardo Fleury Mortimer, da região Sudeste, com Wildson Luiz Pereira Santos e Roberto Ribeiro Silva, de IES da região Centro-oeste. No que diz respeito aos trabalhos resultantes de interações entre pesquisadores pertencentes às regiões Sudeste e Sul, destacam-se aqueles produzidos pelos grupos liderados por Roseli Schnetzler, da região Sudeste, e Lenir Basso Zanon, da região Sul. As demais interações ocorreram, com pouca regularidade, entre grupos de pesquisas diversificados. 


\subsection{A PRODUÇÃO E SUA DISTRIBUIÇÃO POR INSTITUIÇÕES ACADÊMICAS}

Outra questão importante a ser estabelecida a partir da análise dos resumos avaliados diz respeito às IES as quais estão vinculados os autores dos trabalhos. No entanto, nem todos os resumos foram considerados nesta análise: dos oitocentos e setenta e nove trabalhos pertencentes à seção de ED, cinqüenta e dois deles não foram contabilizados por serem procedentes exclusivamente do exterior. O trabalho ED-022, mencionado anteriormente, não foi contabilizado por não se relacionar ao Ensino de Química, e vinte e quatro outros trabalhos (indicados na Tabela 6) também não o foram, porque não mencionavam a instituição de vínculo dos autores.

Cabe ressaltar que há uma diferença entre o número de resumos que não mencionavam a região a que pertencia o trabalho e aqueles que não mencionavam a instituição. De fato, alguns resumos apresentam o endereço do pesquisador, mas não mencionam claramente a sua instituição de origem. Assim, o valor total dos trabalhos analisados neste tópico é diferente daquele que utilizamos na análise anterior, quanto às regiões geográficas.

Tabela 6 - Distribuição dos trabalhos da seção de ED que não mencionam a instituição de produção, no período de 1999 a 2005.

\begin{tabular}{|c|c|}
\hline Reunião & Trabalhos que não mencionam a Instituição de origem dos autores \\
\hline $22^{\mathrm{a}}-1999$ & - \\
\hline $23^{\mathrm{a}}-2000$ & - \\
\hline $24^{\mathrm{a}}-2001$ & ED-014; ED-016; ED-046; ED-086 \\
\hline $25^{\mathrm{a}}-2002$ & ED-004 \\
\hline $26^{\mathrm{a}}-2003$ & ED-007; ED-066; ED-110; ED-127 \\
\hline $27^{\mathrm{a}}-2004$ & ED-041; ED-045; ED-047; ED-105; ED-106; ED-182; ED-183 \\
\hline $28^{\mathrm{a}}-2005$ & ED-016; ED-029; ED-031; ED-043; ED-049; ED-071; ED-092; ED-141 \\
\hline
\end{tabular}

Assim, são oitocentos e dois os trabalhos que fazem parte da análise realizada neste tópico. Neste contexto, verificamos que cento e quatorze IES contribuíram com a produção de setecentos e noventa e três trabalhos. Os outros nove trabalhos foram produzidos por 
pesquisadores ou professores não vinculados a Instituições de Ensino Superior, e sim a escolas de Ensino Básico, Secretarias de Educação e Diretorias de Ensino, por exemplo. Existem dois trabalhos em particular, um apresentado na $26^{\mathrm{a}}$ (ED-024) e outro na $27^{\mathrm{a}}$ (ED-038) RASBQs, realizados a partir de interações entre IES do nosso país e de outros países (Universidade de Brasília e Pädagogische Hochschule Ludwigsburg (Alemanha) e Universidad Central de Las Villas (Cuba) e o Centro Federal de Educação Celso Suckow da Fonseca, localizado no Rio de Janeiro). A Tabela 7 mostra a distribuição da produção segundo as IES que tiveram uma participação de até $1 \%$ sobre o total de trabalhos apresentados entre 1999 a 2005. 
Tabela 7 - Distribuição de parte dos trabalhos da seção de ED de acordo com a Instituição de Ensino Superior de origem de produção no período de 1999 a 2005.

\begin{tabular}{|l|c|c|}
\hline Instituição/Estado & $\begin{array}{c}\text { Número de } \\
\text { trabalhos }\end{array}$ & $\begin{array}{c}\text { Percentual } \\
\mathbf{( \% )}\end{array}$ \\
\hline Universidade de São Paulo (USP) - SP & 92 & 11,16 \\
\hline Universidade Estadual de Campinas (UNICAMP) - SP & 66 & 8,23 \\
\hline Universidade Federal Fluminense (UFF) - RJ & 61 & 7,61 \\
\hline Universidade Federal de Minas Gerais (UFMG) - MG & 52 & 6,48 \\
\hline Universidade Federal Rural de Pernambuco (UFRPE) - PE & 41 & 5,11 \\
\hline Universidade de Brasília (UnB) - DF & 38 & 4,61 \\
\hline Universidade do Estado do Rio de Janeiro (UERJ) - RJ & 33 & 4,11 \\
\hline Universidade Federal do Rio de Janeiro (UFRJ) - RJ & 32 & 3,99 \\
\hline Universidade Estadual Paulista (UNESP) - SP & 30 & 3,74 \\
\hline Universidade Federal de Sergipe (UFS) - SE & 27 & 3,37 \\
\hline Universidade Federal de Goiás (UFG) - GO & 22 & 2,74 \\
\hline Centro Federal de Educação Tecnológica de Química de & 20 & 2,49 \\
Nilópolis (CEFETQ-NILÓPOLIS) - RJ & 19 & 2,37 \\
\hline Universidade Federal de São Carlos (UFSCAR) - SP & 18 & 2,24 \\
\hline Universidade Federal de Viçosa (UFV) - MG & 18 & 2,24 \\
\hline Universidade Federal de Pernambuco (UFPE) - PE & 16 & 1,99 \\
\hline Universidade Estadual de Londrina (UEL) - PR & 14 & 1,74 \\
\hline Universidade Estadual do Sudoeste da Bahia (UESB) - BA & 13 & 1,62 \\
\hline Universidade Católica de Brasília (UCB) - DF & 12 & 1,50 \\
\hline Universidade Federal de Uberlândia (UFU) - MG & 11 & 1,37 \\
\hline Universidade Federal da Bahia (UFBA) - BA & 11 & 1,37 \\
\hline Universidade Estadual do Norte Fluminense (UENF) - RJ & 11 & 1,37 \\
\hline Universidade de Santa Cruz do Sul (UNISC) - RS & 10 & 1,25 \\
\hline Universidade Federal Rural do Rio de Janeiro (UFRRJ) - RJ & 09 & 1,12 \\
\hline Universidade Federal do Rio Grande do Sul (UFRGS) - RS & 09 & 1,12 \\
\hline Universidade Federal do Rio Grande do Norte (UFRN) - RN & 09 & 1,12 \\
\hline Universidade Federal do Paraná (UFPR) - PR & 09 & 1,12 \\
\hline Universidade Federal do Mato Grosso do Sul (UFMS) - MS & $\mathbf{7 1 2}$ & $\mathbf{8 8 , 3 2}$ \\
\hline Universidade Estadual de Maringá (UEM) - PR & & \\
\hline Total & & \\
\hline
\end{tabular}

Uma análise dos dados apresentados na Tabela 7 mostra que cerca de $88 \%$ da produção do período está restrita a apenas vinte e oito IES, sendo que, dentre elas, treze estão localizadas na região Sudeste, seis na região Nordeste, cinco na região Sul e quatro na região Centro-oeste. Logo, as IES situadas na região Sudeste são responsáveis por $56,54 \%$ da produção, confirmando a predominância de trabalhos desta região no item anterior. Faz-se necessário esclarecer que do total apresentado na Tabela 7, setenta e seis trabalhos foram desenvolvidos por mais de uma IES, às vezes pertencentes à mesma região ou a regiões distintas, como mencionamos quanto à 
distribuição dos trabalhos por regiões geográficas. Outro dado que merece ser destacado é que na instituição com o maior percentual de produção, a Universidade de São Paulo, os trabalhos apresentados resultam dos esforços de não apenas um único grupo de pesquisa. $\mathrm{Na}$ verdade, são provenientes tanto do Instituto de Química, quanto da Faculdade de Educação e de unidades em seus campi do interior. Outras instituições também apresentaram esta característica: vários trabalhos produzidos pela UNESP, por exemplo, também são provenientes de esforços de pesquisadores distribuídos em várias unidades em seus campi. Podemos ainda constatar que das vinte e vinte IES, apenas duas delas são administradas pelo setor privado (Universidade Católica de Brasília e Universidade de Santa Cruz do Sul). Fazendo-se uma análise da formação dos pesquisadores orientadores de ambas, esta aponta para o ensino público, o que sugere um predomínio quase absoluto das IES administradas pelo setor público na formação de pesquisadores da área de Ensino de Ciências. A Figura 3 apresenta a classificação das quinze IES de maior produção, segundo o número de trabalhos apresentados na seção de ED das RASBQs avaliadas.

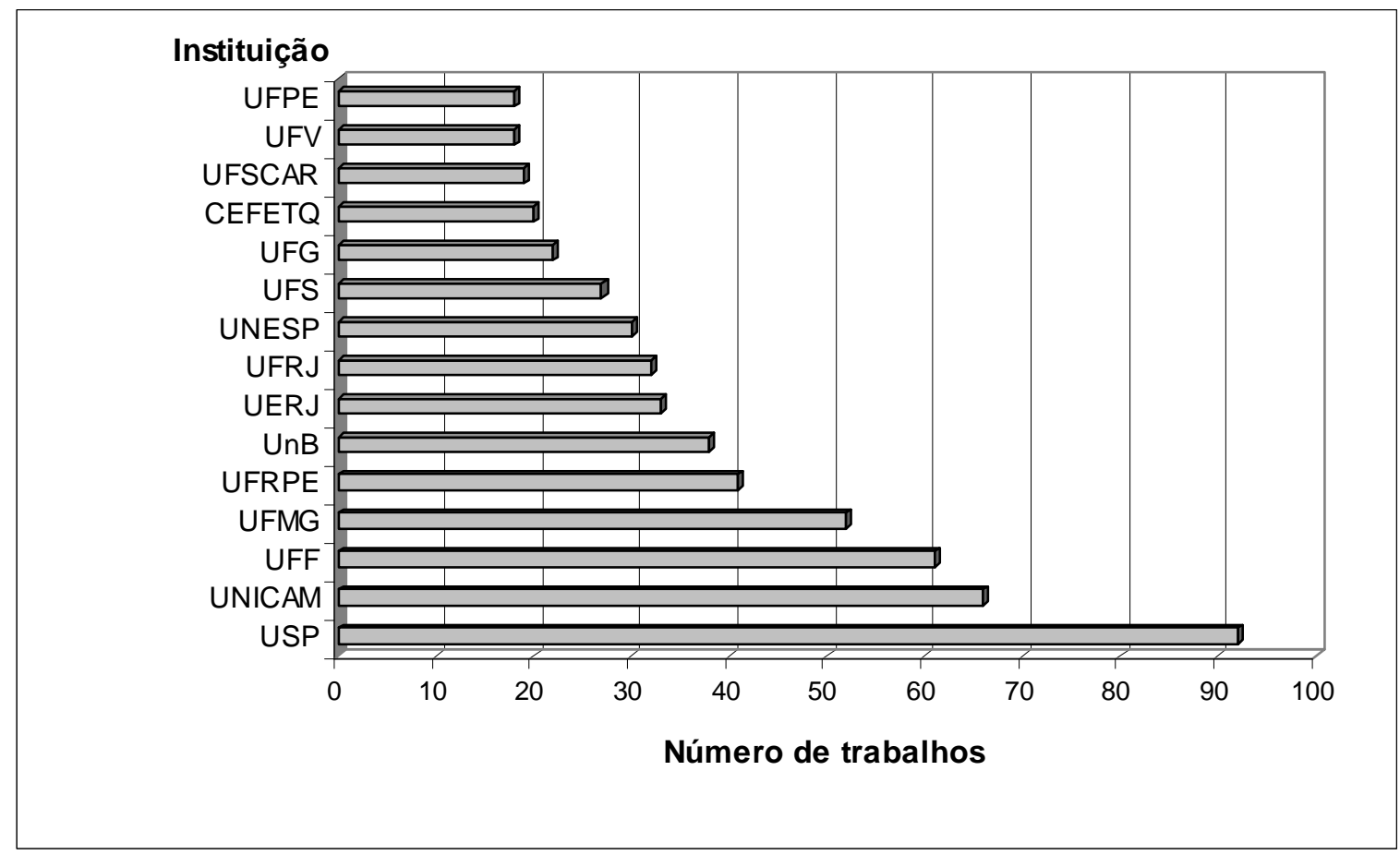

Figura 3 - Gráfico de distribuição de IES com maior número de trabalhos apresentados na seção de ED nas RASBQs no período de 1999 a 2005. 
Embora a maioria dos trabalhos apresentados seja originária de IES, um número relativamente pequeno foi total ou parcialmente produzido em instituições de natureza distinta, que variavam desde escolas e colégios de educação básica, empresas, Secretarias de Educação e Diretorias de Ensino até o Departamento da Polícia Federal.

Além da observação das IES envolvidas na produção dos trabalhos, também nos preocupamos em investigar se estes haviam sido produzidos em departamentos ou institutos mais estreitamente relacionados às áreas de Ciências Humanas ou de Ciências Exatas ou se através da interação de pesquisadores das duas áreas. Tínhamos como intuito verificar se pesquisadores destas áreas distintas têm interagido na produção de trabalhos sobre o Ensino de Química, que trazem em seu bojo características de ambas.

Dos oitocentos e dois trabalhos analisados, sessenta e dois foram produzidos por pesquisadores vinculados a Departamentos/Institutos de Química juntamente com pesquisadores de Departamentos/Institutos relacionados à área de Ciências Humanas, como Educação e Psicologia, por exemplo. Ademais, vinte e quatro dos trabalhos analisados foram produzidos por pesquisadores alocados em Departamentos/Institutos de Química, mas que estavam vinculados a um programa de Pós-Graduação em Educação ou em Educação em Ciências. A Tabela 8 apresenta estes trabalhos e a distribuição dos mesmos no período de 1999 a 2005. 
Tabela 8 - Distribuição dos trabalhos apresentados na seção de ED nas RASBQs de acordo com interações entre áreas de Ciências Humanas e Ciências Exatas no período de 1999 a 2005.

\begin{tabular}{|c|c|c|c|c|}
\hline & $\begin{array}{c}\text { Departamento de Química } \\
\text { X } \\
\text { Departamento de Ensino }\end{array}$ & $(\%)$ & $\begin{array}{l}\text { Programa de Pós- } \\
\text { Graduação em Ensino de } \\
\text { Ciências ou Educação }\end{array}$ & $(\%)$ \\
\hline 1999 & $\begin{array}{l}\text { ED-007; ED-018; ED-039;ED-048; } \\
\text { ED-051; ED-052; ED-053; ED-070; } \\
\text { ED-079 }\end{array}$ & 1,12 & ED-062; ED-074 & 0,25 \\
\hline 2000 & $\begin{array}{l}\text { ED-001; ED-002; ED-006; ED-007; } \\
\text { ED-020; ED-021; ED-022; ED-032; } \\
\text { ED-060; ED-067 }\end{array}$ & 1,24 & ED-010; ED-024 & 0,25 \\
\hline 2001 & $\begin{array}{l}\text { ED-009; ED-013; ED-015; ED-044; } \\
\text { ED-050; ED-051; ED-083; ED-085 }\end{array}$ & 0,99 & $\begin{array}{l}\text { ED-019; ED-088; ED-105; } \\
\text { ED-106 }\end{array}$ & 0,50 \\
\hline 2002 & $\begin{array}{l}\text { ED-002; ED-006; ED-013; ED-049; } \\
\text { ED-083; ED-096 }\end{array}$ & 0,75 & $\begin{array}{l}\text { ED-009; ED-019; ED-078; } \\
\text { ED-095 }\end{array}$ & 0,50 \\
\hline 2003 & $\begin{array}{l}\text { ED-013; ED-014; ED-031; ED-036; } \\
\text { ED-047; ED-051; ED-059; ED-061; } \\
\text { ED-085; ED-097; ED-102; ED-109; } \\
\text { ED-111; ED-125; ED-134 }\end{array}$ & 1,87 & ED-053; ED-076 & 0,25 \\
\hline 2004 & $\begin{array}{l}\text { ED-035; ED-042; ED-050; ED-111; } \\
\text { ED-112; ED-146; ED-154; ED-160; } \\
\text { ED-178 }\end{array}$ & 1,12 & ED-086; ED-087 & 0,25 \\
\hline 2005 & $\begin{array}{l}\text { ED-008; ED-075; ED-108; ED-132; } \\
\text { ED-146 }\end{array}$ & 0,62 & $\begin{array}{l}\text { ED-026; ED-057; ED-058; } \\
\text { ED-102; ED-110; ED-114; } \\
\text { ED-115; ED-152 }\end{array}$ & 1,12 \\
\hline total & 62 trabalhos & 7,71 & 24 trabalhos & 3,12 \\
\hline
\end{tabular}

Observamos que temos em média 7,71 \% de trabalhos desenvolvidos entre departamentos e 3,12\% de trabalhos desenvolvidos dentro de programas de Pós-Graduação em Educação, totalizando 10,83\% dos trabalhos analisados. Assim, consideramos que ocorre uma interação razoável entre pesquisadores das duas grandes áreas na produção dos trabalhos em foco. Este resultado é animador, considerando as vantagens que podem resultar de trabalhos produzidos de forma interdisciplinar.

A partir da constatação de quais IES apresentaram o maior número de trabalhos nas RASBQs, verificamos também quais grupos de pesquisa se destacaram em cada uma delas. Observamos que na USP $10,87 \%$ dos trabalhos são provenientes do grupo de pesquisa liderado por Marcelo Giordan; 9,78\% são provenientes do grupo liderado por Maria Eunice Ribeiro Marcondes, 8,70\% do grupo formado por Viktoria Klara Lakatos Osório, sendo que metade 
destes trabalhos $(4,35 \%)$ foram produzidos em parceria com a pesquisadora Wanda de Oliveira. Ainda encontramos com $7,61 \%$ de representatividade os trabalhos desenvolvidos pelo grupo de Adelaide Faljoni-Alário e 6,52\% do grupo liderado por Silvia Maria Leite Agostinho. Estes grupos localizam-se no campus da USP da cidade de São Paulo. No campus de São Carlos, temos 8,70\% dos trabalhos apresentados pelo grupo liderado por Salete Linhares Queiroz e 5,34\% pelo grupo liderado por Éder Tadeu G. Cavalheiro e ainda no campus de Ribeirão Preto encontra-se o grupo liderado por Yassuko Iamamoto com um total de 5,43\% dos trabalhos pertencentes a esta Instituição. Os outros 36,96\% tiveram uma participação de menos de 3\% sobre o total de trabalhos que foram produzidos por diversos pesquisadores que não pertenciam aos grupos mencionados.

As outras universidades de maior produção da região Sudeste são UNICAMP e UFF. Na UNICAMP, destacam-se os grupos de pesquisa liderados por Pedro Faria dos Santos Filho com 16,66\% de trabalhos, seguido pelos grupos liderados por Adriana Vitorino Rossi (13,63\%), Mathieu Tubino e José de Alencar Simoni (13,63\%), Maria Inês Petrucci S. Rosa (7,58\%) e ainda dois grupos liderados por Antônio Luis Pires Valente e Sebastião F. Fonseca ambos com 6\% dos trabalhos. Os demais grupos participaram com menos de 5\% dos trabalhos provenientes da UNICAMP. Na UFF, o grupo liderado por Lucidea Guimarães Rebello Coutinho contribuiu com 24,59 \% dos trabalhos apresentados pela Instituição, seguido pelo grupo formado por vários pesquisadores e liderado por Nelson Ângelo de Souza que apresentou 16,40\% dos trabalhos no período investigado. Ainda com 6,56\% dos trabalhos temos os grupos liderados por Tânia Guimarães Santa-Rita e o grupo formado por Bianca da Cunha Machado e Carlos Eduardo da Silva Côrtes. Os demais trabalhos foram produzidos por diversos pesquisadores da área, que contribuíram com menos de 5\% do total dos resumos provenientes da Instituição no período estudado.

Analisando a produção das IES da região Nordeste no período entre 1999 a 2005, de acordo com a Tabela 7, temos em destaque a UFRPE e a UFS. Os grupos de pesquisa que 
contribuíram fortemente para esta produção foram aqueles liderados por Rejane Martins Novais Barbosa, com a participação de 46,34\% dos trabalhos da UFRPE, e por Djalma Andrade, com $66,67 \%$ dos trabalhos da UFS.

Para a região Centro-oeste, encontramos a UnB e UFG como as IES com maior atividade na área. Os trabalhos apresentados pela UnB foram produzidos com grande destaque por três grupos de pesquisa distintos. O primeiro tem com líderes Roberto Ribeiro da Silva e Wildson L Pereira Santos e seus trabalhos representam 31,59\% do total; o segundo é liderado por Gerson de Souza Mól com 28,95\% dos trabalhos e por último o grupo liderado por Joice de Aguiar Baptista com 18,42\% dos trabalhos. Quanto à produção da UFG, temos dois grupos em destaque: um liderado por Márlon Herbert Flora Barbosa Soares com 45,45 \% dos trabalhos e o outro grupo liderado por Agustina Rosa Echeverria com 31,82\% do total dos trabalhos apresentados.

$\mathrm{Na}$ região Sul, destaca-se a UNISC e a UFRGS. Analisando os grupos de pesquisa da UNISC verificamos que o grupo liderado por Rosana de Cássia de Souza Schneider e Wolmar Alípio Severo Filho contribuiu com $72,72 \%$ dos trabalhos. Na UFRGS temos dois grupos de pesquisa de destaque, um liderado por César Valmor Machado Lopes e o outro por José Cláudio Del Pino, ambos com 33,33\% de trabalhos do total apresentado.

\subsection{A PRODUÇÃo E SUA DISTRIBUIÇÃO DE ACORDO COM O NÍVEL ESCOLAR ABRANGIDO NO ESTUDO}

A identificação do nível escolar ao qual se relacionam os resumos fez-se possível por meio da utilização dos descritores sobre níveis escolares estabelecidos por Megid $\mathrm{Neto}^{14}$, que se encontram descritos no Capitulo 3 - Referencial Teórico desta dissertação. Alguns dos elementos considerados para a identificação do nível escolar foram: os sujeitos participantes na pesquisa, os materiais didáticos avaliados, os programas de ensino propostos e as experiências educacionais relatadas na pesquisa. Acreditando que a identificação de tais elementos não seria possível apenas 
a partir da leitura do resumo que se encontra disponível nos livros de resumos das RASBQs a partir de 2001 (modelo ilustrado no Apêndice A), devido ao conteúdo extremamente restrito aí apresentado, estabelecemos que a classificação quanto ao nível de escolaridade somente seria realizada para os trabalho que se encontrassem disponíveis para leitura no site da Sociedade Brasileira de Química (SBQ) ${ }^{4}$, a partir de 2001, e para os resumos apresentados nos livros de resumos das reuniões ocorridas em 1999 e 2000. Conforme mencionamos no Capitulo 4 Metodologia de Pesquisa desta dissertação, o formato destes resumos permitia ao autor a apresentação de uma quantidade bem mais elevada de informações do que o formato adotado nos livros de resumos a partir de 2001.

Faz-se necessário frisar que dos oitocentos e setenta e nove trabalhos pertencentes à seção de ED, cinqüenta e dois deles não foram contabilizados por serem procedentes exclusivamente do exterior. $O$ trabalho ED-022, mencionado anteriormente, não foi contabilizado por não se relacionar ao Ensino de Química, e cento e quarenta e oito outros trabalhos também não o foram, porque não estavam disponíveis para leitura no site da Sociedade Brasileira de Química (SBQ) ${ }^{4}$ até o dia 12 de junho de 2006, data da finalização da coleta dos nossos dados. São eles: vinte e seis trabalhos da reunião de 2002 (ED-006, ED-007, ED-010, ED-011, ED-014, ED-017, ED-018, ED-022, ED-024, ED-025, ED-026, ED-031, ED-033, ED-042, ED-044, ED-051, ED-055, ED-060, ED-071, ED-072, ED-076, ED-083, ED-084, ED-092, ED-096 e ED-105); oito trabalhos da reunião de 2003 (ED-002, ED-060, ED-066, ED073, ED-078, ED-114, ED-128 e ED-129); seis trabalhos da reunião de 2004 ( ED-011, ED-012, ED-030, ED-050, ED-074, ED-095, ED-155 ); todos os cento e oito trabalhos da reunião de 2001. Assim, para as análises dos percentuais de representatividade quanto aos níveis de escolaridade, utilizamos como base para cálculo seiscentos e setenta e oito trabalhos. Destes trabalhos, noventa e seis foram classificados em dois níveis ou em três níveis de escolaridade. Por esta razão, a somatória do número de trabalhos apresentados na Tabela 9 é de setecentos e 
oitenta e não mais os seiscentos e setenta e oito calculados anteriormente. Cabe ainda ressaltar que entre os trabalhos em estudo nenhum foi classificado como destinado ao Ensino Infantil.

Tabela 9 - Distribuição dos trabalhos na seção de ED nas RASBQs de acordo com o nível escolar abrangido no período de 1999 a 2005.

\begin{tabular}{|c|c|c|c|c|c|c|c|c|c|}
\hline Nível escolar & $\mathbf{1 9 9 9}$ & $\mathbf{2 0 0 0}$ & $\mathbf{2 0 0 1}$ & $\mathbf{2 0 0 2}$ & $\mathbf{2 0 0 3}$ & $\mathbf{2 0 0 4}$ & $\mathbf{2 0 0 5}$ & total & $\mathbf{( \% )}$ \\
\hline Ensino Fundamental & 17 & 11 & - & 03 & 07 & 11 & 10 & 59 & 8,70 \\
\hline Ensino Médio & 54 & 50 & - & 44 & 71 & 59 & 92 & 370 & 54,57 \\
\hline Ensino Superior & 23 & 38 & - & 32 & 52 & 64 & 72 & 281 & 41,44 \\
\hline Geral & 07 & 05 & - & 08 & 14 & 21 & 15 & 70 & 10,32 \\
\hline
\end{tabular}

Considerando os resultados da Tabela 9, podemos constatar que a maior porcentagem de trabalhos da seção de ED é dedicada ao Ensino Médio (54,57\%), seguida por trabalhos voltados ao Ensino Superior $(41,44 \%)$ e uma baixa produtividade com relação ao Ensino Fundamental (8,70\%). Esta baixa porcentagem de trabalhos voltados ao Ensino Fundamental pode estar associada ao fato da introdução de tópicos relacionados ao Ensino de Química ocorrer apenas nas últimas etapas deste nível escolar ( $7^{a}$ e $8^{a}$ séries). De fato, a grande maioria dos trabalhos apresentados na seção de ED voltados para o Ensino Fundamental trata de propostas de aplicação de projetos, de desenvolvimento de materiais didáticos e a introdução de conceitos básicos de Química para a $7^{\mathrm{a}}$ e $8^{\mathrm{a}}$ série do Ensino Fundamental. Algumas pesquisas dedicadas a estas séries tratam também da identificação de concepções dos alunos e das suas dificuldades na compreensão de alguns conceitos. Em número menor encontram-se os trabalhos de caráter mais abrangente, que abarcam todas as séries do Ensino Fundamental, e os trabalhos que relatam experiências sobre a capacitação de professores deste nível de ensino.

Quanto à alta taxa de produção em relação aos trabalhos voltados para o Ensino Médio, esta pode estar relacionada ao fato de que durante esta fase escolar, o Ensino de Química atravessa todas as séries. Os assuntos abordados nos trabalhos relacionados ao Ensino Médio são variados, mas podemos perceber a preocupação no que diz respeito à elaboração e aplicação de 
diversos materiais didáticos com o intuito de facilitar o processo de ensino-aprendizagem de alguns conceitos químicos, à análise de livros didáticos que geralmente são adotados neste nível de escolaridade, à reflexão sobre as políticas educacionais para o Ensino Médio (especialmente os Parâmetros Curriculares Nacional para o Ensino Médio - PCNEM), além do desenvolvimento e aplicação de novas metodologias de ensino.

Após o Ensino Médio, destaca-se a produção de trabalhos relacionados ao Ensino Superior. A observação dos dados apresentados na Tabela 9 revela que a produção de trabalhos dedicados a este nível de ensino vem aumentando regularmente, e tem se destacado principalmente nas últimas quatro reuniões. Embora não seja possível fazer afirmações acerca das razões que ditaram este aumento, podemos especular que esteja relacionado às modificações que foram feitas nas grades curriculares de alguns cursos oferecidos nas universidades brasileiras, visando a adequação dos cursos às exigências da nova Lei de Diretrizes e Bases da Educação Nacional de 1996, no que diz respeito às Diretrizes Curriculares para os Cursos de Química ${ }^{27}$ e ainda as mudanças que o desenvolvimento tecnológico vem instaurando a nível mundial.

Alguns dos assuntos abordados nos trabalhos voltados ao Ensino Superior são: apresentação de propostas para melhoria da aprendizagem dos alunos a partir da utilização dos mais variados recursos didáticos, com destaque para materiais didáticos que encontram uso em laboratórios de ensino; descrição de programas que almejam a aproximação da Universidade com a Escola e com a Indústria, bem como a integração do ensino de graduação com o de PósGraduação; identificação de concepções de estudantes e professores sobre assuntos variados; elaboração e/ou aplicação de atividades teóricas e experimentais desenvolvidas por alunos de bacharelado ou de licenciatura dentro de disciplinas ligadas ao Ensino de Química. A Figura 4 sintetiza a distribuição dos trabalhos na seção de ED por nível de escolaridade.

Os trabalhos classificados no descritor Geral, relativo aos estudos que abordam os vários níveis escolares de forma genérica ou não particular, são representativos dentro do montante total $(10,32 \%)$ e ultrapassam o número dedicado ao Ensino Fundamental. Estes são muito 
distintos entre si, podendo-se, no entanto, apontar duas tendências que são detectadas com maior freqüência nos trabalhos incluídos nesta classificação. A primeira delas se relaciona as tecnologias educacionais e engloba trabalhos que relatam a criação de softwares e sites educacionais voltados para o Ensino de Química, sem especificar o nível escolar dos alunos que pretende atingir, e que podem ser de interesse do público em geral. A outra tendência está relacionada à Educação Ambiental e abarca trabalhos que tratam de conscientização do cidadão com relação ao seu papel na comunidade. Estes estudos relatados têm como alvo um número considerável de pessoas, como por exemplo, todos os membros de uma escola ou de uma comunidade de uma determinada localidade.

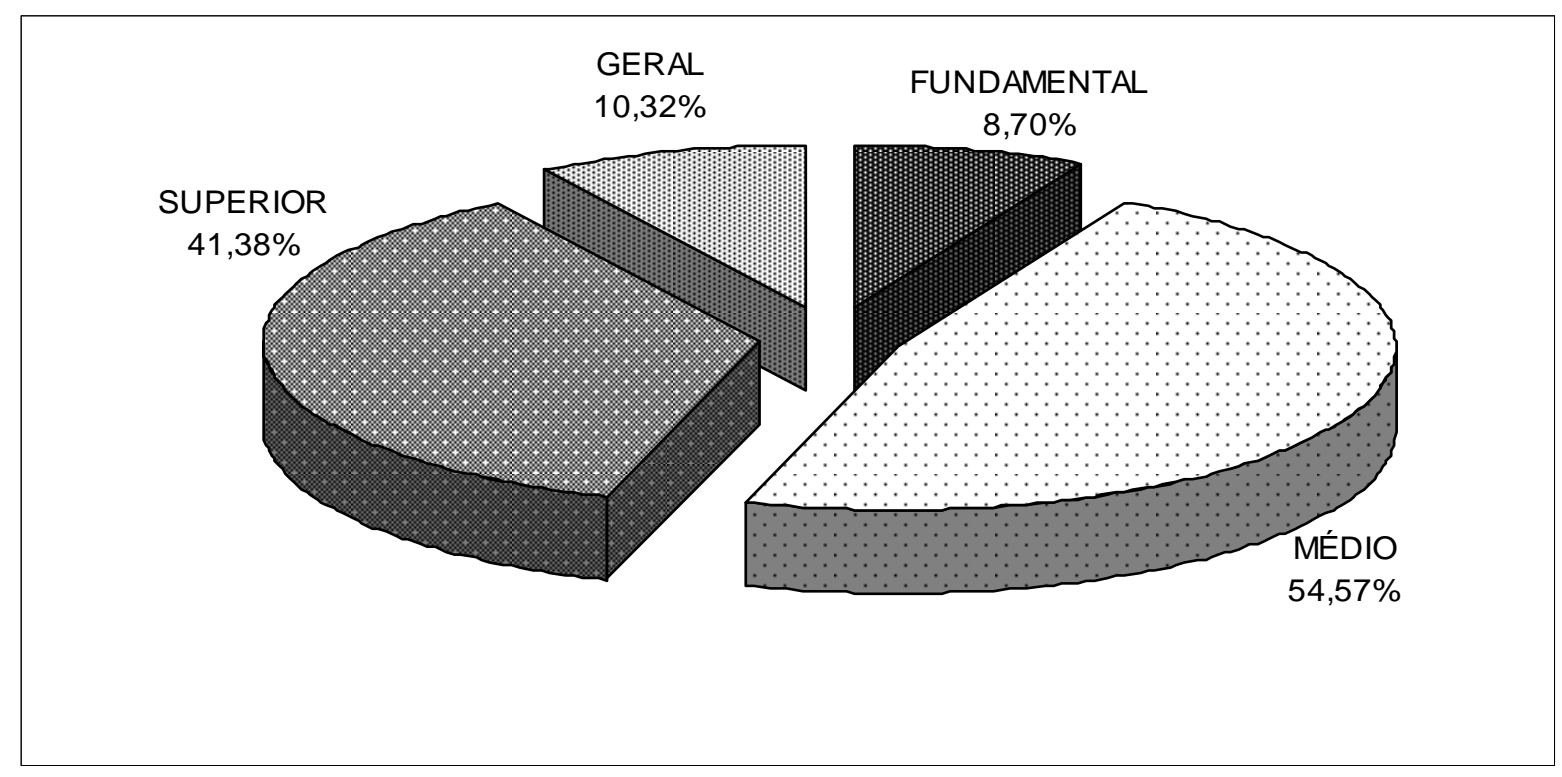

Figura 4 - Distribuição dos trabalhos de acordo com o nível de escolaridade brasileira apresentados na seção de ED nas RASBQs no período de 1999 a 2005.

Conforme mencionamos anteriormente, noventa e seis trabalhos foram classificados como destinados a dois ou três níveis de escolaridade. Podemos verificar a distribuição destas produções nas reuniões em estudo na Tabela 10. 
Tabela 10 - Distribuição dos trabalhos com mais de um nível de escolaridade apresentados na seção de ED das RASBQs no período de 1999 a 2005.

\begin{tabular}{|c|c|c|c|c|}
\hline & $\begin{array}{c}\text { Fundamental } \\
\text { E Médio }\end{array}$ & Médio e Superior & $\begin{array}{l}\text { Fundamental } \\
\text { e Superior }\end{array}$ & $\begin{array}{l}\text { Fundamental } \\
\text { Médio e } \\
\text { Superior }\end{array}$ \\
\hline 1999 & $\begin{array}{l}\text { ED-014; ED-016; } \\
\text { ED-030; ED-034; } \\
\text { ED-040; ED-053; } \\
\text { ED-057; ED-070 }\end{array}$ & $\begin{array}{l}\text { ED-001; ED-005; ED-007; } \\
\text { ED-008; ED-012; ED-027; } \\
\text { ED-082 }\end{array}$ & ED-077 & ED-004 \\
\hline 2000 & ED-038; ED-061 & $\begin{array}{l}\text { ED-031; ED-034; ED-042; } \\
\text { ED-049; ED-057; ED-065; } \\
\text { ED-069; ED-084; ED-086 }\end{array}$ & - & ED-033 \\
\hline 2001 & - & - & - & - \\
\hline 2002 & - & $\begin{array}{l}\text { ED-052; ED-053; ED-062; } \\
\text { ED-063; ED-077; ED-079; } \\
\text { ED-090 }\end{array}$ & - & - \\
\hline 2003 & ED-003 & $\begin{array}{l}\text { ED-017; ED-019; ED-036; } \\
\text { ED-041; ED-053; ED-087; } \\
\text { ED-089; ED-113; ED-117; } \\
\text { ED-118; ED-123; ED-135 }\end{array}$ & - & $\begin{array}{l}\text { ED-038; } \\
\text { ED-109 }\end{array}$ \\
\hline 2004 & $\begin{array}{l}\text { ED-055; ED-096; } \\
\text { ED-170 }\end{array}$ & $\begin{array}{l}\text { ED-021; ED-032; ED-034; } \\
\text { ED-038; ED-042; ED-059; } \\
\text { ED-082; ED-102; ED-105; } \\
\text { ED-158; ED-160; ED-171; } \\
\text { ED-190 }\end{array}$ & ED-041 & ED-031 \\
\hline 2005 & $\begin{array}{l}\text { ED-056; ED-073; } \\
\text { ED-083; ED-086; } \\
\text { ED-100 }\end{array}$ & $\begin{array}{l}\text { ED-001; ED-015; ED-016; } \\
\text { ED-018; ED-022; ED-025; } \\
\text { ED-028; ED-042; ED-043; } \\
\text { ED-070; ED-071; ED-076; } \\
\text { ED-082; ED-102; ED-108; } \\
\text { ED-110; ED-146; ED-151; } \\
\text { ED-152; ED-154; ED-156 }\end{array}$ & & ED-112 \\
\hline TOTAL & 19 trabalhos & 69 trabalhos & 02 trabalhos & 06 trabalhos \\
\hline$(\%)$ & 2,84 & 10,30 & 0,30 & 0,90 \\
\hline
\end{tabular}

A maior parte dos trabalhos é destinada aos níveis de Ensino Médio e Superior (10,30\%), seguido dos níveis de Ensino Fundamental e Médio (2,84\%) e apenas 0,30\% dos trabalhos foram produzidos abrangendo tanto o Ensino Fundamental quanto o Nível Superior. Apenas 0,90\% do total dos trabalhos eram voltados aos três níveis: Ensino Fundamental, Médio e Superior. 


\subsection{A PRODUÇÃO E SUA DISTRIBUIÇÃO DE ACORDO COM O FOCO TEMÁTICO}

Classificamos os resumos apresentados na seção de ED das RASBQS no período de 1999 a 2005 pelo foco temático, ou seja, a partir do assunto tratado no trabalho. Para tanto, tomamos por base os descritores específicos utilizados por Megid Neto ${ }^{14}$ na sua tese de Doutorado e que foram apresentados no Capitulo 3 - Referencial Teórico desta dissertação. Analisamos seiscentos e setenta e oito trabalhos, dentre os oitocentos e setenta e nove trabalhos apresentados na seção de ED das RASBQS no período em estudo. Foram excluídos da análise os mesmos trabalhos mencionados no tópico anterior desta dissertação (item 5.4), pelas razões já explicitadas.

Cada trabalho foi classificado em um ou mais focos temáticos, de acordo com o conteúdo abordado. Na maioria dos trabalhos em que detectamos mais de um foco temático, assumimos como foco temático principal do trabalho o tema privilegiado no estudo e como foco temático secundário aquele menos explorado no desenvolvimento da pesquisa. No entanto, durante a nossa análise, nos deparamos também com alguns trabalhos que possuíam mais do que um foco temático e nos quais ambos os focos possuíam a mesma relevância. Assim, os trabalhos com mais de um foco temático foram classificados como possuindo dois focos temáticos principais ou como possuindo um foco temático principal e um foco temático secundário.

Foram classificados quarenta e um trabalhos com dois focos temáticos principais. São eles: ED-007, ED-019, ED-033, ED-040, ED-063, ED-071, ED-083 da reunião de 2000; ED003, ED-013, ED-030, ED-035, ED-079 da reunião de 2002; ED-019, ED-025, ED-102, ED105 E ED-109 da reunião de 2003; ED-021, ED-068, ED-082, ED-083, ED-137, ED-150, ED151, ED-165 da reunião de 2004; ED-018, ED-023, ED-025, ED-030, ED-031, ED-034, ED044, ED-058, ED-071, ED-092, ED-112, ED-113, ED-136, ED-139, ED-153, ED-155 da reunião de 2005. Além desses trabalhos, existem sessenta e nove trabalhos com foco temático principal e foco temático secundário e quatro trabalhos que apresentam três focos temáticos 
(ED-047 da reunião de 1999; ED-015 da reunião de 2000; ED-007 e ED-048 da reunião de 2005).

Os trabalhos investigados apresentam, na sua grande maioria, foco temático associado a elementos do processo de ensino-aprendizagem. A Tabela 11 ilustra o número de trabalhos relacionados a cada um dos focos. É necessário destacar que nesta Tabela o número de trabalhos excede os seiscentos e setenta e oito mencionados anteriormente, uma vez que cada trabalho apresentado com mais de um foco temático (seja ele secundário ou principal) foi computado mais de uma vez, em cada um dos focos a eles associados. Considerando que cento e dez trabalhos apresentaram dois focos temáticos e quatro apresentaram três focos temáticos, o número de trabalhos computados na Tabela 11 é de setecentos e noventa e seis resumos. Todos os percentuais foram calculados sobre seiscentos e setenta e oito trabalhos.

Tabela 11 - Distribuição dos trabalhos da seção de ED das RASBQs de acordo com os focos temáticos no período de 1999 a 2005.

\begin{tabular}{|c|c|c|c|c|c|c|c|c|c|}
\hline Foco Temático & $\mathbf{1 9 9 9}$ & $\mathbf{2 0 0 0}$ & $\mathbf{2 0 0 1}$ & $\mathbf{2 0 0 2}$ & $\mathbf{2 0 0 3}$ & $\mathbf{2 0 0 4}$ & $\mathbf{2 0 0 5}$ & Total & $\mathbf{( \% )}$ \\
\hline Currículos e Programas & 15 & 08 & - & 09 & 05 & 12 & 12 & 61 & 9,00 \\
\hline Conteúdo-Método & 21 & 30 & - & 28 & 42 & 37 & 44 & 202 & 29,79 \\
\hline Recursos Didáticos & 22 & 26 & - & 26 & 40 & 40 & 48 & 202 & 29,79 \\
\hline Características do Professor & 05 & 05 & - & 05 & 05 & 09 & 18 & 47 & 6,93 \\
\hline Características do Aluno & 04 & 11 & - & 03 & 07 & 10 & 21 & 56 & 8,25 \\
\hline Formação de Conceitos & 14 & 08 & - & 07 & 11 & 10 & 09 & 59 & 8,70 \\
\hline $\begin{array}{c}\text { Formação Continuada de } \\
\text { Professores }\end{array}$ & 08 & 07 & - & 01 & 09 & 05 & 12 & 42 & 6,19 \\
\hline $\begin{array}{c}\text { Formação Inicial de } \\
\text { Professores }\end{array}$ & 02 & 06 & - & 05 & 06 & 06 & 09 & 34 & 5,01 \\
\hline Políticas Públicas & 02 & 03 & - & 01 & 01 & - & 01 & 8 & 1,18 \\
\hline Organização da Escola & 02 & 04 & - & 04 & 05 & 06 & 02 & 23 & 3,39 \\
\hline $\begin{array}{c}\text { Programa de Ensino Não } \\
\text { Escolar }\end{array}$ & 02 & 01 & - & 01 & 01 & 06 & 04 & 15 & 2,21 \\
\hline Filosofia da Ciência & 01 & - & - & - & - & 01 & - & 02 & 0,29 \\
\hline História da Ciência & 04 & 01 & - & 01 & 01 & 02 & 01 & 10 & 1,47 \\
\hline História do Ensino de Ciências & 0 & 0 & - & - & - & - & 02 & 02 & 0,29 \\
\hline Outro & 05 & 05 & - & 02 & 05 & 11 & 05 & 33 & 4,87 \\
\hline
\end{tabular}

Observando a Tabela 11, constatamos que uma elevada percentagem dos trabalhos (cerca de 30\%) se dedicam à investigação de Recursos Didáticos e da relação Conteúdo-Método no Ensino de Química. Em seguida, se destacam trabalhos vinculados aos focos Currículos e 
Programas (9,00 \%), Formação de Conceitos (8,70\%), Características do Aluno (8,25\%) e Características do Professor (6,93\%). Trabalhos dedicados à Formação Continuada (6,19\%) e Inicial $(5,01 \%)$ de Professores também foram apresentados com freqüência nas RASBQs analisadas. Em contrapartida, as temáticas Filosofia da Ciência e História do Ensino de Ciências foram pouco exploradas nos trabalhos (aproximadamente 0,30\%). A Figura 5 sintetiza a distribuição dos trabalhos na seção de ED por foco temático.

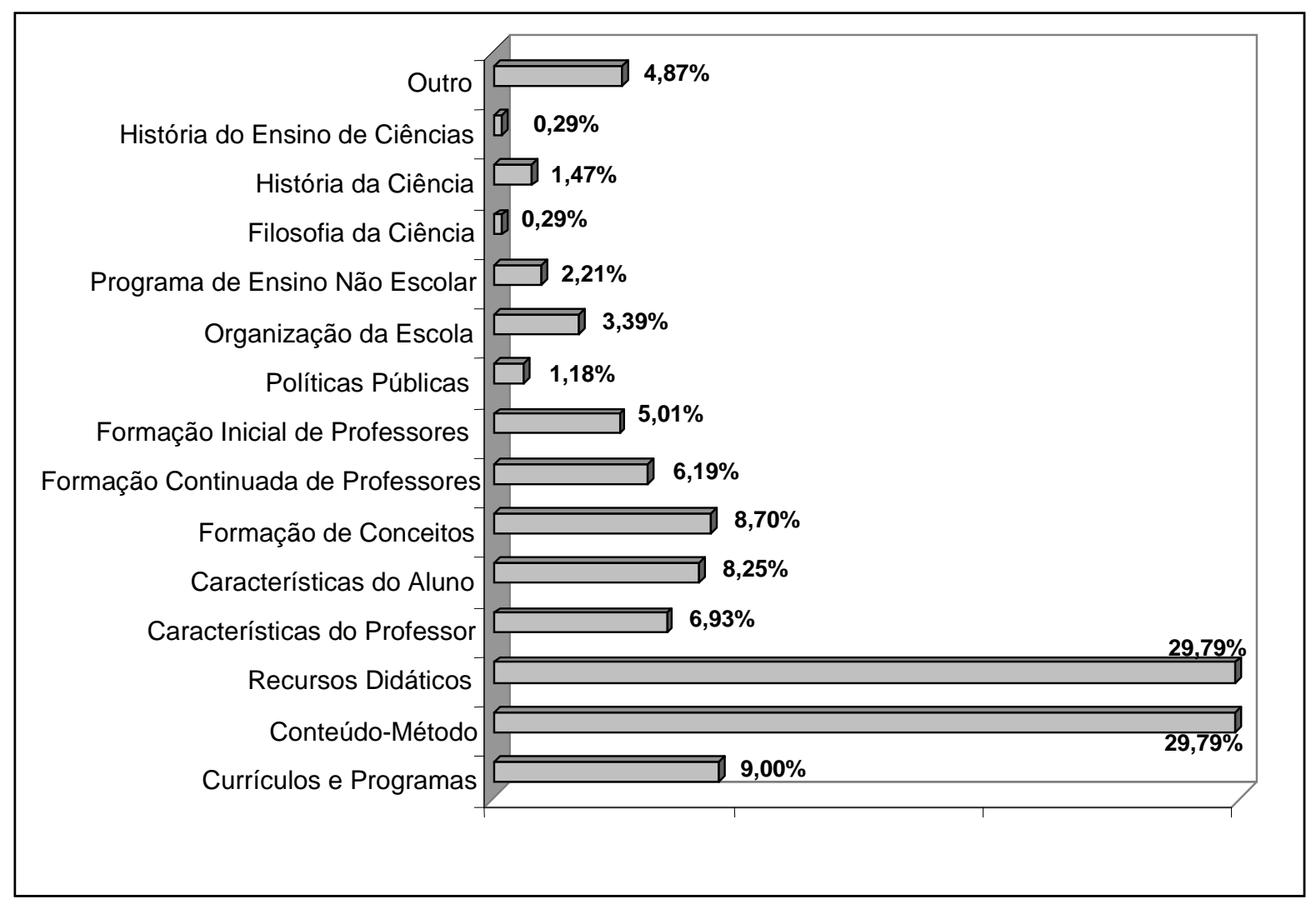

Figura 5 - Distribuição dos trabalhos de acordo com o foco temático apresentado na seção de ED nas RASBQS no período de 1999 a 2005.

A seguir são apresentadas características gerais dos trabalhos classificados em cada um dos focos temáticos e são discutidos os conteúdos presentes em alguns deles, uma vez que uma descrição detalhada de cada um é inviável. 


\subsubsection{Trabalhos Sobre Currículos e Programas}

Identificamos sessenta e um resumos cujo foco temático foi Currículos e Programas. Alguns se destinam a mais de um nível de escolaridade, sendo o Ensino Médio o mais explorado, seguido pelo Ensino Superior e Fundamental.

Inicialmente, destacamos os trabalhos que apresentavam propostas de inovações e/ou estudos dos currículos ou cursos. No caso de inovação curricular, encontramos trabalhos como: o ED-018 que relata o projeto de reestruturação do curso de Química das Faculdades Integradas Maria Imaculada do Estado de São Paulo, apresentado na reunião de 2000; o ED-109, apresentado na reunião de 2004, que faz uma avaliação da inovação do currículo do curso de Química e Química Industrial da UFF reformulado em 2003; o ED-013 da reunião de 2005, que estuda a reforma curricular de Química realizada no Estado de Roraima.

No que diz respeito a análise de tópicos ministrados no currículo vigente, citamos o ED009, apresentado em 1999, que investiga como se dá a abordagem do tema cárie dentária no Ensino Fundamental. Já os trabalhos ED-074 da reunião de 2000 e ED-044 da reunião de 2004 versam sobre a criação de cursos de Química. O primeiro avalia a implantação do curso de Química Industrial no período noturno na UNISC e o segundo apresenta a proposta da criação e a elaboração da estrutura curricular do curso de Licenciatura em Química no CEFETQNilópolis.

Um outro tema abordado com freqüência está relacionado à introdução de novas disciplinas no currículo vigente de algumas IES. Entre estes trabalhos destacamos o ED-008, da reunião de 2002, que avalia a disciplina de Química Ambiental introduzida em 2001 nos cursos de Licenciatura e Bacharelado em Química pela UFMS e o ED-065, da reunião de 2004, que relata a criação da disciplina Tratamento de Resíduos Gerados em Laboratórios, no curso de Bacharelado em Química da USP. Esta foi criada com o objetivo de esclarecer o futuro profissional sobre a questão dos descartes de resíduos químicos. 
Além dos trabalhos que relatam a criação de novas disciplinas, existem aqueles que tratam da reestruturação de algumas delas. Neste caso, destacamos o ED-005, apresentado em 2005, que trata da revisão na estrutura da disciplina Química Geral do curso de graduação da UNESP/Araraquara, renomeada como Química Fundamental e o ED-022, apresentado em 2000, que estuda a reestruturação da disciplina de Química Inorgânica para o curso Técnico em Química no CEFETQ-Nilópolis.

Identificamos ainda alguns trabalhos que tratam de implantações de programas educacionais visando uma maior integração entre a Universidade e a Escola Básica. A título de exemplo citamos o ED-012, apresentado em 1999, o qual relata um programa de palestras que foi oferecido pela UNESP/Araraquara para alunos do Ensino Médio chamado de "Palestra na Escola", e o ED-145, da reunião de 2005, que apresenta o projeto LabVirtQuímica da Escola do Futuro da USP. Ainda na reunião de 1999, identificamos o ED-059 e o ED-078 que apresentam um programa de Integração Graduação/Pós-graduação, onde o primeiro visa aproximar os alunos de ambos os níveis em um projeto sobre Química de Produtos Naturais e seu uso na Agricultura e o segundo envolve os alunos num projeto de Química Computacional. Na reunião de 2000, o ED-045 apresenta um programa de Integração Universidade e Indústria, no qual algumas visitas as indústrias são promovidas para alunos de graduação visando o estabelecimento de relações entre os conhecimentos adquiridos em aula a realidade profissional dentro de uma empresa. Já na reunião realizada em 2002 encontramos os trabalhos ED-015 e ED- 020 que estudam os programas Pró-Ciências e Pró-Médio de inovação curricular do Ensino Médio no Estado de Minas Gerais.

Na reunião de 2003 destacamos o ED-015 que trata de um programa de estágio de que foi oferecido à estudantes do Ensino Médio, em laboratórios de pesquisa da USP, no campus de São Paulo denominado "Ciências nas Férias". Na reunião de 2005 destacamos o ED-089 que estuda o programa de Tutoria implementado pela UFV para diminuir as reprovações em disciplinas básicas do curso de Bacharelado em Química. 
Ainda dentro deste foco temático, temos estudos voltados aos documentos que constituem os Parâmetros Curriculares Nacionais (PCN) e suas aplicações como o ED-043, da reunião de 2002, que investiga se existe a discussão e / ou implementação dos PCN na prática pedagógica cotidiana nas escolas de Goiânia. Outro assunto explorado foi o desenvolvimento de projetos educacionais, como o ED-004 e ED-066, das reuniões realizadas em 2002 e 2005, respectivamente. $\mathrm{O}$ primeiro apresenta um projeto de alfabetização científica denominado $L a$ main à la patê - Com a mão na massa - e o segundo o projeto Saberes Populares, que visa valorizar os conhecimentos populares no currículo de Ciências (neste trabalho em particular, o processo de desidratação de frutas).

Destacamos ainda dentro dos estudos relacionados a projetos, o trabalho ED-159, apresentado na reunião de 2004 e produzido por pesquisadores da UnB, que investiga o projeto de Educação à Distância (EAD) mais difundido no nosso país, o Telecurso 2000.

Para finalizar as investigações sobre o foco citamos um único trabalho que tratava do processo de avaliação no Ensino de Química, o ED-169, apresentado na reunião de 2004 que propõem a elaboração de questões com conteúdo contextualizado nas provas aplicadas a alunos do Ensino Médio.

\subsubsection{Trabalhos Sobre Conteúdo-Método}

Identificamos duzentos e dois trabalhos que analisavam a relação ConteúdoMétodo no Ensino de Química. Deste total, constatamos que cerca de 60\% dos trabalhos eram estudos voltados ao Ensino Médio.

De maneira geral, os aspectos abordados neste foco tratavam de estudos avaliativos de estratégias e técnicas diversificadas utilizados pelo professor, no processo de ensinoaprendizagem de conteúdos pertencentes à Química. Entre estes métodos diversificados, verificamos que alguns tiveram certa freqüência em relação a outros, como o uso da experimentação, de tecnologias computacionais e atividades lúdicas. Além destes métodos de 
ensino, identificamos muitos trabalhos que introduziam os conteúdos químicos, contextualizando a abordagem destes, e ainda a exploração de conteúdos de algumas disciplinas relacionando-os com temas interdisciplinares, de forma a apresentar aos alunos a Química em seu cotidiano.

Entre os trabalhos que tratavam da aplicação de métodos diversificados que não apresentaram uma certa freqüência (25\% dos trabalhos), podemos citar o trabalho ED-046, apresentado em 2002, que avalia a utilização de mapas conceituais sobre reações de oxi-redução, no curso de Licenciatura em Química da UNICENTRO. Inicialmente a turma foi dividida em grupos, nos quais cada um deles teria que construir um mapa a partir de palavras-chave sobre o assunto fornecidas pelo professor. Após esta etapa foi promovida uma discussão junto aos estudantes de todos os grupos sobre as correlações que eles estabeleceram na construção dos mapas, e a proposta da construção de um novo mapa pela classe, para o professor verificar se havia ocorrido uma evolução das relações entre os conceitos antes e depois da aplicação do método.

Outro trabalho que podemos citar seria o ED-051, apresentado na reunião de 2003, e desenvolvido por pesquisadores da UFRGS, que adotou como estratégia de ensino de transformações químicas, a metodologia de resolução de problemas. O ED-192, apresentado em 2004, utilizou como estratégia de ensino o trabalho em grupo, via peer tutoring, em que alunos do Centro Regional Universitário de Espírito Santo do Pinhal, que apresentavam um alto rendimento escolar, ajudavam outros alunos que, na primeira avaliação obtiveram notas abaixo de cinco, e que após os estudos realizados via peer tutoirng, conseguiram recuperar as suas notas.

Identificamos ainda três trabalhos $(1,5 \%)$ que apresentavam o desenvolvimento de uma metodologia de ensino de conteúdos químicos para alunos que possuíam deficiência visual. Dois destes trabalhos, o ED-160 e o ED-108, apresentados, respectivamente, nas reuniões de 2004 e 2005, foram produzidos pela UnB, pelo grupo de pesquisadores liderado por Gerson S. Mol. O primeiro trabalho trata da avaliação parcial da aplicação de uma Grafia Química em Braille utilizada para portadores de deficiência visual para estudo dos símbolos e representações 
existentes na linguagem química. O segundo, estuda os métodos alternativos de ensino utilizados para os deficientes visuais, após as adaptações realizadas nos módulos da coleção Química e Sociedade em Grafia Química Braille e de roteiros de atividades experimentais para estes estudantes, para que percebessem a ocorrência de fenômenos químicos por meio de outros sentidos. O outro trabalho, o ED-085, que também se destina a deficientes visuais, foi elaborado por pesquisadores da UFRJ e apresentado na reunião da SBQ ocorrida em 2000. Este avalia a aplicação de alguns materiais didáticos desenvolvidos para estes alunos para a construção de conhecimentos a respeito de conceitos de cadeia e conectividade estrutural fundamentais em Química Orgânica.

Entre os trabalhos que investigava a experimentação (17\% dos trabalhos), tecnologias computacionais $(6 \%)$ e atividades lúdicas $(6 \%)$ como metodologia de ensino podemos destacar os seguintes: ED-089, apresentado em 2002, que por meio de um experimento de iodação de compostos aromáticos, possibilitou aos alunos visualizarem e relacionarem a prática-teoria dos conhecimentos adquiridos sobre substituição eletrofílica aromática, em particular a halogenação. Quanto ao uso de meios computacionais, podemos citar como exemplo o ED-075, desenvolvido por pesquisadores da UFPE e UFRPE que foi apresentado em 2005, este relata a utilização de simulação gráfica de reações e transformações da matéria (sublimação da naftalina e formação de ferrugem, respectivamente) e avalia o potencial de aprendizagem dos alunos após a aplicação do recurso. Em relação às investigações sobre a aplicação de atividades lúdicas como metodologia de ensino, podemos citar o trabalho ED-123, apresentado em 2002, que avalia a aprendizagem de balanceamento de reações por meio de clipes coloridos, nos quais cada elemento participante da reação em estudo é representado por um clipe de cor diferente. Este método foi aplicado a alunos do curso de Licenciatura em Química da UFSCar e a alunos do Ensino Médio de uma escola pública do município de São Carlos.

Enfim, sobre a temática que envolve estudos sobre a contextualização e abordagem de temas interdisciplinares de conteúdos químicos, conforme as propostas de ensino 
dos PCNEM, estes totalizam os 45,5\% dos trabalhos classificados neste foco temático. Esta porcentagem nos faz refletir sobre a grande tendência do Ensino de Química nestes últimos anos, que seria trabalhar os conteúdos químicos, relacionando-os com o cotidiano dos estudantes, e assim motivar e estimular os alunos a estudarem Química, considerada até então, uma disciplina abstrata e decorativa. A título de exemplo destes métodos alternativos de abordagem de conteúdo, podemos citar os trabalhos: o ED-081, apresentado na reunião realizada em 2004, que tinha como objetivo desenvolver o conhecimento químico a partir do tema "Alimentos", introduzindo conceitos químicos relacionados ao tema para alunos do Ensino Médio do Colégio Estadual Luiz Viana Filho, em Jequié - BA; o ED-010, apresentado em 2005, buscou além do ensino de conceitos químicos, conscientizar os alunos do efeito do álcool sobre o processo metabólico no organismo, através do estudo de transformações químicas, e conscientizá-los dos riscos da ingestão de álcool.

Quanto à abordagem interdisciplinar, podemos tomar como exemplo o ED-125, apresentado em 2005, desenvolvido pelo CEFET - Bambuí, no qual os alunos analisaram os tipos de agrotóxicos mais utilizados em Bambuí e as possíveis doenças causadas pelo seu uso no combate de pragas na agricultura.

\subsubsection{Trabalhos Sobre Recursos Didáticos}

Neste foco temático de investigação identificamos duzentos e dois trabalhos. Em nossa análise, encontramos os seguintes temas que constituem este foco temático: descrição de uma proposta de atividade experimental, restringindo-se à apresentação do material em si ou das etapas para a execução do experimento; estudos relacionados aos livros didáticos de Química utilizados por professores; desenvolvimento e estudo de materiais ou recursos didáticos como jogos, filmes, softwares, Internet e ainda a produção de instrumentos alternativos de laboratório.

A maior parte dos trabalhos apresentados (59\%) diz respeito à proposição/aplicação de técnicas e materiais diversificados em laboratórios de ensino. Esta porcentagem alta não 
surpreende, uma vez que a Química é um ramo das Ciências Naturais que possui como uma de suas características a atividade experimental. A título de exemplo, podemos citar os seguintes trabalhos: ED-027, apresentado na reunião de 1999, que descreve a síntese do polímero formoluréia desde o material, reagentes até o procedimento experimental alternativos; ED-030, apresentado na reunião de 2000, que propõe um método rápido e de baixo custo para obtenção da enzima peroxidase, a partir de extratos vegetais; ED-093, da reunião realizada em 2002, que estuda a oxidação da lignina de bagaço de cana obtida por explosão a vapor em condições alcalinas.

Outros exemplos que podemos citar, ainda sobre o tema atividades experimentais, seriam o ED-111 e o ED-106, apresentados respectivamente nas reuniões de 2004 e 2005. O primeiro realiza um experimento de identificação de íons ferro em medicamentos (sulferrol e vitafer) e em alimentos (chouriço). O segundo (ED-106) apresenta uma proposta de experimento simples e criativo de reciclagem química de um dos polímeros mais importantes da atualidade, o poliestireno. Há ainda cinco trabalhos que descrevem a construção de instrumentos de laboratório, como o ED-067, apresentado na reunião de 2002, que descreve a construção de uma balança simples e de baixo custo que pode ser utilizada em atividades de laboratório das escolas públicas do Ensino Médio.

Um outro tema abordado com freqüência (13\%) está relacionado à introdução de novas tecnologias educacionais, ou seja, o uso de simuladores computacionais, desenvolvimento de softwares e a Internet como recurso didático para auxiliar no aprendizado do aluno. Entre estes trabalhos destacamos o ED-157, apresentado em 2005, que descreve a construção de um sítio da Internet, unindo os princípios da Química e os recursos da Internet para a promoção da Educação Ambiental no Ensino Básico; o ED-006, apresentado na reunião de 1999, que desenvolve um programa computacional para projetar e simular as condições de uma coluna de destilação aplicado na disciplina Operações Unitárias da UEL e um único trabalho, o ED-080, da reunião realizada em 1999, que trata do desenvolvimento de um banco de dados para a revista 
Química Nova a fim de facilitar a pesquisa em assuntos específicos de Química por alunos de graduação.

Ainda dentro deste foco temático, temos estudos voltados aos livros didáticos de Química, que são utilizados, na maioria das vezes, como único subsídio do professor para ministrar suas aulas. Para exemplificar estes estudos, destacamos o ED-076, apresentado em 2000, que investiga como o conceito eletronegatividade é abordado em alguns livros didáticos destinados ao Ensino Médio e o ED-101 que analisa como o tema polímeros é tratado em alguns livros didáticos utilizados por estudantes do Ensino Médio, sendo que este trabalho foi apresentado na reunião de 2004.

Identificamos ainda alguns trabalhos que tratam da elaboração e estudo de materiais didáticos que podem ser utilizados no Ensino de Química. Os jogos, filmes, modelos e textos são os materiais mais foram explorados pelos pesquisadores. Destacamos entre os trabalhos, o ED078, apresentado em 2003, que elaborou o jogo Corrida Química, composto por seis corredores (peças), roleta e um jogo de cartas que poderia conter uma charada, uma reação química a ser balanceada ou ainda alguma questão de Química Geral. A proposta foi aplicada numa turma de alunos do Ensino Médio, durante uma Feira de Ciências promovida por uma escola particular no Estado de Minas Gerais. O ED-028, da reunião realizada em 2005, analisa quatro filmes da série ‘Materiais E Suas Propriedades’ (produzido pelo Channel 4 Learning, na Grã-Bretanha em 1997) como ferramenta auxiliar em aulas de Química.

Com relação aos modelos e textos utilizados como material didático, citamos como exemplos, o ED-029 e o ED-008, que foram apresentados em 2003 e 2005, respectivamente. O primeiro, da UFMG, descreve a construção de modelos moleculares a partir de garrafas de refrigerantes de PET incolores; o segundo trabalho trata da produção de um texto didático e de um experimento sobre o tema biodiesel para ser trabalhado com alunos do Ensino Médio, contribuindo para o desenvolvimento de valores e atitudes em relação ao meio ambiente. 
Para finalizar as investigações sobre o foco, não poderíamos deixar de mencionar o nível de escolaridade privilegiado nestes trabalhos. Verificamos que a maior parte da produção identificada neste foco foi destinada ao Ensino Superior (cerca de 41\% dos trabalhos), uma vez que a maioria dos trabalhos que envolviam atividades experimentais eram destinados a este nível de escolaridade.

\subsubsection{Trabalhos Sobre Características do Professor}

Foram classificados neste foco quarenta e sete trabalhos que versavam sobre as condições profissionais do professor da área de Química, sobre a identificação do seu perfil quanto à estrutura intelectual, seus conhecimentos e suas concepções sobre Ciências. A maioria dos trabalhos visava diagnosticar a prática pedagógica dos professores, desde o discurso por eles adotado em sala de aula até a maneira como escolhem o livro didático, a elaboração de aulas e avaliações para seus alunos. Cabe destacar que 47\% dos trabalhos investigam a atuação de professores no Ensino Médio.

Muitos dos trabalhos classificados neste foco dizem respeito não apenas às características do professor, mas também às características dos alunos. São exemplos de trabalhos deste tipo: ED-015, ED-033, ED-040 da reunião de 1999; ED-109 da reunião de 2003; ED-165 da reunião de 2004; ED-018, ED-058, ED-113 e ED155 da reunião de 2005. Logo, muitos dos trabalhos classificados neste foco temático foram também classificados no foco Características dos Alunos.

Dentre os trabalhos analisados, destacamos os seguintes: o ED-033, apresentado em 2000, que versa sobre a identificação das idéias de alunos e professores do Ensino Fundamental e Médio acerca do conceito de Fotossíntese; o ED-006, da reunião de 2003, que analisa o conhecimento de professores em formação inicial e em serviço sobre combustão; o ED-110, da reunião de 2003, que investiga as concepções alternativas dos professores sobre soluções e sobre o processo de dissolução; o ED-145, apresentado em 2005, que analisa as representações sobre o 
conceito de rapidez numa transformação química no pensamento dos professores de Ensino Médio.

Com relação aos trabalhos que investigam a prática pedagógica do professor podemos citar o ED-015, da reunião de 2000, que analisa se houve ou não mudança na prática pedagógica de professores que participaram do Programa de Aperfeiçoamento e Formação Continuada de professores de Química e Ciências - FoCo, do Estado de Minas Gerais. São ainda exemplos de trabalho desta natureza: ED-012, apresentado em 2003, que investiga como os professores de Química do Ensino Médio da cidade de Curitiba, preparam suas avaliações; o ED-026, da reunião de 2005, que analisa como os professores definem a escolha do livro didático a ser utilizado como material de apoio às aulas e, ainda na mesma reunião, temos o ED-088 que analisa as dificuldades dos professores em ensinar conteúdos de Química e quais os fatores que contribuem para estas dificuldades.

Entre os trabalhos que identificam o perfil dos professores quanto às suas características sociográficas, podemos citar o ED-012, da reunião de 2002, que caracteriza os professores do Ensino Médio das cidades de São João Del-Rei, Tiradentes e Santa Cruz de Minas quanto a formação, faixa etária, sexo, faixa salarial e carga horária de trabalho e ainda quanto às suas práticas no processo de ensino. Na reunião realizada em 2005 encontramos o ED-100 que investiga os dados pessoais, dados funcionais, aspectos relacionados ao processo de ensinoaprendizagem e ainda aspectos relacionados ao local de trabalho dos professores na região de Araraquara - São Paulo.

Identificamos ainda três trabalhos que investigam a concepção de Ciências dos professores. São eles: ED-034, da reunião de 1999, no qual, através da aplicação de um questionário, solicita-se aos professores de Ciências e de Química de diversas regiões do Rio Grande do Sul, definam as Ciências Naturais e a Química; ED-060, da reunião de 2000, que questiona professores do Ensino Básico do Rio Grande do Sul sobre o que eles entendem como sendo o conhecimento científico; ED-035, da reunião de 2004, que investiga como professores 
universitários relacionam a integração entre Ciência, Tecnologia e Sociedade no Ensino de Química.

\subsubsection{Trabalhos Sobre Características do Aluno}

Identificamos cinqüenta e seis trabalhos que possuíam aspectos relacionados com a composição deste foco temático. Deste total, constatamos que 37,5\% foram apresentados na reunião realizada em 2005 e que a maioria deles se destinava ao Ensino Médio (57\%) e ao Ensino Superior (37\%).

Cabe destacar que dentre os cinqüenta e seis trabalhos identificados como pertencentes ao foco Características do Aluno, dez (ED-006, ED-015, ED-033, ED-040 e ED-083 da reunião de 2000 e os ED-007, ED-023, ED-025, ED-048 e ED-136 da reunião de 2005) foram também classificados como pertencentes, de forma expressiva (foco principal), a outros focos temáticos: Características do Professor, Conteúdo-Método, Recursos Didáticos, Currículos e Programas e por último, a Formação Inicial de Professores. Os trabalhos tratavam de assuntos relacionados com o perfil dos alunos em estudo, investigações de suas condições sócio-econômicas e culturais e das implicações destes fatores no rendimento escolar, da identificação do conhecimento prévio do aluno e ainda das atitudes e características de um aluno ou grupo de alunos dentro do contexto do processo de ensino-aprendizagem.

Os trabalhos mais freqüentemente encontrados investigam o perfil dos alunos sob vários aspectos. Um exemplo de trabalho desta natureza seria o ED-063, da reunião de 1999, o qual analisa o perfil de estudantes que utilizavam a Internet como fonte de informação para realização de tarefas escolares. Para tanto, foi aplicado um questionário, via correio eletrônico, aos estudantes que acessavam o Serviço de Orientação Via Telemática da SBQ. Outro trabalho, o ED-082, da reunião de 2002, traça o perfil dos estudantes de uma escola pública, matriculados no período diurno e noturno, tentando identificar semelhanças e diferenças entre tais alunos a partir de considerações sobre a situação socioeconômica dos mesmos. 
No ano de 2003, o ED-103 apresenta o resultado de uma investigação feita com alunos do Ensino Médio do colégio Estadual do Paraná, Colégio Estadual Júlio de Mesquita e da Escola Técnica da UFPR sobre as motivações que os levam a gostar de estudar Química. O trabalho ED-049, apresentado em 2004, traz uma investigação sobre as expectativas dos alunos ingressantes no curso de Licenciatura em Química da UnB e o que os motivou na escolha deste curso. Na reunião realizada em 2005, podemos citar como exemplo o ED-010, no qual é feito um levantamento junto a alunos do Ensino Médio sobre qualquer tipo de contato que tivessem tido anteriormente com bebidas alcoólicas e sobre o conhecimento que possuíam a respeito das conseqüências que estas trazem ao organismo.

No descritor direcionado a identificação do conhecimento prévio do aluno, temos vários trabalhos dos quais podemos destacar o ED-061, da reunião de 2003, que buscou identificar as concepções dos estudantes no Ensino Médio a respeito de minerais e como poderiam relacionálos à Química. Na reunião realizada em 2004, temos o ED-153 que investigou as idéias de alunos do curso de Licenciatura em Química da UFPE, sobre o que era um experimento e como eles poderiam utilizá-los em sua vida profissional. O ED-093, da reunião de 2005, traz um diagnóstico realizado junto aos alunos ingressantes em todos os curso oferecidos pelo Instituto de Química da USP, sobre os conhecimentos químicos adquiridos durante a sua formação no Ensino Básico.

Enfim, sobre a temática que envolve estudos das atitudes e características de um aluno ou grupo de alunos no processo de ensino-aprendizagem, o ED-017, apresentado em 2002, exemplifica um estudo comparativo sobre o desempenho de alunos do ensino médio e superior em reconhecer certos conceitos transmitidos a partir de uma proposta de ensino baseada na experimentação. O ED-039, da reunião realizada em 2004, investiga a conduta de um grupo de estudantes e de um grupo de professores, sobre a construção do conhecimento por meio de aulas prática de Química e faz uma comparação nas dificuldades de ambos os grupos. 


\subsubsection{Trabalhos Sobre Formação de Conceitos}

Identificamos cinqüenta e nove resumos cujo foco temático foi Formação de Conceitos. De maneira geral, os aspectos neles abordados foram os seguintes: o desenvolvimento de conceitos científicos no processo de ensino aprendizagem de estudantes; a evolução ou mudança conceitual e a relação entre modelos de pensamento, faixa etária ou nível de escolaridade de indivíduos.

Dentre os trabalhos classificados neste foco destacamos o ED-045 e o ED-026, que foram apresentados nas reuniões de 1999 e 2000, respectivamente. Estes se diferenciam dos demais pois investigam a construção de conceitos químicos por alunos do Ensino Fundamental (Instituto Benjamin Constant) que são deficientes visuais. No primeiro trabalho foram abordados conceitos de propriedades organolépticas e densidade específica da matéria através da realização de atividades experimentais. No segundo trabalho o conceito de Estrutura Atômica foi desenvolvido com o auxílio de material didático preparado especialmente para estes alunos. Outro trabalho classificado neste foco e que tem um caráter único é o ED-007, apresentado em 2000, que descreve o desenvolvimento de um sistema conceitual para estudo de conceitos de forma comparativa, utilizando analogia, modelo, metáfora e alegoria, desenvolvido por pesquisadores da UFMG, UnB e UCB.

Identificamos neste conjunto de trabalhos, quatorze resumos que descrevem investigações a respeito do desenvolvimento de conceitos de alunos e professores que implicaram em um processo de mudança e/ou evolução conceitual. Estes trabalhos que avaliam ou estudam a evolução conceitual trazem como característica básica a realização de um pré-teste e pós-teste para validar se houve ou não a mudança ou a evolução dos conceitos durante o processo de ensino-aprendizagem. Trabalhos desta natureza são: o ED-002, apresentado na reunião de 2000, que analisa o processo de evolução do conceito de reação química; o ED-150, apresentado na reunião de 2004, que visou verificar a evolução do conceito de transformação química utilizando 
com metodologia de ensino a experimentação; o ED-033, apresentado na reunião de 2005, que estuda a evolução conceitual do conceito de solução entre alunos do Ensino Médio.

A maioria dos trabalhos que foram classificados de acordo com os descritores do foco temático relacionado à Formação de Conceitos trata de estudos relacionados com a estrutura cognitiva dos estudantes e o processo de ensino-aprendizagem de conceitos científicos. Estes, geralmente, versam a respeito da construção do conhecimento dos conceitos químicos a partir da constatação das concepções ou idéias prévias dos alunos e a utilização de métodos diferenciados de ensino para abordagem de um determinado conceito científico. A título de exemplo, podemos citar os seguintes trabalhos: ED-139, apresentado na reunião de 2005, que tem como objetivo investigar atividades que contribuam para a formação de conceitos e estabelecimento de relações entre o conhecimento científico e a vida cotidiana dos alunos; ED-068, apresentado na reunião de 2004, que descreve a experiência da abordagem de conceitos de isomeria a partir de um préteste para identificar o conhecimento prévio do aluno. Outros exemplos são o ED-021, da reunião realizada em 2002, que analisa o processo de ensino aprendizagem do conceito de entropia e o ED-093 que, para abordar conceitos químicos relacionados à poluição atmosférica, fez um levantamento prévio das idéias que os alunos tinham a respeito deste assunto.

Cabe ainda salientar dois aspectos importantes relacionados aos trabalhos cujo foco temático é Formação de Conceitos. O primeiro diz respeito ao nível de escolaridade: diferentemente do que verificamos para os demais focos, uma grande porcentagem de trabalhos se destina ao Ensino Fundamental (22\%). Existem também muitos trabalhos destinados ao Ensino Médio (64\%), enquanto os outros níveis de escolaridade não possuem uma representatividade significativa.

O segundo aspecto diz respeito ao local de produção dos trabalhos: cerca de 19\% dos trabalhos são procedentes do grupo de pesquisa liderado por Djalma Andrade, da UFS, representado $40 \%$ do total de trabalhos apresentados pela referida universidade nas RASBQ, durante o período compreendido entre 1999 a 2005. 


\subsubsection{Trabalhos Sobre Formação Continuada de Professores}

Identificamos quarenta e dois resumos cujo foco temático foi Formação Continuada de Professores. Neste foco estão incluídos trabalhos que tratam dos programas de aperfeiçoamento, atualização, cursos de capacitação ou treinamento para professores em serviço da área de Ciências e Química. A maior parte dos trabalhos apresentados $(80 \%)$ diz respeito a investigações realizadas junto a professores do Ensino Médio.

A metade dos trabalhos analisados trata de cursos de formação continuada de professores e a maioria deles está vinculada ao projeto Pró-Ciências de capacitação de professores, que conta com o apoio pela CAPES. Destacamos alguns dos trabalhos desta natureza: ED-035, da reunião de 2003, no qual o curso de capacitação para professores do Ensino Médio da região de São José do Rio Preto, tinha como objetivo a Educação Ambiental em concordância com a realidade da comunidade em que o professor atuava; o ED-083, da reunião de 2004, que tinha como objetivo desenvolver habilidades dos professores na realização de atividades práticas e teóricas inovadoras; ED-003, da reunião de 2005, que relata o programa de formação continuada "Teia do Saber" promovido pela Secretaria de Estado da Educação de São Paulo, para desenvolvimento de fundamentos teórico-metodológicos em Educação Ambiental.

Identificamos também alguns trabalhos que relatam a formação de grupos de estudos entre professores do Ensino Básico e Superior e entre alunos dos cursos de licenciatura, de forma a trocarem experiências e conhecimentos relacionados ao processo de ensino-aprendizagem, criando dessa maneira uma parceria Universidade-Escola. Entre esses trabalhos destacam-se o ED-017, da reunião de 2005, o ED-042 e o ED-134, apresentados em 2003, nos quais são descritos encontros realizados entre os professores e os alunos da UNESP e os professores de uma escola pública do Estado de São Paulo visando oferecer um melhor embasamento aos professores do Ensino Médio para que assim pudessem ministrar aulas de laboratório de Química. Estes trabalhos foram produzidos pelo mesmo grupo de pesquisa da UNESP, liderado por Maria Ângela de M. Cordeiro. 
Enfim, entre os resumos analisados identificamos alguns que se destacam pelo seu caráter singular e que descrevemos sucintamente a seguir: o ED-081 e o ED-115, ambos da reunião realizada em 2005. O primeiro trata de oficinas pedagógicas para professores em serviço e para licenciandos que tem como papel motivar, incentivar, mostrar e demonstrar novas atividades que poderão ajudá-los durante o processo de ensino-aprendizagem e o segundo relata uma dinâmica de ação reflexiva sobre a Coordenação Pedagógica da rede pública de ensino do Distrito Federal no que tange à formação permanente do professor do Ensino Médio. Nesta categoria temos ainda o ED-021, apresentado em 2000, que descreve um trabalho planejado por professores participantes de um dos Cursos Emergenciais de Licenciatura Parcelada em Química (curso de treinamento), que são oferecidos nas cidades de Almenara e Diamantina, no Estado de Minas Gerais, e que tinha como objetivo a produção de um material didático-pedagógico de baixo custo para aulas práticas de Química no Ensino Médio (em média $\mathrm{R} \$ 0,50$ por aula).

\subsubsection{Trabalhos Sobre Formação Inicial de Professores}

Para este foco temático, identificamos trinta e quatro trabalhos apresentados que tratavam de propostas para alunos dos cursos de Licenciatura em Ciências e em Química. O nível escolar privilegiado nos estudos foi o Ensino Superior (70\%), uma vez que os trabalhos tinham como objetivo a formação dos alunos dos cursos de Licenciatura. A maioria deles tratava do desenvolvimento de atividades para a formação inicial de professores, mas também encontramos trabalhos que visavam o desenvolvimento de atividades aplicadas em escolas de Ensino Médio durante o período destinado ao estágio dos licenciandos e ainda a participação em programas de aperfeiçoamento e estudos dos PCNEM.

Entre os trabalhos que identificamos alguns merecem um destaque especial, pois não tratavam de nenhum destes assuntos descritos acima. São eles: o ED-048, apresentado na reunião de 2002, que faz uma análise psicológica no processo de formação dos professores de Química quanto a questão de sua autonomia dentro da sala de aula e o ED-071 que relata a criação de um 
espaço coletivo reunindo professores em serviço do Ensino Médio, professores universitários e alunos da Licenciatura em Ciências para reflexões das práticas docentes e desenvolvimentos de novas práticas para melhoria do currículo de Química, sendo este apresentado na reunião realizada em 2005 .

Os trabalhos que descreviam a participação dos licenciandos em cursos, nos quais eram estudados os PCNEM, foi o ED-002, da reunião realizada em 2002, que avalia as dificuldades dos alunos do curso de Licenciatura em Química da UFRJ, em se preparar uma aula ou atividade em Química de forma contextualizada, tendo em mãos o PCNEM como guia da proposta e o ED-036, apresentado em 2005, que contém a mesma proposta do ED-002, sendo este uma continuação (parte II) do referido trabalho apresentado em 2002.

Os trabalhos ED-034 e ED-025, apresentados respectivamente nas reuniões de 2000 e 2005, tratam dos alunos matriculados na disciplina de Prática de Ensino de Química, que no período de estágio interagem com estudantes do Ensino Médio. No primeiro trabalho, os licenciados da UFG, elaboraram um material instrucional a ser utilizado nas aulas sobre o acidente radioativo ocorrido em 1987, na cidade de Goiânia; o segundo trabalho tratava de uma investigação que os licenciandos deveriam fazer nas escolas da cidade de Campinas, a respeito da seguinte questão: ‘Qual é o lugar da Química na escola?’. O objetivo foi verificar na pesquisa que fizeram, se há ainda a existência do dilema entre o científico e cotidiano, após as novas orientações curriculares.

Em relação a abordagem que mais se evidenciou nos trabalhos, que seriam as atividades realizadas para os alunos da Licenciatura, podemos exemplificá-los com o ED-031, apresentado em 2003, cujo objetivo principal era de propiciar aos estudantes do curso de Licenciatura em Ciências da UFBA a aplicação de uma metodologia fundamentada na prática experimental, afim de abordar conteúdos químicos, a partir do levantamento prévio das concepções dos alunos, para a elaboração da estratégia. O trabalho ED-015, da reunião realizada em 2004, buscou analisar as idéias dos licenciandos em Química da UFRPE, sobre a utilização de analogias no 
processo de ensino-aprendizagem, de modo a contribuir no processo formativo do futuro docente. E para finalizar, temos como exemplo o ED-112, apresentado em 2005, que traz uma proposta de interação de um grupo de alunos da Licenciatura em Química da UESB e um grupo de professores em serviço, para que estes pudessem contribuir na formação dos licenciandos através de suas experiências profissionais na área.

\subsubsection{Trabalhos Sobre Políticas Públicas}

Identificamos apenas oito resumos cujo foco temático foi Políticas Públicas. Dentre eles, quatro abrangem aspectos da Educação Ambiental (ED-013 e ED-021 apresentados na reunião de 1999; ED-087, apresentado na reunião de 2000; ED-040, apresentado na reunião de 2005) como: a reciclagem de plástico e de alumínio, a utilização responsável de embalagens descartáveis oferecidas nas redes de supermercado e o destino dado ao lixo nas grandes cidades. Com uma abordagem um pouco diferenciada dos trabalhos anteriormente mencionados, o trabalho ED116, apresentado na reunião de 2003, trata de uma questão de interesse de trabalhadores rurais de uma determinada região de Minas Gerais: a intoxicação de seres humanos por defensivos agrícolas.

Os três trabalhos restantes tratam de assuntos diversificados: o ED-025, apresentado na reunião de 2000, trata de questões relacionadas ao ensino de química, estudadas por um grupo constituído por membros das seis IES públicas do Estado de São Paulo (G6); o ED-065, apresentado na mesma reunião que o ED-025, traça um paralelo entre a formação do químico e a expectativa das empresas quanto ao profissional que desejam receber; o ED-080 trata de um programa desenvolvido pelo DCE-UNICAMP que tem se dedicado ao atendimento de alunos deficientes visuais.

A maior parte destes trabalhos que foram classificados destinava-se ao Ensino Médio, porém cabe ressaltar que a proposta deles seria transpor as investigações para o público em geral 
e não só os indivíduos participantes do contexto escolar, pois os assuntos tratados visam os interesses da coletividade.

\subsubsection{Trabalhos Sobre Organização da Escola}

Neste foco temático de investigação encontramos vinte e três trabalhos. Diferentemente do que verificamos para uma grande parte dos demais focos, neste caso, existe uma elevada porcentagem de trabalhos destinados ao Ensino Superior (65,22\%). Nenhum trabalho se destina ao Ensino Fundamental ou foi classificado como pertencente ao descritor Geral.

Os trabalhos que foram classificados neste foco, de maneira geral, tratam da gestão escolar nos aspectos relativos à organização de dados referentes ao corpo discente da instituição, como estudos a respeito da evasão escolar e de alunos egressos e ainda nos aspectos relativos ao destino de resíduos produzidos pela escola. Destacamos dentre os trabalhos analisados, o ED098, apresentado na reunião de 2002, que discute o interesse dos alunos pela Química após a criação de uma sala ambiente de Ciências no Colégio Estadual Padre Anchieta-RJ, local onde eram desenvolvidas as aulas experimentais, e o ED-057, da reunião de 2003, que relata o estabelecimento do compromisso da UNEB na adoção de cotas para estudantes afrodescendentes.

São seis os trabalhos relacionados ao gerenciamento de resíduos gerados na instituição (ED-066 apresentado em 2000; ED-067, ED-072, ED-127 apresentados em 2003; ED-053 apresentado na reunião de 2004; ED-068 apresentado em 2005) que investigam a melhor maneira de coletar e tratar os resíduos provenientes dos laboratórios de ensino e buscam desenvolver no aluno uma conscientização no âmbito ambiental. Dentre as instituições mencionadas nos trabalhos estão: a UNICAMP, Universidade Federal do Ceará, UNIVATES, Centro de Ensino Médio Elefante Branco, Universidade Presbiteriana Mackenzie e a Universidade Federal Fluminense, respectivamente. 
Existem ainda trabalhos que se relacionam à gestão de resíduos, mas que não dizem respeito à gestão de resíduos produzidos em laboratórios de ensino. São eles o ED-032 e o ED046, apresentados respectivamente em 2000 e 2004. Em ambos o gerenciamento de resíduos provenientes do lixo é abordado. No primeiro o destino final do lixo produzido em uma escola pública, começando pela coleta seletiva do lixo, é discutido. No segundo, é descrita a implantação do processo de compostagem do lixo orgânico gerado na merenda escolar.

Estudos relacionados à evasão de alunos em curso de graduação em Química e estudos que tratam do destino de alunos egressos de determinadas instituições foram abordados com constância em trabalhos classificados como pertencentes ao foco temático Organização da Escola. Os trabalhos ED-083, ED-067, apresentados respectivamente nas reuniões de 1999 e 2000, os ED-098 e ED-180 da reunião de 2004 e o ED-087 apresentado em 2005, têm como objetivo identificar os principais fatores que deflagram a evasão dos alunos do curso de Química das seguintes universidades: Universidade Estadual do Sudoeste da Bahia, UFMG, UFF, Universidade Federal Rural do Rio de Janeiro e a Universidade Estadual de Maringá, respectivamente.

O trabalho ED-005, apresentado em 2002, trata de uma pesquisa sobre os egressos do curso de Bacharelado em Química do Instituto de Química de São Carlos e visou obter elementos capazes de subsidiar o curso no sentido de atender as exigências do mercado de trabalho.

Identificamos ainda 2 trabalhos que tinham como objetivo orientar os alunos sobre segurança dentro de um laboratório. O ED-106, apresentado na reunião de 2002, que descreveu uma pesquisa de campo realizada com alunos do curso experimental de Química Orgânica da UFF, a partir da qual foi desenvolvido um manual de segurança e primeiros socorros em caso de acidentes dentro do laboratório, e o ED-068, apresentado na reunião de 2003, que relatou a criação de fichas de segurança sobre determinados reagentes para prevenção de acidentes durante 
as atividades desenvolvidas nas aulas práticas de Química Orgânica, ministradas no curso de Ciências Farmacêuticas da Universidade de Fortaleza.

\subsubsection{Trabalhos Sobre Programa de Ensino Não Escolar}

Identificamos quinze resumos cujo foco temático foi Programa de Ensino Não-Escolar. Verificamos que $66 \%$ deles foram apresentados nas reuniões de 2004 e 2005 , o que nos leva a crer que tal assunto vem sendo discutido mais recentemente no âmbito da pesquisa acadêmica sobre o ensino de química.

A abordagem central de quatro dos trabalhos está associada a atividades oferecidas para alunos dos diversos níveis de ensino e para o público em geral em espaços não-formais de ensino. São eles: ED-075, apresentado na reunião de 2003, que trata de atividades desenvolvidas na Casa da Descoberta (espaço criado na UFF com o intuito de divulgar a ciência para estudantes e o público em geral); ED-113, apresentado na reunião de 2004, relacionado a atividades realizadas no Parque da Ciência do Museu da Vida na FIOCRUZ; ED-061 e ED-158, apresentados na reunião de 2005, relacionados a atividades realizadas no Jardim Zoológico do Rio de Janeiro e no Museu Municipal de Ribeirão Preto, respectivamente.

Cinco dos trabalhos tratam de atividades realizadas em espaços formais de ensino, como universidades e escolas públicas, porém voltadas para estudantes e o público em geral. Os trabalhos ED-070 (apresentado na reunião de 2000), ED-069 (apresentado na reunião de 2002) e ED-167 (apresentado na reunião de 2004) relatam a divulgação da Química através de peças teatrais produzidas por alunos de graduação e/ou Pós-Graduação em Química, Física e Artes Cênicas da UFMG, apresentadas no campus da UFMG, em eventos científicos e em diversas escolas de ensino médio em Belo Horizonte. O trabalho ED-168, apresentado na reunião de 2004, relata as atividades desenvolvidas pelo Grupo de Extensão e Pesquisas Espeológicas Guano Speleto da (UFMG) visando divulgar a espeleologia, ciência que estuda as cavernas, junto ao público em geral. O trabalho ED-139, apresentado na reunião de 2005, relata o oferecimento 
de oficinas temáticas (versando sobre "Solo e Química" e "Água do Mar Como Fonte de Materiais”, por exemplo) a alunos de nível médio da rede pública de São Paulo.

Os seis trabalhos restantes apresentam abordagens diferenciadas, entre as quais estão: o oferecimento de um curso de formação dirigido aos trabalhadores de piso de fábrica do grupo Siemens, no Paraná (ED-079, apresentado na reunião de 1999) e de atividades de ensino, relacionadas à química, a comunidades distintas como moradores de um bairro do Rio de Janeiro e trabalhadores rurais e donas de casa de comunidades carentes do Agreste de Pernambuco.

Os trabalhos aqui apresentados possuem em comum o fato de apresentarem nível de escolaridade Geral, uma vez que também pretendem atingir um público amplo e não apenas de estudantes de um determinado nível de ensino.

\subsubsection{Trabalhos Sobre Filosofia da Ciência}

Identificamos apenas dois resumos cujo foco temático foi Filosofia da Ciência. Ainda assim, em todos os trabalhos, o foco principal apontado era outro que não a Filosofia da Ciência. Ou seja, em todos eles a Filosofia da Ciência foi tratada de maneira que consideramos como sendo secundária. No trabalho ED-047, apresentado na reunião de 1999 e relacionado ao Ensino Médio, os autores investigaram a evolução conceitual dos alunos a respeito de modelos atômicos após intervenções didáticas utilizando metodologias diferenciadas; sendo que uma das metodologias foi idealizada a partir de considerações pautadas na História e na Filosofia da Ciência.

O trabalho ED-014, apresentado na de 2004, destinado ao Ensino Superior, investiga as concepções de Ciência e o trabalho experimental que orientam os acadêmicos do curso de Química da Universidade Federal de Pelotas. 


\subsubsection{Trabalhos Sobre História da Ciência}

Identificamos apenas dez resumos cujo foco temático foi História da Ciência. A maior produção de trabalhos sobre este foco se deu no ano de 1999, quando quatro trabalhos foram apresentados na $22^{\mathrm{a}}$ reunião. A partir de então o número de trabalhos diminuiu sensivelmente, resultando em apenas uma ou duas apresentações por RASBQ. A grande maioria dos trabalhos está voltada para o Ensino Médio (60\%) e visa discutir um determinado conteúdo de Química lançando mão da perspectiva histórica. Um exemplo de trabalhos deste tipo é o ED-080, apresentado na reunião de 2003 por pesquisadores da USP, que introduz os estudantes do Ensino Superior de Química ao conteúdo ministrado na disciplina de Química de Coordenação através da abordagem de controvérsias estabelecidas no início da constituição deste campo entre cientistas que justificavam a estrutura de compostos de coordenação através de modelos diferentes.

Em um único trabalho (ED-072, apresentado na reunião de 1999 por pesquisadores da UFF) verificamos o estabelecimento de relações entre a História da Química e a Formação de Professores: o objetivo principal do trabalho foi mostrar ao professor do Ensino Médio como o conhecimento da história de uma dada teoria poderia auxiliá-lo a simplificar o ensinoaprendizagem de conteúdos considerados demasiadamente teóricos. A relação entre a História da Química e o Livro Didático foi também observada em uma única ocasião no trabalho ED-079, apresentado na reunião de 2004 por pesquisadores da UFRJ, no qual consta uma análise de como a História da Química é apresentada nos livros didáticos mais utilizados no Ensino Médio do Rio de Janeiro.

Verificamos também a ocorrência de um trabalho (ED-141 apresentado na reunião de 2005 por pesquisadores da USP) no qual se procurou investigar como a História da Ciência poderia auxiliar a compreensão da teoria atômica de Dalton. 


\subsubsection{Trabalhos Sobre História do Ensino de Ciências}

Identificamos apenas dois resumos cujo foco temático foi História do Ensino de Ciências. Ambos foram apresentados na reunião de 2005 (ED-42 e ED-137) e apresentam perfis completamente distintos. Enquanto o primeiro está relacionado aos níveis de escolaridade médio e superior, o segundo foi classificado no descritor Geral.

O ED-42 analisa como se deu a recepção da Tabela Periódica dos Elementos no Brasil através da análise dos livros didáticos de química, escritos por brasileiros e utilizados no nível médio e superior no final do século XIX e início do século XX. Faz também uma análise do programa de ciências adotado no Imperial Colégio de Pedro II que a partir de 1855 tornou-se oficialmente modelo para as instituições secundárias brasileiras.

O ED-137 apresenta uma pesquisa sobre as realizações do Professor Reinaldo Carvalho Silva, considerado pelos autores do trabalho como um pioneiro no ensino de química. A análise da prática pedagógica do referido Professor e entrevistas com ex-alunos seus permitiram o delineamento do seu perfil.

\subsubsection{Trabalhos Sobre Foco Temático Outro}

Neste descritor foram alocados trinta e três trabalhos que não encontravam correspondência com os demais e/ou cuja incidência de casos no conjunto de documentos classificados era bastante pequena. Dentre eles destacam-se seis trabalhos relacionados a exames vestibulares das seguintes instituições: UFRJ (ED-081, apresentado na reunião de 2002); UESB (ED-085, apresentado na reunião de 2004); UNICAMP (ED-062, apresentado na reunião de 2000; ED-084, apresentado na reunião de 2003; ED-138, apresentado na reunião de 2004; ED160, apresentado na reunião de 2005). Assim, observamos uma concentração significativa de trabalhos sobre exames vestibulares realizados por pesquisadores do Instituto de Química da UNICAMP. 
Também se destacam trabalhos relacionados à linguagem e cognição. Sete trabalhos apresentam esta característica e enfatizam, principalmente, a mediação do professor e a importância das interações discursivas e da linguagem em sala de aula e no processo de elaboração conceitual em química. Cabe destacar que metade dos trabalhos com esta característica foram produzidos por pesquisadores da Faculdade de Educação da UFMG e evidenciam a investigação no Brasil de temáticas pertinentes às tendências internacionais ${ }^{28}$ (ED014, apresentado na reunião de 2000; ED-049, apresentado na reunião de 2002; ED-014 apresentado na reunião de 2003). Os outros quatro trabalhos são provenientes de grupos de pesquisas da região Nordeste (ED-042, apresentado na reunião de 1999), e ED-001 apresentado na reunião de 2000) e Centro-oeste (ED-007, apresentado na reunião de 2000, e ED-043, apresentado na reunião de 1999). Todos os trabalhos acima citados, relacionados às questões de linguagem no Ensino de Química, foram direcionados para o Ensino Médio, com exceção dos ED-001 (2000) que teve como nível escolar de estudo o Ensino Fundamental e o ED-049 (2002) que teve como nível de escolaridade abrangido o descritor Geral.

Neste foco temático também foram alocados três trabalhos relacionados a revisões bibliográficas ou a consultas sobre um determinado tema em bases de dados variadas. Todos eles foram apresentados na reunião de 2005 e dois foram produzidos por pesquisadores do Instituto de Química de São Carlos da USP (ED-037, ED-129 e ED-130).

Dois trabalhos que trataram de aspectos relacionados à formação de pós-graduandos em Química (ED-076, apresentado em 1999 e ED-008, da reunião realizada em 2003) e dois que versaram sobre a contribuição da Revista Química Nova (ED-071, na reunião de 1999) e da Revista Eletrônica QMCWEB.org na formação de alunos e na divulgação da Química (ED-049, apresentado em 2003) foram também incluídos neste foco.

Os demais trabalhos alocados neste foco apresentaram características extremamente diversificadas e não serão descritos aqui, uma vez que possuem uma representatividade muito baixa frente aos demais trabalhos analisados. 


\section{CONSIDERAÇÕES FINAIS}

Esta pesquisa teve como objetivo oferecer ao leitor uma visão "panorâmica" de uma parte importante da produção acadêmica brasileira sobre Ensino de Química nos últimos cinco anos. A narrativa cronológica dos resumos investigados revela que este número tem aumentado consideravelmente com o passar dos anos, passando de 85 trabalhos no ano de 1999 para 161 no ano de 2005. Uma consolidação da área de Ensino de Química pode ser vislumbrada a partir desta constatação.

$\mathrm{Na}$ narrativa que aponta para as regiões geográficas de produção dos resumos, evidenciamos uma maior participação de membros da comunidade acadêmica da região Sudeste em relação às outras regiões, principalmente em relação à região Norte, representada por apenas cinco trabalhos em todo o período analisado, sendo que a última reunião, realizada em 2005, concentrou $60 \%$ desta produção. Muitos são os fatores que conspiram para tal situação, destacando-se entre eles as enormes diferenças encontradas nas condições de produção das pesquisas no Brasil, o número de IES, tanto de administração pública quanto privada, instaladas nas regiões e ainda o local onde foram sediadas as reuniões, geralmente na região Sudeste, que favoreceram esta maior representatividade.

Uma outra característica identificada no estudo e relacionada com a região geográfica de produção são as IES a que estão vinculados os autores dos trabalhos. Das inúmeras IES existentes em nosso país (2.293 instituições), verificamos que ainda é muito pequena a participação delas em relação a este número, uma vez que a maioria dos trabalhos produzidos, concentraram-se em torno de vinte e oito instituições. Entre estas, destaca-se a USP, com 11\% da produção total apresentada no período. Esta produção é resultado de todas as investigações realizadas nos vários grupos de pesquisadores da área, estabelecidos nos diversos campi da universidade. 
Além da observação das IES envolvidas na produção dos trabalhos conseguimos identificar uma tendência de interação entre pesquisadores da área de Ciências Exatas com a área de Ciências Humanas. Esta constatação foi considerada, por nós, animadora, uma vez que estas relações entre áreas contribuem significativamente na produção e avaliação das investigações em Ensino de Química.

Quanto aos pesquisadores vinculados às IES, cada região teve alguns destaques. $\mathrm{Na}$ região Sudeste, os grupos de destaque foram os liderados por Marcelo Giordan, Maria Eunice Ribeiro Marcondes, ambos vinculados a USP; o liderado por Pedro Faria dos Santos Filho estabelecido na UNICAMP e o grupo de Lucidea Guimarães Rebello Coutinho da UFF. Os grupos liderados por Rejane Martins Novais Barbosa da UFRPE, e por Djalma Andrade da UFS foram os destaques da região Nordeste. Na região Centro-oeste destaca-se os liderados por Roberto Ribeiro da Silva e Wildson L Pereira Santo da UnB e Márlon Herbert Flora Barbosa Soares da UFG. Já para a região Sul, os grupos de pesquisa liderados por Rosana de Cássia de Souza Schneider e Wolmar Alípio Severo Filho da UNISC e o de César Valmor Machado Lopes e José Cláudio Del Pino foram os destaques.

$\mathrm{Na}$ organização da produção quanto ao nível escolar abrangido no estudo, percebemos que os pesquisadores optam, principalmente, pelo Ensino Médio, com destaque para as escolas públicas e o Ensino Fundamental foi o menos privilegiado nas investigações. Esta característica da produção acadêmica estar voltada ao Ensino Médio pode estar relacionada ao fato de que no Ensino Básico, que inclui o Ensino Fundamental e o Ensino Médio, este último apresenta a disciplina de Química na estrutura curricular em todas as séries que congregam esta etapa escolar, enquanto que o Ensino Fundamental introduz conhecimentos que envolvem conceitos químicos apenas nas últimas séries ( $7^{\mathrm{a}}$ e $8^{\mathrm{a}}$ séries).

As pesquisas voltadas para o Ensino Superior destacam-se logo atrás daquelas destinadas ao Ensino Médio, nas quais podemos verificar um crescimento regular nas últimas quatro reuniões, que nos leva a especular que este crescimento esteja relacionado às modificações 
ocorridas nas grades curriculares de alguns cursos oferecidos pelas universidades brasileiras, visando à adequação dos cursos de acordos com as modificações ocorridas na legislação educacional do Brasil ${ }^{27}$.

$\mathrm{Na}$ análise realizada por nós a respeito do foco temático de estudo desenvolvidos nos trabalhos, constatamos que dois focos foram privilegiados em relação aos demais: ConteúdoMétodo e Recursos Didáticos. Estes tratavam, de maneira geral, da produção, aplicação, aprimoramento e avaliação de métodos e recursos didáticos dentro do processo de ensinoaprendizagem de conhecimentos químicos e tiveram uma ampla abordagem nos estudos direcionados a alunos do Ensino Médio e Ensino Superior, respectivamente. Além destas temáticas de estudo, verificamos que a preocupação com a reestruturação do currículo escolar, da forma que os conceitos foram desenvolvidos no pensamento do aluno e/ou professores, investigações relacionadas à formação continuada e inicial dos professores também foram exploradas com uma certa freqüência, porém não como os dois focos citados anteriormente. Em relação aos demais focos, percebemos que há uma baixa produção com temas voltados para o Ensino de Química, que relacionam História da Ciência e História do Ensino de Ciências. Quanto aos trabalhos identificados de acordo com os descritores utilizados para classificá-los como pertencentes ao foco temático Outro, alguns apresentaram uma significativa ocorrência em relação aos demais, como os estudos que tratavam sobre exames vestibulares e trabalhos relacionados à linguagem e cognição, que a nosso ver mereceriam um foco temático específico para os assuntos abordados nos referidos trabalhos.

Uma consideração final diz respeito a uma comparação desta pesquisa com a realizada por Schnetzler ${ }^{1}$. Assim como na investigação realizada por ela, no período de 1977 a 2001, também constatamos que grande parte dos resumos apresentados nas RASBQs durante o período que investigamos (1999 a 2005) também não se relacionavam a investigações na área de Ensino de Química, mas relatos de experiência, descrições de inovações tecnológicas, novas propostas de ensino ou atividades práticas de laboratório. 
Assim, podemos perceber que importantes constatações, que podem vir a ser alcançadas através de trabalhos de pesquisa acadêmica e que são capazes de subsidiar o trabalho pedagógico escolar, ainda precisam ser veementemente buscadas, no que diz respeito ao Ensino de Química em nosso país. 


\section{REFERÊNCIAS BIBLIOGRÁFICAS}

1. SCHNETZLER, R.P. A pesquisa em ensino de química no Brasil: conquistas e perspectivas. Química Nova, v.25, Supl.1, p.14-24, 2002.

2. FRAZER, M.J. A Pesquisa em Educação Química. Química Nova, v.5, n.4, p. 126-128, 1982.

3. FERREIRA, N.S. de A. As pesquisas denominadas "Estado da Arte". Educação \& Sociedade, v. 23, n. 79, p. 257-272, 2002.

4. SOCIEDADE BRASILEIRA DE QUÍMICA. Disponível em:< http://www.sbq.org.br>. Acesso em: 12 jun. 2006.

5. SOARES, M. B. Alfabetização no Brasil: o estado do conhecimento. Brasília: INEP/REDUC, 1989.151p.

6. FIORENTINI, Dário. Rumos da pesquisa brasileira em Educação Matemática: o caso da produção científica em cursos de pós-graduação. 1994. 414f. Tese (Doutorado em Educação) - Faculdade de Educação, Universidade Estadual de Campinas, Campinas, 1994.

7. FERREIRA, Norma Sandra DE Almeida. Pesquisa em leitura: um estudo dos resumos de dissertações de mestrado e teses de doutorado defendidas no Brasil de 1980 a 1995. 1999. 110f. Tese (Doutorado em Educação) - Faculdade de Educação, Universidade Estadual de Campinas, Campinas, 1999.

8. ANDRÉ, M.; SIMÕES, R.H.S.; CARVALHO, J.M.;BRZEZINSKI,I. Estado da arte da formação de professores no Brasil. Educação \& Sociedade , v.20, n. 68, p. 301-309, 1999.

9. MOSTAFA, S. P.; MÁXIMO,L.F. A produção científica da Anped e da Intercom no GT da educação e comunicação. Ciência da Informação, v. 32, n.1, p.96-101, 2003.

10. AZEVEDO, J.M.L.; AGUIAR, M.A. A produção do conhecimento sobre a política educacional no Brasil: um olhar a partir da Anped. Educação \& Sociedade, v.22,n.77, p. 49-70, 2001.

11. HADDAD, S. Ensino supletivo no Brasil: o estado da arte. Brasília:

INEP/MEC/REDUC, 1987.136p.

12. PINTO, A. C.; ANDRADE, J. B.; VIEIRA, P. C.; PARDINI, V. L. A Química no Brasil através da Química Nova. São Paulo: SBQ, 2004.412p.

13. FRACALANZA, Hilário. O que sabemos sobre os livros didáticos para o ensino de Ciências no Brasil. 1993. 301f. Tese (Doutorado em Educação) - Faculdade de Educação, Universidade Estadual de Campinas, Campinas, 1993. 
14. MEGID NETO, Jorge Tendências da pesquisa acadêmica sobre o ensino de Ciências no nível fundamental. 1999. 236f. Tese (Doutorado em Educação) - Faculdade de Educação, Universidade Estadual de Campinas, Campinas, 1999.

15. DUARTE, M. da C. O estado da arte na pesquisa em educação em Ciências em Portugal. Revista Brasileira de Pesquisa em educação em Ciências, v. 2, p.5-24, 2002.

16. NARDI, R. Memórias da Educação em Ciências no Brasil: a pesquisa em ensino de Física. Investigações em Ensino de Ciências, v. 10, n. 1, p.1, 2005. Disponível em <http://www.if.ufrgs.br/public/ensino/vol10/n1/v10_n1_a4.htm>. Acesso em: 2 jun. 2006.

17. QUEIROZ, S.L.; NASCIMENTO, F.B.; REZENDE, F.S. Análise dos trabalhos apresentados nas Reuniões Anuais da Sociedade Brasileira de Química na seção de Ensino de Química de 1999 a 2003. In: ENCONTRO NACIONAL DE PESQUISAS EM EDUCAÇÃO EM CIÊNCIAS, 4, 2003, Bauru. Atas...Bauru: Associação Brasileira de Pesquisa em Educação em Ciências, 2003. 1 CD-ROM

18. FRANCISCO, C. A.; SÁ, P. L.; QUEIROZ, S. L. A abordagem de temas concernentes à Educação Ambiental por pesquisadores da área de Educação em Ciências. In: CONGRESSO BRASILEIRO DE QUÍMICA, 44, 2004, Fortaleza. Anais... Fortaleza: Associação Brasileira de Química, 2004. 1 CD-ROM

19. FRANCISCO, C. A.; OLIVEIRA, J. R. S.; QUEIROZ, S. L. A pesquisa acadêmica brasileira sobre as temáticas das concepções alternativas dos alunos e da abordagem CTS de ensino. In: REUNIÃO ANUAL DA SOCIEDADE BRASILEIRA DE QUÍMICA, 28. 2005, Poços de Caldas. Resumos...Poços de Caldas: Sociedade Brasileira de Química, 2005. Disponível em $<$ http://www.sbq.org.br $>$. Acesso em: 12 jun. 2006.

20. FRANCISCO, C. A.; QUEIROZ, S. L. Análise dos trabalhos apresentados nos Encontros de Debates sobre o Ensino de Química de 1999 a 2003. In: ENCONTRO NACIONAL DE PESQUISA EM EDUCAÇÃ̃O EM CIÊNCIAS, 5, 2005, Bauru. Atas... Bauru: Associação Brasileira de Pesquisa em Educação em Ciências, 2005. 1 CD-ROM

21. FRANCISCO, C. A.; QUEIROZ, S. L. Aprendizagem Significativa e Ensino de Química: Uma análise dos trabalhos em eventos da área de Educação em Química no Brasil. Aceito em: ENCUENTRO INTERNACIONAL DE APRENDIZAJE SIGNIFICATIVO, 5, 2006, Madrid.

22. FRANCISCO, C. A.; QUEIROZ, S. L. Análise dos trabalhos apresentados nos Encontros Nacionais de Ensino de Química no período de 2000 a 2002. Aceito em: ENCONTRO NACIONAL DE ENSINO DE QUÍMICA, 13, 2006, Campinas.

23. MEGID NETO, Jorge. Pesquisa em ensino de Física do $2^{\circ}$. grau no Brasil. 1990. $283 f$. Dissertação (Mestrado em Educação) - Faculdade de Educação, Universidade Estadual de Campinas, Campinas, 1990.

24. KAWAMURA, M.R.; SÁLEM, S. Ensino de Física no Brasil: Catálogo de dissertações e teses (1972-1992): catálogo analítico. São Paulo: USP/IFUSP.1996. 84p. 
25. COORDENAÇÃO DE APERFEIÇOAMENTO DE PESSOAL DE NÍVEL SUPERIOR

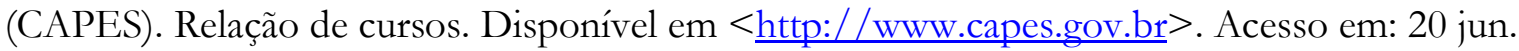
2006.

26. INSTITUTO NACIONAL DE ESTUDOS E PESQUISAS EDUCACIONAIS ANÍSIO

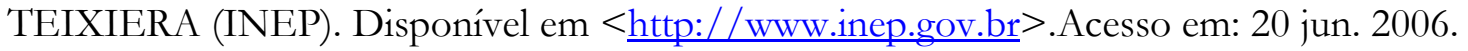

27. ZUCCO, C.; PESSINE, F.B.T.; ANDRADE, J.B. Diretrizes Curriculares para os Cursos de Química. Química Nova, v. 22, n.3, p. 454-461, 1999.

28. LEMKE, J. L. Talking Science: language, learning and values. Norwood: Ablex Publishing, 1990. 261p. 


\section{Modelo "Template do Resumo", a partir da $24^{a}$ até a $28^{a}$ RASBQ}

Inserir o título aqui (letra: Arial, 9, negrito)

Inserir os nomes dos autores aqui (letra: Arial, 8).

Inserir os endereços aqui (letra: Arial, itálico, 8)

Palavras Chave: Inserir aqui as palavras chave (letra: Arial 8) separadas por vírgula (máximo de 3 palavras até 30 dígitos).

Resumo: escreva aqui o texto, letra: Arial 9. Podem ser usadas figuras pequenas.

O tamanho da moldura deve ser respeitado. Resumos com medidas alteradas não serão publicados. 
Modelo "Template do trabalho ", a partir da $24^{\mathrm{a}}$ até a $28^{\mathrm{a}} \mathrm{RASBQs}$

Inserir o título aqui (Com este estilo de letra: Arial, 14). 0 título deve ser claro e conciso (Não ultrapasse duas linhas e utilize parágrafo único, não tecle "enter" no título).

Inserir o nome dos autores aqui, separados por vírgula (com este estilo de letra: Arial, 10). Escrever por extenso pelo menos o nome inicial e o sobrenome final (ex: Luana de O. Dias) ou todo o nome por extenso (Ex: Luana de Oliveira Dias). Não abrevie o primeiro nome. Após o nome colocar numeral em sobrescrito relacionado ao endereço e indique entre parenteses a categoria dos autores: Pesquisador (PQ), Prof. de ensino fundamental/médio (FM), Pós-graduando (PG), Estudante (IC), Técnivo (TC). Coloque um asterisco para indicar o autor principal. Indicar o e-mail do autor principal.

Inserir aqui o(s) endereço(s) (com este estilo de letra: Arial, itálico, 9).

Palavras Chave: Inserir aqui as palavras chave (letra: Arial, itálico, 9) separadas por vírgula (máximo de 3 palavras até 30 dígitos).

\section{Introdução}

Inserir aqui a introdução (letra: Arial, 10).

\section{Resultados e Discussão}

Inserir aqui resultado e discussão (letra: Arial, 10).

Inserir as figuras no espaço que achar conveniente.

Figura X. Inserir aqui título de fígura.

Caso não tenha tabelas, simplesmente delete o espaço abaixo, destinado à mesma.

Tabela X. Estilo Word VD_Table_Title. Inserir a tabela desejada após o título da mesma. Em seguida selecionar toda a tabela e aplicar o estilo Word TC_Table_Body

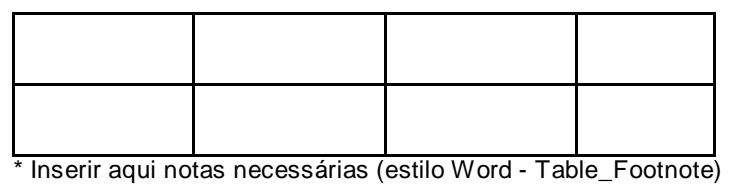

Caso haja dificuldade em colar a figura ou tabela no texto em duas colunas ou desejar que a figura saia em texto de uma coluna, colocar a figura, tabela ou

esquema no final do documento, indicando no texto onde deseja que a mesma seja inserida.

\section{Conclusōes}

Inserir aqui conclusões (letra: Arial, 10).

\section{Agradecimentos}

Inserir aqui agradecimentos. Procure usar este tipo de letra, embora possa usar letras maiúsculas.

Use o espaço abaixo para referências, seguindo o estilo indicado.

${ }^{1}$ Curtis, M. D.; Shiu, K.; Butler, W. M. e Huffmann, J. C. J. Am. Chem. Soc. 1986, 108, 3335

${ }^{2}$ Curtis, M. D.; Shiu, K.; Butler, W. M. e Huffmann, J. C. J. Am. Chem. Soc. 1986, 108, 3335 . 
Planilha de classificação da $22^{a}$ RASBQ - 1999

\begin{tabular}{|c|c|c|c|c|c|c|c|c|}
\hline ANO & TRABALHO & INSTITUIÇÃO 1 & INSTITUIÇÃO 2 & INSTITUIÇÃO 3 & INSTITUIÇÃO 4 & REGIÃO 1 & REGIÃO 2 & REGIÃO 3 \\
\hline 1999 & ED-001 & UFMG & & & & SUDESTE & & \\
\hline 1999 & ED-002 & UFRRJ & & & & SUDESTE & & \\
\hline 1999 & ED-003 & UERJ & C. DE APLICAÇÃO & & & SUDESTE & & \\
\hline 1999 & $\overline{\mathrm{ED}-004}$ & UFU & & & & SUDESTE & & \\
\hline 1999 & ED-005 & UFV & & & & SUDESTE & & \\
\hline 1999 & ED-006 & UEL & & & & SUL & & \\
\hline 1999 & ED-007 & $\begin{array}{l}\text { UFRRJ } \\
\end{array}$ & & & & SUDESTE & & \\
\hline 1999 & ED-008 & UFF & C.E.LICEU NILO PEÇANHA & & & SUDESTE & & \\
\hline 1999 & ED-009 & UNIJUí & & & & SUL & & \\
\hline 1999 & ED-010 & UFPI & & & & NORDESTE & & \\
\hline 1999 & ED-011 & UEL & C.ESOUZA NAVES & & & SUL & & \\
\hline 1999 & $\overline{E D-012}$ & UNESP & & & & SUDESTE & & \\
\hline 1999 & ED-013 & UERJ & & & & SUDESTE & & \\
\hline 1999 & ED-014 & UNICAMP & & & & SUDESTE & & \\
\hline 1999 & ED-015 & UFF & C.E PE. ANCHIETA & ETFQ & & SUDESTE & & \\
\hline 1999 & ED-016 & UFF & & & & SUDESTE & & \\
\hline 1999 & ED-017 & UFF & C.ESALESIANO STA. ROSA & C.E. ALCINA RODRIGUES LIMA & & SUDESTE & & \\
\hline 1999 & $\frac{D D-017}{\mathrm{ED}-018}$ & UFRGS & ESC.TEC.DA UFRGS & & & $\frac{\text { SUL }}{\text { SUL }}$ & & \\
\hline 1999 & ED-019 & UNESP & & & & SUDESTE & & \\
\hline 1999 & ED-020 & UFC & & & & NORDESTE & & \\
\hline 1999 & ED-021 & UNIFAL & & & & SUDESTE & & \\
\hline 1999 & ED-022 & NÃO PERTENCE A SECĊ̃OO & & & & & & \\
\hline 1999 & $\frac{E D-022}{E D-023}$ & NATPEKIENCE $A$ UFA & C.EPE.ANCHIETA & $\overline{\text { ETFQ }}$ & & SUDESTE & & \\
\hline 1999 & ED-024 & UFF & & & & SUDESTE & & \\
\hline 1999 & ED-025 & UNICAMP & & & & SUDESTE & & \\
\hline 1999 & ED-026 & UNICAMP & & & & SUDESTE & & \\
\hline 1999 & ED-027 & UFV & & & & SUDESTE & & \\
\hline 1999 & ED-028 & UFS & $\overline{\text { S.E. }}$ & EPSG MILTON DORTAS & EPSG LEÃO MAGNO BRASIL & NORDESTE & & \\
\hline 1999 & ED-029 & UFRPE & & & & NORDESTE & & \\
\hline 1999 & ED-030 & UNICENTRO & & & & SUL & & \\
\hline 1999 & ED-031 & UFF & & & & SUDESTE & & \\
\hline 1999 & ED-032 & USP & C. SÃO DOMINGOS & ESC LOURENCO CASTANHO & & SUDESTE & & \\
\hline 1999 & ED-033 & UFU & & & & SUDESTE & & \\
\hline 1999 & ED-034 & UFRGS & & & & SUL & & \\
\hline 1999 & ED-035 & UFS & & & & NORDESTE & & \\
\hline 1999 & $\overline{\mathrm{ED}-036}$ & UFRPE & & & & NORDESTE & & \\
\hline 1999 & $\frac{E D-500}{E D-037}$ & $\frac{U T M P}{\text { USP }}$ & & & & $\frac{\text { NUNDESTE }}{\text { SUDESTE }}$ & & \\
\hline 1999 & ED-038 & UNIDERP & & & & CENTRO-OESTE & & \\
\hline 1999 & $\frac{D D-500}{\mathrm{ED}-039}$ & UFPE & & & & NORDESTE & & \\
\hline 1999 & ED-040 & UFMG & C.TEC.DE PEDAGOGIA DA UFMG & & & SUDESTE & & \\
\hline 1999 & ED-041 & UFRPE & & & & NORDESTE & & \\
\hline 1999 & $\frac{E D-401}{E D-042}$ & UFRPE & & & & NORDESTE & & \\
\hline 1999 & ED-043 & UCB & FUND. EDUC. DF & & & CENTRO-OESTE & & \\
\hline 1999 & ED-044 & C. IMACULADA CONCEICCÃO & UFF & & & SUDESTE & & \\
\hline 1999 & ED-045 & UERJ & INST. BENJAMIM CONSTANT & & & SUDESTE & & \\
\hline 1999 & ED-045 & UCB & UNESP & USC & & CENTRO-OESTE & SUDESTE & \\
\hline 1999 & ED-047 & UFRPE & ESC. PE.ZEZINHO & ESC. OLIVEIRA LIMA & & NORDESTE & & \\
\hline 1999 & ED-048 & UFPE & & & & NORDESTE & & \\
\hline 1999 & ED-049 & UFRPE & & & & NORDESTE & & \\
\hline 1999 & ED-050 & $\mathrm{UnB}$ & UFMG & & & CENTRO-OESTE & SUDESTE & \\
\hline 1999 & ED-051 & UFG & & & & CENTRO-OESTE & & \\
\hline 1999 & $\overline{E D-052}$ & UFG & & & & CENTRO-OESTE & & \\
\hline 1999 & ED-053 & UFRJ & C.DE APLICACČ̃̃O & & & SUDESTE & & \\
\hline
\end{tabular}




\begin{tabular}{|c|c|c|c|c|c|c|c|c|}
\hline 1999 & ED-054 & UnB & $\mathrm{UCB}$ & & & CENTRO-OESTE & & \\
\hline 1999 & ED-055 & UFG & & & & $\begin{array}{l}\text { CENTRO-OESTE } \\
\end{array}$ & & \\
\hline 1999 & ED-056 & UFF & & & & SUDESTE & & \\
\hline 1999 & ED-057 & UFBA & & & & NORDESTE & & \\
\hline 1999 & ED-058 & ESC.VERA CRUZ & & & & SUDESTE & & \\
\hline 1999 & ED-059 & UFRRJ & & & & SUDESTE & & \\
\hline 1999 & ED-060 & UFMA & & & & NORDESTE & & \\
\hline 1999 & ED-061 & PUC-RS & & & & SUL & & \\
\hline 1999 & ED-062 & UFF & C.SALESIANO STA. ROSA & C.E PROF. ALCINA R. LIMA & $\begin{array}{l}\text { C. CINECISTA A. PARALHES } \\
\end{array}$ & SUDESTE & & \\
\hline 1999 & ED-063 & USP & & & & SUDESTE & & \\
\hline 1999 & ED-064 & UFSCAR & & & & SUDESTE & & \\
\hline 1999 & ED-065 & UFF & & & & SUDESTE & & \\
\hline 1999 & ED-066 & UFF & C.SALESIANO STA. ROSA & C.E PROF. ALCINA R. LIMA & C. CINECISTA A. PARALHES & SUDESTE & & \\
\hline 1999 & ED-067 & UFBA & & & & NORDESTE & & \\
\hline 1999 & ED-068 & UFS & SEC. EDUCAḈ̃OO & EEPSG MILTON DORTAS & & NORDESTE & & \\
\hline 1999 & ED-069 & UFV & & & & SUDESTE & & \\
\hline 1999 & ED-070 & $\mathrm{UnB}$ & UFMG & & & CENTRO-OESTE & SUDESTE & \\
\hline 1999 & ED-071 & USP & & & & SUDESTE & & \\
\hline 1999 & $\overline{E D-072}$ & UFF & & & & SUDESTE & & \\
\hline 1999 & $\begin{array}{c}\mathrm{ED}-073 \\
\end{array}$ & UFRPE & C. SIMON BOLIVAR & E. PAULO PESSOA GUERRA & & NORDESTE & & \\
\hline 1999 & ED-074 & UFF & C.SALESIANO STA. ROSA & C.E PROF. ALCINA R. LIMA & $\begin{array}{l}\text { C. CINECISTA A. PARALHES } \\
\end{array}$ & SUDESTE & & \\
\hline 1999 & ED-075 & UNICAMP & & & & SUDESTE & & \\
\hline 1999 & ED-076 & UFMG & UENF & & & SUDESTE & & \\
\hline 1999 & ED-077 & USP & UNIMES & USJT & UNIMAR & SUDESTE & & \\
\hline 1999 & ED-078 & UFS & & & & NORDESTE & & \\
\hline 1999 & ED-079 & UFPR & CEFET & SENAI & & SUL & & \\
\hline 1999 & ED-080 & UFV & & & & SUDESTE & & \\
\hline 1999 & ED-081 & UFF & & & & SUDESTE & & \\
\hline 1999 & $\mathrm{ED}-082$ & UFPI & & & & NORDESTE & & \\
\hline 1999 & ED-083 & UESB & C. ALVARO AUGUSTO SILVA & & & NORDESTE & & \\
\hline 1999 & ED-084 & UFRPE & & & & NORDESTE & & \\
\hline 1999 & ED-085 & UMC & & & & SUDESTE & & \\
\hline & & & & & & & & \\
\hline
\end{tabular}




\begin{tabular}{|c|c|c|c|c|c|}
\hline INTERAÇÃOO H X E & NÍVEL ESCOLAR 1 & NÍVEL ESCOLAR 2 & NIVEL ESCOLAR 3 & FOCO TEMÁTICO PRINCIPAL & FOCO TEMÁTCO SECUNDÁRIO \\
\hline & MÉDIO & SUPERIOR & & CONTEUUDO-METODO & \\
\hline & MÉDIO & & & RECURSO DIDÁTICO & \\
\hline & MÉDIO & & & CONTEÚDO-MÉTODO & \\
\hline & FUNDAMENTAL & MÉDIO & $\begin{array}{l}\text { SUPERIOR } \\
\end{array}$ & CONTEÚDO-MÉTODO & \\
\hline & MÉDIO & SUPERIOR & & RECURSO DIDÁTICO & \\
\hline & SUPERIOR & & & RECURSO DIDÁTICO & \\
\hline \multirow[t]{11}{*}{ IQXIE } & MÉDIO & SUPERIOR & & CONTEÚDO-MÉTODO & FORMAÇÃO INICIAL DE PROFESSORES \\
\hline & MÉDIO & SUPERIOR & & CONTEÚDO-METTODO & CURRÍCULOS E PROGRAMAS \\
\hline & FUNDAMENTAL & & & CURRÍCULOS E PROGRAMAS & \\
\hline & SUPERIOR & & & RECURSO DIDÁTICO & \\
\hline & MÉDIO & & & RECURSO DIDÁTICO & \\
\hline & MÉDIO & SUPERIOR & & CURRÍCULOS E PROGRAMAS & \\
\hline & MÉDIO & & & CONTEÚDO-MÉTODO & POLÍTICAS PÚBLICAS \\
\hline & FUNDAMENTAL & MÉDIO & & RECURSO DIDÁTICO & FORMAÇÃO CONT. DE PROFESSORES \\
\hline & MÉDIO & & & CONTEÚDO-MÉTODO & \\
\hline & FUNDAMENTAL & MÉDIO & & RECURSO DIDATICO & \\
\hline & FUNDAMENTAL & & & CONTEÚDO-MÉTODO & \\
\hline \multirow[t]{16}{*}{ IQXIE } & MÉDIO & & & CONTEÚDO-MÉTODO & \\
\hline & SUPERIOR & & & RECURSO DIDÁTICO & \\
\hline & MÉDIO & & & RECURSO DIDÁTICO & \\
\hline & GERAL & & & POLÍTICAS PÚBLICAS & PROGRAMA DE ENSINO NÃO ESCOLAR \\
\hline & & & & & \\
\hline & 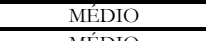 & & & $\begin{array}{c}\text { CONTEÚDO-MÉTODO } \\
\end{array}$ & \\
\hline & MÉDIO & & & FORMAÇÃO CONT.DE PROFESSORES & RECURSO DIDÁTICO \\
\hline & MÉDIO & & & HISTÓRIA DA CIÊNCIA & \\
\hline & SUPERIOR & & & RECURSO DIDÁTICO & \\
\hline & MÉDIO & SUPERIOR & & RECURSO DIDÁTICO & \\
\hline & MÉDIO & & & FORMAÇÃO DE CONCEITOS & \\
\hline & MÉDIO & & & FORMAÇÃO DE CONCEITOS & \\
\hline & FUNDAMENTAL & MÉDIO & & RECURSO DIDATICO & \\
\hline & FUNDAMENTAL & & & CONTEÚDO-METODO & \\
\hline & MEEDIO & & & FORMACCÃO DE CONCEITOS & RECURSO DIDÁTICO \\
\hline & SUPERIOR & & & CARACTERÍSTICAS DO ALUNO & $\begin{array}{l}\text { FORMAÇÃO INICIAL DE PROFESSORES } \\
\end{array}$ \\
\hline \multirow[t]{5}{*}{ DEXDC.BIOLÓGICAS } & FUNDAMENTAL & MÉDIO & & $\begin{array}{l}\text { CARACTERÍSTICAS DO PROFESSOR } \\
\end{array}$ & \\
\hline & MEDIO & & & CARACTERISTICAS DO ALUNO & \\
\hline & MÉDIO & & & CARACTERISTICAS DO PROFESSOR & RECURSO DIDÁTICO \\
\hline & GERAL & & & CURRÍCULOS E PROGRAMAS & \\
\hline & SUPERIOR & & & CONTEÚDO-MÉTODO & CURRÍCULOS E PROGRAMAS \\
\hline IQXIE & MÉDIO & & & FORMACCÃO DE CONCEITOS & \\
\hline \multirow{8}{*}{$\frac{\mathrm{FE}}{\mathrm{FE}}$} & FUNDAMENTAL & MÉDIO & & FORMAÇÃO CONT.DE PROFESSORES & \\
\hline & MÉDIO & & & FORMAÇÃO DE CONCEITOS & \\
\hline & MÉDIO & & & OUTRO & \\
\hline & MÉDIO & & & OUTRO & \\
\hline & MÉDIO & & & CONTEÚDO-MÉTODO & \\
\hline & FUNDAMENTAL & & & FORMACCÃO DE CONCEITOS & CONTEÚDO-MÉTODO \\
\hline & GERAL & & & RECURSO DIDÁTICO & \\
\hline & MÉDIO & & & FORMAČ́̃ D DE CONCEITOS & HISTÓRIA/FILOSOFIA DA CIĖNCIA \\
\hline \multirow[t]{3}{*}{ DQXDE } & FUNDAMENTAL & & & CURRÍCULOS E PROGRAMAS & \\
\hline & MÉDIO & & & FORMACCAO DE CONCEITOS & \\
\hline & MÉDIO & & & RECURSO DIDÁTICO & \\
\hline$\overline{\text { FEXIQ }}$ & FUNDAMENTAL & & & RECURSO DIDÁTICO & \\
\hline FEXIQ & FUNDAMENTAL & & & RECURSO DIDÁTICO & \\
\hline FE & FUNDAMENTAL & MÉDIO & & CURRÍCULOS E PROGRAMAS & ORGANIZAÇ̃̃O DA ESCOLA \\
\hline
\end{tabular}




\begin{tabular}{|c|c|c|c|c|}
\hline DQXDE & MÉDIO & & $\begin{array}{l}\text { CARACTERÍSTICAS DO PROFESSOR } \\
\end{array}$ & \\
\hline & MÉDIO & & CARACTERISTICAS DO PROFESSOR & FORMAÇÃO CONT.DE PROFESSORES \\
\hline & $\begin{array}{l}\text { FUNDAMENTAL } \\
\end{array}$ & MÉDIO & FORMAÇÃO DE CONCEITOS & \\
\hline & MÉDIO & & FORMAÇÃO DE CONCEITOS & \\
\hline & MÉDIO & & CURRÍCULOS E PROGRAMAS & CONTEÚDO-MÉTODO \\
\hline & SUPERIOR & & CURRÍCULOS E PROGRAMAS & \\
\hline & MÉDIO & & FORMAÇÃO CONT.DE PROFESSORES & \\
\hline & MÉDIO & & CURRÍ́CULOS E PROGRAMAS & \\
\hline PG EM ENS.DE QUíM. & MÉDIO & & FORMACCÃO DE CONCEITOS & \\
\hline \multirow[t]{7}{*}{$\mathrm{FE}$} & GERAL & & CARACTERÍSTICAS DO ALUNO & \\
\hline & FUNDAMENTAL & & HISTÓRIA DA CIÊNCIA & CONTEÚDO-MÉTODO \\
\hline & MÉDIO & & CONTEÚDO-MÉTODO & \\
\hline & MÉDIO & & CONTEÚDO-MÉTODO & \\
\hline & SUPERIOR & & CONTEÚDO-MÉTODO & CURRÍCULOS E PROGRAMAS \\
\hline & MÉDIO & & FORMACČ̃O DE CONCEITOS & \\
\hline & SUPERIOR & & RECURSO DIDÁTICO & CURRÍCULOS E PROGRAMAS \\
\hline FEXIQ & FUNDAMENTAL & MÉDIO & $\begin{array}{l}\text { CARACTERÍSTICAS DO PROFESSOR } \\
\end{array}$ & \\
\hline \multirow[t]{3}{*}{$\mathrm{FE}$} & GERAL & & OUTRO & \\
\hline & MÉDIO & & HISTÓRIA DA CIÊNCIA & FORMAÇÃO CONT.DE PROFESSORES \\
\hline & MÉDIO & & FORMACĊ̃O DE CONCEITOS & \\
\hline \multirow{2}{*}{ PG EM ENS.DE QUíM. } & MÉDIO & & FORMAÇÃO DE CONCEITOS & \\
\hline & SUPERIOR & & OUTRO & \\
\hline \multirow{3}{*}{ DQXDC. POLÍTICAS } & SUPERIOR & & OUTRO & \\
\hline & SUPERIOR & & CONTEÚDO-MÉTODO & \\
\hline & SUPERIOR & & CURRÍCULOS E PROGRAMAS & \\
\hline \multirow[t]{8}{*}{ DQXDMXDE } & GERAL & & PROGRAMA DE ENSINO NÂO ESCOLAR & CURRÍCULOS E PROGRAMAS \\
\hline & GERAL & & RECURSO DIDÁTICO & \\
\hline & MÉDIO & & FORMAÇÃO CONT.DE PROFESSORES & \\
\hline & MÉDIO & $\overline{\text { SUPERIOR }}$ & RECURSO DIDÁTICO & \\
\hline & SUPERIOR & & ORGANIZAÇÃO DA ESCOLA & CARACTERÍSTICAS DO ALUNO \\
\hline & MÉDIO & & CURRÍCULOS E PROGRAMAS & FORMAÇÃO CONT.DE PROFESSORES \\
\hline & SUPERIOR & & CONTEÚDO-MÉTODO & \\
\hline & & & & \\
\hline
\end{tabular}


Planilha de classificação da $23^{\mathrm{a}}$ RASBQ - 2000

\begin{tabular}{|c|c|c|c|c|c|c|c|c|}
\hline ANO & TRABALHO & INSTITUIÇÃO 1 & INSTITUIÇÃO 2 & INSTITUIÇÃO 3 & INSTITUIÇÃO 4 & $\begin{array}{ll}\text { REGIÃO } 1 \\
\end{array}$ & $\begin{array}{l}\text { REGIÃO } 2 \\
\end{array}$ & INTERAÇÃO H X E \\
\hline 2000 & ED-001 & UFS & & & & NORDESTE & & DQXDPSI.XPG EM EDUCAÇÃO \\
\hline 2000 & ED-002 & UFS & & & & NORDESTE & & DQXDPSI.XPG EM EDUCAÇÃO \\
\hline 2000 & ED-003 & UFRGS & & & & SUL & & \\
\hline 2000 & ED-004 & UFRRJ & & & & SUDESTE & & \\
\hline 2000 & ED-005 & FUNREI & & & & SUDESTE & & \\
\hline 2000 & ED-006 & $\begin{array}{l}\text { UFPE } \\
\end{array}$ & & & & NORDESTE & & DQXDMET.E TEC. DE ENSINO \\
\hline 2000 & ED-007 & UFMG & UnB & $\mathrm{UCB}$ & & SUDESTE & CENTRO-OESTE & DQXFE \\
\hline 2000 & ED-008 & UFRPE & C. E. SÃO JOSÉ & & & NORDESTE & & \\
\hline 2000 & ED-009 & $\begin{array}{l}\text { UFRPE } \\
\end{array}$ & C. E. SÃO JOSÉ & & & NORDESTE & & \\
\hline 2000 & ED-010 & UFF & & & & SUDESTE & & DQXPG EM ENSINO DE CIĖNCIAS \\
\hline 2000 & ED-011 & UNISC & & & & SUL & & \\
\hline 2000 & ED-012 & UEL & & & & SUL & & \\
\hline 2000 & ED-013 & UNIDERP & UFMS & & & CENTRO-OESTE & & \\
\hline 2000 & ED-014 & $\begin{array}{l}\text { UFMG } \\
\end{array}$ & & & & SUDESTE & & $\mathrm{FE}$ \\
\hline 2000 & ED-015 & $\overline{\text { UFMG }}$ & & & & SUDESTE & & FE \\
\hline 2000 & ED-016 & UFS & SEE & EPSG DR. MILTON DORTAS & & NORDESTE & & \\
\hline 2000 & ED-017 & COLÉGIO SANTA CRUS- SP & & & & SUDESTE & & \\
\hline 2000 & ED-018 & $\begin{array}{l}\text { FIMI } \\
\end{array}$ & FCACSL & & & SUDESTE & & \\
\hline 2000 & ED-019 & UERJ & & & & SUDESTE & & \\
\hline 2000 & ED-020 & UFRJ & & & & SUDESTE & & IQXFE \\
\hline 2000 & ED-021 & $\begin{array}{l}\text { UFV } \\
\end{array}$ & UEMG & FEPAM & & $\begin{array}{l}\text { SUDESTE } \\
\text { SUS }\end{array}$ & & DQXFAC.FIL.E LETRAS \\
\hline 2000 & ED-022 & UFF & UERJ & $\begin{array}{l}\text { PUC -RJ } \\
\end{array}$ & $\begin{array}{l}\text { CEFETQ- NILÓPOLIS } \\
\end{array}$ & SUDESTE & & DQXFE \\
\hline 2000 & ED-023 & UFF & CEFETQ- NILÓPOLIS & C.E. PADRE ANCHIETA & & $\begin{array}{l}\text { SUDESTE } \\
\end{array}$ & & \\
\hline 2000 & $\overline{E D-024}$ & UFF & UERJ & & & SUDESTE & & DQXPG EM ENSINO DE CIĖNCIAS \\
\hline 2000 & ED-025 & USP & UNESP & UNICAMP & UFSCAR & SUDESTE & & \\
\hline 2000 & ED-026 & UERJ & INST. BENJAMIN CONSTANT & & & SUDESTE & & \\
\hline 2000 & ED-027 & C.E. LICEU NILO PEÇANHA & C.E. GOMES F. DE ANDRADE & & & SUDESTE & & \\
\hline 2000 & ED-028 & UNESP & & & & SUDESTE & & \\
\hline 2000 & ED-029 & UFS & SEE & EPSG DR. MILTON DORTAS & & NORDESTE & & \\
\hline 2000 & ED-030 & UNIP & UNICAMP & & & SUDESTE & & \\
\hline 2000 & ED-031 & UNOPAR & & & & SUL & & \\
\hline 2000 & ED-032 & USP & & & & $\begin{array}{l}\text { SUDESTE } \\
\end{array}$ & & DQXIPSICOLOGIA \\
\hline 2000 & ED-033 & UFG & & & & CENTRO-OESTE & & $\mathrm{FE}$ \\
\hline 2000 & ED-034 & UFG & & & & CENTRO-OESTE & & \\
\hline 2000 & ED-035 & UFRPE & & & & NORDESTE & & \\
\hline 2000 & ED-036 & UFPE & ESC. OLIVEIRA LIMA & ESC. SIMON BOLIVAR & & NORDESTE & & \\
\hline 2000 & ED-037 & FUNREI & $\begin{array}{ll}\text { UFMG } \\
\end{array}$ & & & SUDESTE & & DCNXFAE \\
\hline 2000 & ED-038 & $\begin{array}{l}\text { UFMG } \\
\end{array}$ & & & & SUDESTE & & \\
\hline 2000 & ED-039 & USP & & & & SUDESTE & & \\
\hline 2000 & ED-040 & UFMG & & & & SUDESTE & & \\
\hline 2000 & ED-041 & UFMG & & & & SUDESTE & & \\
\hline 2000 & $\begin{array}{l}\mathrm{ED}-042 \\
\end{array}$ & UFRRJ & & & & SUDESTE & & \\
\hline 2000 & ED-043 & UFG & & & & CENTRO-OESTE & & \\
\hline 2000 & ED-044 & UNICAMP & & & & SUDESTE & & \\
\hline 2000 & ED-045 & UNICAMP & & & & SUDESTE & & \\
\hline 2000 & ED-046 & UNICAMP & & & & SUDESTE & & \\
\hline 2000 & ED-047 & $\mathrm{UCB}$ & & & & CENTRO-OESTE & & \\
\hline 2000 & ED-048 & UFSC & & & & SUL & & \\
\hline 2000 & ED-049 & UCB & UNESP & USC & & CENTRO-OESTE & $\begin{array}{l}\text { SUDESTE } \\
\end{array}$ & \\
\hline 2000 & ED-050 & UFV & & & & SUDESTE & & \\
\hline 2000 & ED-051 & UFV & & & & SUDESTE & & \\
\hline 2000 & ED-052 & UNESP & & & & $\begin{array}{l}\text { SUDESTE } \\
\end{array}$ & & \\
\hline 2000 & ED-053 & UFRPE & & & & NORDESTE & & \\
\hline
\end{tabular}




\begin{tabular}{|c|c|c|c|c|c|c|c|c|}
\hline 2000 & ED-054 & CDCC- USP & E. E. AZARIAS LEITE & & & SUDESTE & & \\
\hline 2000 & ED-055 & UFF & & & & SUDESTE & & \\
\hline 2000 & ED-056 & UERJ & & & & SUDESTE & & \\
\hline 2000 & ED-057 & CEFETQ- NILÓPOLIS & UFRJ & & & SUDESTE & & \\
\hline 2000 & ED-058 & $\begin{array}{l}\text { UNICENTRO } \\
\end{array}$ & USP & & & SUL & SUDESTE & \\
\hline 2000 & ED-059 & CEFETQ- NILÓPOLIS & & & & SUDESTE & & \\
\hline 2000 & ED-060 & UFRGS & & & & $\begin{array}{l}\text { SUL } \\
\end{array}$ & & IQXFEXICBSAÚDE \\
\hline 2000 & ED-061 & UFU & & & & SUDESTE & & \\
\hline 2000 & ED-062 & UNICAMP & & & & SUDESTE & & \\
\hline 2000 & ED-063 & $\begin{array}{ll}\text { USP } \\
\end{array}$ & UNIMES & & & SUDESTE & & \\
\hline 2000 & ED-064 & UNESP & UFSCAR & & & SUDESTE & & \\
\hline 2000 & ED-065 & UNICAMP & USP & & & SUDESTE & & \\
\hline 2000 & ED-066 & UNICAMP & & & & SUDESTE & & \\
\hline 2000 & ED-067 & UFMG & & & & SUDESTE & & ICEXFE \\
\hline 2000 & ED-068 & $\begin{array}{l}\text { UFMG } \\
\end{array}$ & & & & SUDESTE & & \\
\hline 2000 & ED-069 & UFRRJ & & & & SUDESTE & & $\overline{\mathrm{IE}}$ \\
\hline 2000 & ED-070 & UFMG & & & & SUDESTE & & \\
\hline 2000 & ED-071 & UFMG & & & & SUDESTE & & $\mathrm{FE}$ \\
\hline 2000 & $\mathrm{ED}-072$ & $\begin{array}{l}\text { UFMG } \\
\end{array}$ & & & & SUDESTE & & FE \\
\hline 2000 & ED-073 & $\begin{array}{ll}\text { UNISC } \\
\end{array}$ & & & & SUL & & \\
\hline 2000 & ED-074 & $\begin{array}{l}\text { UNISC } \\
\end{array}$ & & & & SUL & & \\
\hline 2000 & ED-075 & UNISC & & & & SUL & & \\
\hline 2000 & ED-076 & UFRPE & & & & NORDESTE & & \\
\hline 2000 & ED-077 & UFSC & & & & SUL & & \\
\hline 2000 & ED-078 & UFSCAR & USP & & & SUDESTE & & \\
\hline 2000 & ED-079 & UFSCAR & & & & SUDESTE & & \\
\hline 2000 & ED-080 & UFRJ & 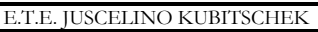 & & & SUDESTE & & \\
\hline 2000 & ED-081 & PUC - RJ & E. E. AGRIPINO GRIECO & C. MIL. RJ & E. E. JOÃO KOPKE & SUDESTE & & \\
\hline 2000 & ED-082 & PUC - RJ & E. E. AGRIPINO GRIECO & & & SUDESTE & & \\
\hline 2000 & ED-083 & PUC-RJ & E. E.AGRIPINO GRIECO & C. MIL. RJ & E. E. JOÃO KOPKE & SUDESTE & & \\
\hline 2000 & ED-084 & UFRJ & & & & $\begin{array}{l}\text { SUDESTE } \\
\text { SUDS }\end{array}$ & & \\
\hline 2000 & ED-085 & UFRJ & C.PEDRO II & & & SUDESTE & & \\
\hline 2000 & ED-086 & UFRJ & & & & SUDESTE & & \\
\hline 2000 & ED-087 & UFRN & & & & NORDESTE & & \\
\hline 2000 & ED-088 & UFC & & & & NORDESTE & & \\
\hline 2000 & ED-089 & UERJ & & & & $\begin{array}{l}\text { SUDESTE } \\
\end{array}$ & & \\
\hline 2000 & $\overline{E D-090}$ & $\begin{array}{l}\text { UEL } \\
\end{array}$ & C.E. ANTŌNIO DE MORAES & & & $\begin{array}{l}\text { SUL } \\
\end{array}$ & & \\
\hline
\end{tabular}




\begin{tabular}{|c|c|c|c|c|c|}
\hline NÍVEL1 & NíVEL 2 & NÍVEL 3 & FOCO TEMÁTICO PRINCIPAL & FOCO TEMÁTICO SECUNDÁRIO & FOCO TEMÁTICO TERCIÁRIO \\
\hline FUNDAMENTAL & & & FORMAÇÃO DE CONCEITOS & OUTRO & \\
\hline FUNDAMENTAL & & & FORMAÇÃO DE CONCEITOS & & \\
\hline MÉDIO & & & CONTEÚDO-MÉTODO & & \\
\hline SUPERIOR & & & RECURSO DIDÁTICO & & \\
\hline FUNDAMENTAL & & & CONTEÚDO-MÉTODO & & \\
\hline MEDDIO & & & RECURSO DIDÁTICO & E CARACTERÍSTICAS DO ALUNO & \\
\hline GERAL & & & FORMAÇÃO DE CONCEITOS & OUTRO & \\
\hline FUNDAMENTAL & & & FORMAÇÃO DE CONCEITOS & & \\
\hline FUNDAMENTAL & & & RECURSO DIDÁTICO & & \\
\hline MÉDIO & & & RECURSO DIDÁTICO & & \\
\hline MÉDIO & & & FORMAÇÃO CONT. DE PROFESSORES & & \\
\hline MÉDIO & & & FORMAÇÃO CONT. DE PROFESSORES & & \\
\hline MÉDIO & & & FORMAÇÃO CONT. DE PROFESSORES & & \\
\hline MÉDIO & & & OUTRO & & \\
\hline MÉDIO & & & CARACTERÍSTICAS DO PROFESSOR & E CARACTERÍSTICAS DO ALUNO & FORMAÇÃO CONT. DE PROFESSORES \\
\hline MÉDIO & & & FORMAÇÃO CONT. DE PROFESSORES & & \\
\hline MÉDIO & & & CONTEÚDO-MÉTODO & HISTÓRIA DA CIĖNCIA & \\
\hline SUPERIOR & & & CURRÍCULOS E PROGRAMAS & CARACTERÍSTICAS DO ALUNO & \\
\hline MÉDIO & & & CONTEÚDO-MÉTODO & E FORMAÇূ̃O CONT. DE PROFESSORES & \\
\hline MÉDIO & & & RECURSO DIDÁTICO & & \\
\hline MÉDIO & & & FORMAÇÃO CONT. DE PROFESSORES & & \\
\hline MÉDIO & & & CURRÍCULOS E PROGRAMAS & & \\
\hline MÉDIO & & & CONTEÚDO-MÉTODO & & \\
\hline MÉDIO & & & CONTEÚDO-MÉTODO & ORGANIZAÇÃO DA ESCOLA & \\
\hline SUPERIOR & & & POLITTCAS PÚBLICAS & CURRÍCULOS E PROGRAMAS & \\
\hline FUNDAMENTAL & & & FORMAÇÃO DE CONCEITOS & RECURSO DIDÁTICO & \\
\hline GERAL & & & CONTEÚDO-MÉTODO & & \\
\hline MÉDIO & & & RECURSO DIDÁTICO & & \\
\hline MÉDIO & & & FORMAÇÃO DE CONCEITOS & & \\
\hline SUPERIOR & & & RECURSO DIDATICO & & \\
\hline MÉDIO & $\begin{array}{l}\text { SUPERIOR } \\
\end{array}$ & & FORMAÇÃO DE CONCEITOS & $\begin{array}{l}\text { CARACTERÍSTICAS DO ALUNO } \\
\end{array}$ & \\
\hline MÉDIO & & & ORGANIZAÇÃO DA ESCOLA & & \\
\hline FUNDAMENTAL & MÉDIO & SUPERIOR & CARACTERÍSTICAS DO PROFESSOR & E CARACTERÍSTICAS DO ALUNO & \\
\hline MÉDIO & SUPERIOR & & FORMAÇÃO INICIAL DE PROFESSORES & CONTEÚDO-MÉTODO & \\
\hline MÉDIO & & & OUTRO & & \\
\hline MÉDIO & & & CARACTERÍSTICAS DO ALUNO & & \\
\hline MÉDIO & & & CURRÍCULOS E PROGRAMAS & & \\
\hline FUNDAMENTAL & MÉDIO & & RECURSO DIDÁTICO & & \\
\hline SUPERIOR & & & RECURSO DIDÁTICO & & \\
\hline SUPERIOR & & & CARACTERISTTICAS DO PROFESSOR & E CARACTERÍSTICAS DO ALUNO & \\
\hline SUPERIOR & & & $\begin{array}{l}\text { CARACTERÍSTICAS DO ALUNO } \\
\end{array}$ & & \\
\hline MÉDIO & SUPERIOR & & CONTEÚDO-MÉTODO & $\begin{array}{l}\text { FORMAÇÃO INICIAL DE PROFESSORES } \\
\end{array}$ & \\
\hline SUPERIOR & & & CONTEÚDO-MÉTODO & & \\
\hline SUPERIOR & & & CONTEÚDO-MÉTODO & & \\
\hline SUPERIOR & & & CURRÍCULOS E PROGRAMAS & & \\
\hline MÉDIO & & & CONTEÚDO-MÉTODO & & \\
\hline SUPERIOR & & & CONTEÚDO-MÉTODO & & \\
\hline SUPERIOR & & & RECURSO DIDÁTICO & & \\
\hline MÉDIO & SUPERIOR & & RECURSO DIDÁTICO & & \\
\hline SUPERIOR & & & RECURSO DIDÁTICO & & \\
\hline SUPERIOR & & & CONTEÚDO-MÉTODO & & \\
\hline SUPERIOR & & & RECURSO DIDÁTICO & & \\
\hline GERAL & & & RECURSO DIDÁTICO & & \\
\hline
\end{tabular}




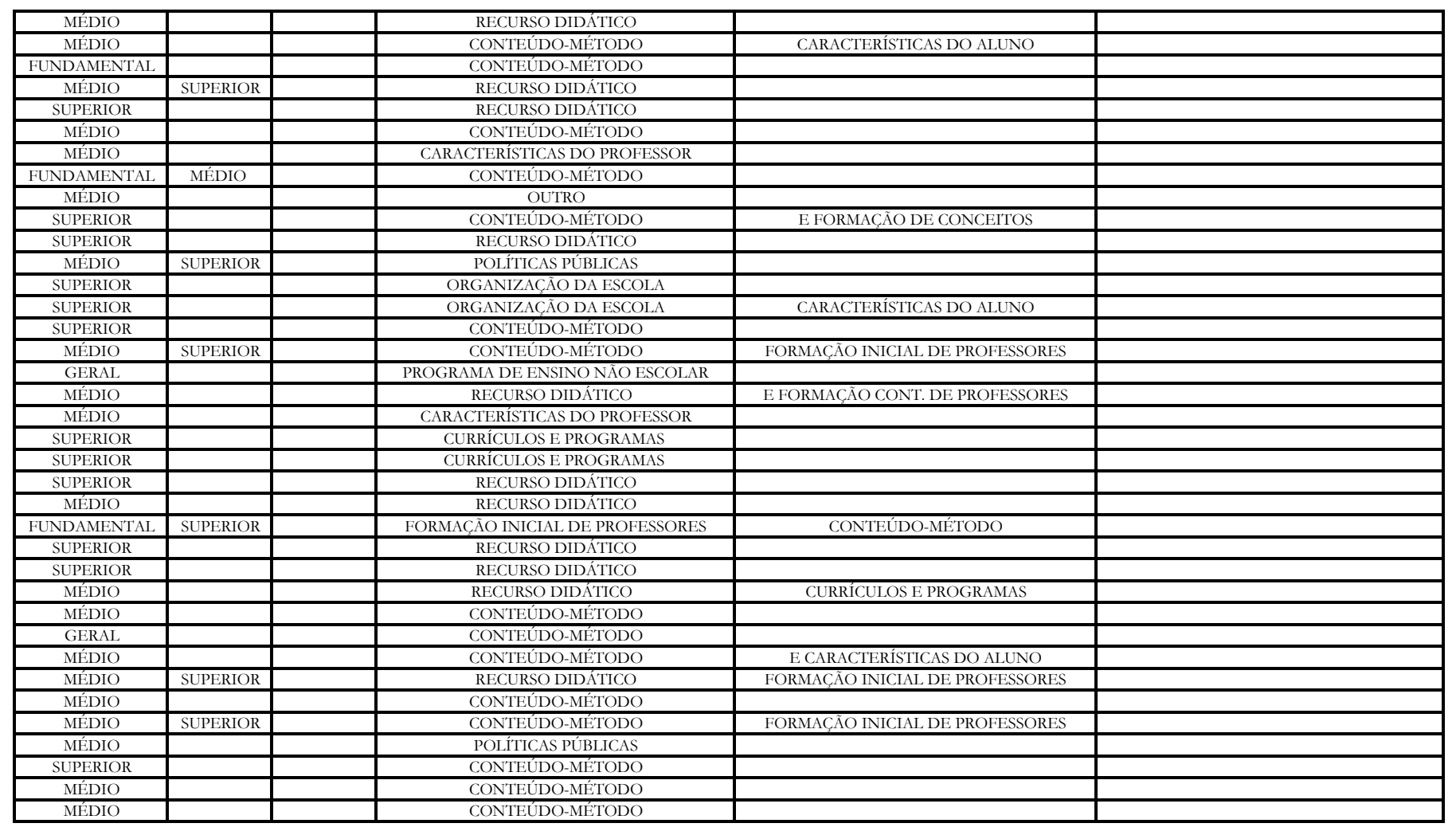


Planilha de classificação da $24^{a}$ RASBQ - 2001

\begin{tabular}{|c|c|c|c|c|c|c|c|c|}
\hline ANO & TRABALHO & INSTITUIÇÃO1 & INSTITUIÇÁAO 2 & INSTITUIÇÁAO 3 & INSTITUIÇÃO 4 & REGIÁO1 1 & REGIÁO 2 & INTERAÇÃO H X E \\
\hline 2001 & ED-001 & UNIMEP & UNIJUí & UFU & UNICAMP & SUDESTE & SUL & \\
\hline 2001 & ED-002 & UFRJ & & & & SUDESTE & & \\
\hline 2001 & ED-003 & UNICAMP & & & & SUDESTE & & \\
\hline 2001 & ED-004 & UFSC & & & & SUL & & \\
\hline 2001 & ED-005 & UNICAMP & & & & SUDESTE & & \\
\hline 2001 & ED-006 & FUNREI & & & & SUDESTE & & \\
\hline 2001 & ED-007 & C. E.DR. ALBERT SABIN & UERJ & & & SUDESTE & & \\
\hline 2001 & ED-008 & UERJ & & & & SUDESTE & & \\
\hline 2001 & ED-009 & UERJ & C. DE APLICAÇÃO & & & SUDESTE & & DQXFE \\
\hline 2001 & ED-010 & FURG & & & & SUL & & \\
\hline 2001 & ED-011 & UFPR & & & & NORTE & & \\
\hline 2001 & ED-012 & UNICAMP & & & & SUDESTE & & \\
\hline 2001 & ED-013 & UFRJ & & & & SUDESTE & & IQXFE \\
\hline 2001 & ED-014 & NÃO MENCIONA & & & & & & \\
\hline 2001 & ED-015 & USP & & & & $\begin{array}{l}\text { SUDESTE } \\
\end{array}$ & & IFXIQXFE \\
\hline 2001 & ED-016 & NÃO MENCIONA & & & & SUDESTE & & \\
\hline 2001 & ED-017 & UnB & & & & CENTRO-OESTE & & \\
\hline 2001 & ED-018 & UFG & & & & CENTRO-OESTE & & \\
\hline 2001 & ED-019 & UFRN & & & & NORDESTE & & PG EM EDUCAÇÃO \\
\hline 2001 & $\mathrm{ED}-020$ & UEL & & & & SUL & & \\
\hline 2001 & ED-021 & $\overline{\text { UFMG }}$ & & & & SUDESTE & & FAC.DE FARMÁCIA \\
\hline 2001 & ED-022 & USP & & & & SUDESTE & & $\mathrm{FE}$ \\
\hline 2001 & ED-023 & C. SANTA CRUZ -SP & & & & SUDESTE & & \\
\hline 2001 & ED-024 & CEFETQ-NILÓPOLIS & & & & SUDESTE & & \\
\hline 2001 & ED-025 & UFRJ & & & & SUDESTE & & \\
\hline 2001 & ED-026 & $\begin{array}{l}\text { S.E. DF } \\
\text { SF }\end{array}$ & $\overline{\mathrm{UCB}}$ & & & $\begin{array}{l}\text { CENTRO-OESTE } \\
\end{array}$ & & \\
\hline 2001 & ED-027 & $\frac{\text { UFV }}{\text { UFV }}$ & & & & SUDESTE & & \\
\hline 2001 & ED-028 & UFV & & & & SUDESTE & & \\
\hline 2001 & ED-029 & UFV & & & & SUDESTE & & \\
\hline 2001 & ED-030 & UFV & & & & SUDESTE & & \\
\hline 2001 & ED-031 & UFV & & & & SUDESTE & & \\
\hline 2001 & $\overline{E D-032}$ & UFV & & & & SUDESTE & & \\
\hline 2001 & ED-033 & UMC & & & & SUDESTE & & \\
\hline 2001 & ED-034 & UNICAMP & & & & SUDESTE & & \\
\hline 2001 & ED-035 & UFBA & & & & NORDESTE & & \\
\hline 2001 & ED-036 & UFBA & C. ACADĖMICO ALAGOINHAS & C.E.LUIZ V. SALVADOR & & NORDESTE & & \\
\hline 2001 & ED-037 & UFV & & & & $\begin{array}{l}\text { SUDESTE } \\
\end{array}$ & & \\
\hline 2001 & ED-038 & UERJ & C. DE APLICAÇÃO & & & SUDESTE & & \\
\hline 2001 & ED-039 & UEL & C.E.SOUZA NAVES & C. UNIVERSITÁRIO & UNOPAR & SUL & & \\
\hline 2001 & ED-040 & UFRJ & & & & SUDESTE & & \\
\hline 2001 & ED-041 & UNIV. DE PERNAMBUCO & FFPNM & & & NORDESTE & & \\
\hline 2001 & $\mathrm{ED}-042$ & UnB & & & & CENTRO-OESTE & & \\
\hline 2001 & ED-043 & UERJ & C. DE APLICAÇÃO & & & SUDESTE & & \\
\hline 2001 & ED-044 & USP & & & & SUDESTE & & IQXFE \\
\hline 2001 & ED-045 & USP & & & & SUDESTE & & \\
\hline 2001 & ED-046 & NÃO MENCIONA & & & & & & \\
\hline 2001 & ED-047 & UFRPE & & & & NORDESTE & & \\
\hline 2001 & ED-048 & UFRPE & & & & NORDESTE & & \\
\hline 2001 & ED-049 & UFRPE & & & & NORDESTE & & \\
\hline 2001 & $\mathrm{ED}-050$ & USP & & & & SUDESTE & & IFXIQXFE \\
\hline 2001 & ED-051 & UFMG & & & & SUDESTE & & DQXFE \\
\hline 2001 & $\overline{E D-052}$ & UFU & & & & SUDESTE & & \\
\hline 2001 & ED- -053 & UFPR & & & & SUL & & \\
\hline
\end{tabular}




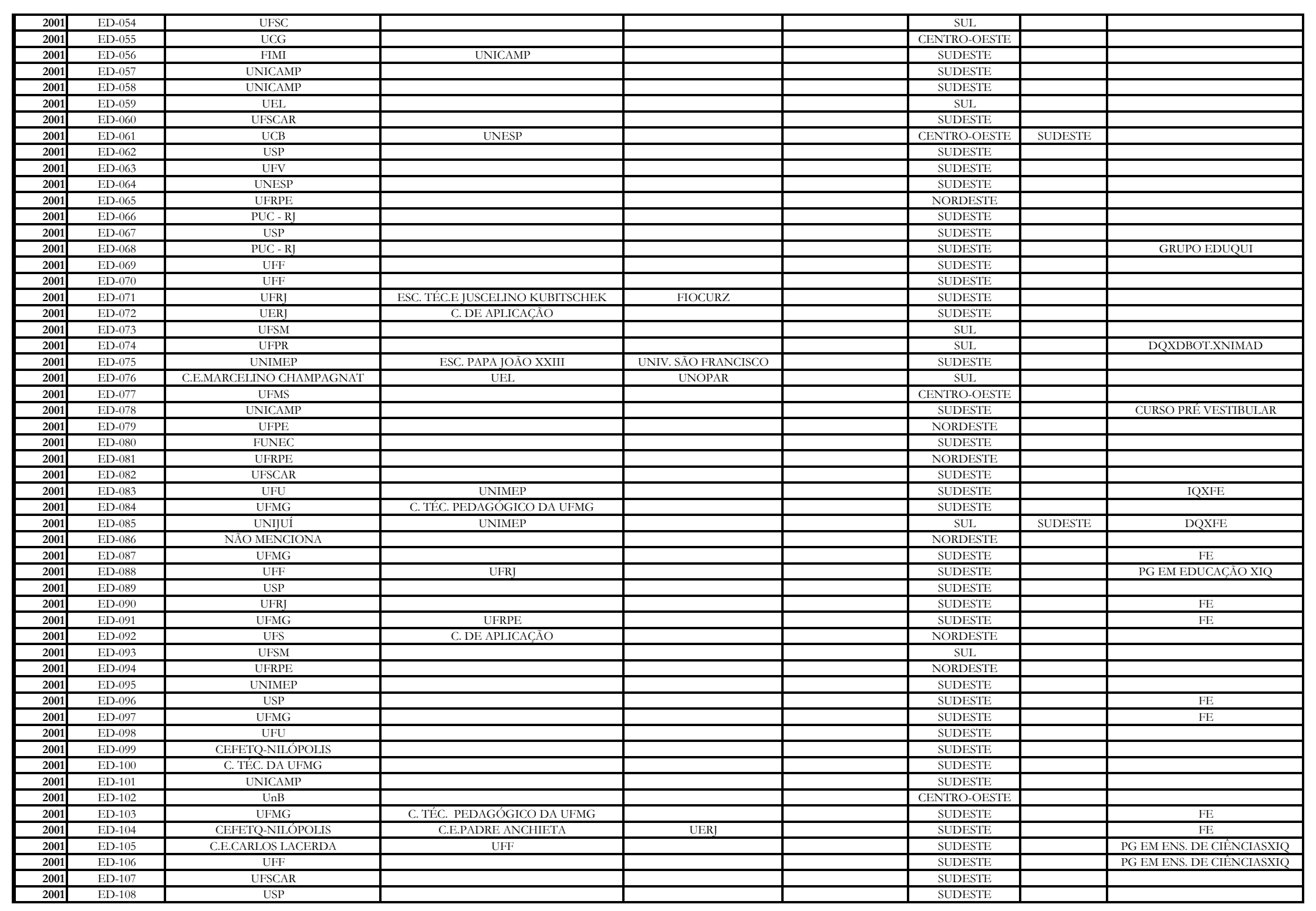


Planilha de classificação da $25^{a}$ RASBQ - 2002

\begin{tabular}{|c|c|c|c|c|c|c|c|c|}
\hline ANO & TRABALHO & INSTITUIÇÃ̄O 1 & INSTITUIÇÃO 2 & INSTITUIÇÃO 3 & INSTITUIÇÃO 4 & REGIÃO 1 & REGIÃO 2 & INTERAÇÃO H X E \\
\hline 2002 & ED-001 & $\mathrm{UnB}$ & & & & CENTRO-OESTE & & \\
\hline 2002 & ED-002 & UFRJ & & & & SUDESTE & & IQXFE \\
\hline 2002 & ED-003 & UNESP & & & & SUDESTE & & \\
\hline 2002 & $\begin{array}{c}E D-004 \\
\end{array}$ & NÃO MENCIONA & & & & SUDESTE & & \\
\hline 2002 & ED-005 & USP & & & & SUDESTE & & \\
\hline 2002 & ED-006 & USP & & & & SUDESTE & & IQXFE \\
\hline 2002 & ED-007 & $\begin{array}{l}\text { UNICAMP } \\
\end{array}$ & & & & SUDESTE & & \\
\hline 2002 & ED-008 & UFMS & & & & CENTRO-OESTE & & \\
\hline 2002 & ED-009 & UFRPE & & & & NORDESTE & & PG EDUC.EM CIĖNCIAS \\
\hline 2002 & ED-010 & UENF & & & & SUDESTE & & \\
\hline 2002 & ED-011 & FURG & & & & SUL & & \\
\hline 2002 & $\mathrm{ED}-012$ & FUNREI & & & & SUDESTE & & \\
\hline 2002 & ED-013 & $\begin{array}{l}\text { UFPR } \\
\end{array}$ & & & & SUL & & DQXDE \\
\hline 2002 & ED-014 & UFMG & & & & SUDESTE & & $\mathrm{FE}$ \\
\hline 2002 & ED-015 & FUNREI & UFMG & & & SUDESTE & & \\
\hline 2002 & ED-016 & UNICAMP & & & & SUDESTE & & \\
\hline 2002 & ED-017 & FAFI & $\begin{array}{l}\mathrm{UFC} \\
\end{array}$ & & & SUDESTE & NORDESTE & \\
\hline 2002 & ED-018 & FURG & & & & SUL & & \\
\hline 2002 & ED-019 & UFRN & & & & NORDESTE & & PG EM EDUCAÇÃO \\
\hline 2002 & ED-020 & FUNREI & & & & SUDESTE & & \\
\hline 2002 & $\mathrm{ED}-021$ & UFRPE & UFMG & & & NORDESTE & SUDESTE & \\
\hline 2002 & ED-022 & UEL & & & & SUL & & \\
\hline 2002 & ED-023 & USP & & & & SUDESTE & & \\
\hline 2002 & ED-024 & UFJF & & & & SUDESTE & & \\
\hline 2002 & ED-025 & UFG & & & & CENTRO-OESTE & & \\
\hline 2002 & ED-026 & USP & & & & SUDESTE & & \\
\hline 2002 & ED-027 & UNISC & & & & SUL & & \\
\hline 2002 & ED-028 & UFPE & & & & NORDESTE & & \\
\hline 2002 & ED-029 & UFSC & FURB & & & $\begin{array}{l}\text { SUL } \\
\end{array}$ & & \\
\hline 2002 & ED-030 & UFF & & & & SUDESTE & & \\
\hline 2002 & ED-031 & UERJ & C. DE APLICAÇÃO & & & SUDESTE & & \\
\hline 2002 & ED-032 & USP & & & & SUDESTE & & \\
\hline 2002 & ED-033 & UFSC & & & & $\begin{array}{l}\text { SUL } \\
\end{array}$ & & \\
\hline 2002 & ED-034 & USP & & & & SUDESTE & & \\
\hline 2002 & ED-035 & USP & & & & SUDESTE & & \\
\hline 2002 & ED-036 & UERJ & C. DE APLICAÇÃO & & & SUDESTE & & \\
\hline 2002 & ED-037 & UERJ & C. DE APLICAÇÃO & & & SUDESTE & & \\
\hline 2002 & ED-038 & UFMG & INST.PITÁGORAS DE ENSINO & REDE PITÁGORAS & & SUDESTE & & \\
\hline 2002 & ED-039 & UNESP & & & & SUDESTE & & \\
\hline 2002 & ED-040 & UFRPE & UFPE & & & NORDESTE & & \\
\hline 2002 & ED-041 & CEFETEQ-NILÓPOLIS & & & & SUDESTE & & \\
\hline 2002 & ED-042 & UFRPE & C. N. SRA. DO CARMO & & & NORDESTE & & \\
\hline 2002 & ED-043 & UFG & & & & CENTRO-OESTE & & \\
\hline 2002 & ED-044 & UnB & & & & CENTRO-OESTE & & \\
\hline 2002 & ED-045 & ESC.E SÍLVIO ROMERO & COL DE APLIC. UFS & & & NORDESTE & & \\
\hline 2002 & ED-046 & USP & UNICENTRO & & & SUDESTE & SUL & \\
\hline 2002 & ED-047 & UFPE & & & & NORDESTE & & \\
\hline 2002 & ED-048 & UnB & & & & CENTRO-OESTE & & $\mathrm{FE}$ \\
\hline 2002 & ED-049 & UnB & UFMG & & & CENTRO-OESTE & SUDESTE & IQXFE \\
\hline 2002 & ED-050 & UFU & C. PIRACICABANO & & & SUDESTE & & \\
\hline 2002 & ED-051 & UNICAMP & & & & SUDESTE & & \\
\hline 2002 & ED-052 & UFSCAR & USP & & & SUDESTE & & \\
\hline 2002 & ED-053 & UNICAMP & & & & SUDESTE & & \\
\hline
\end{tabular}




\begin{tabular}{|c|c|c|c|c|c|c|c|c|}
\hline 2002 & ED-054 & UFMA & USP & & & NORDESTE & SUDESTE & \\
\hline 2002 & ED-055 & UFRPE & & & & NORDESTE & & \\
\hline 2002 & ED-056 & UNICAMP & & & & SUDESTE & & \\
\hline 2002 & ED-057 & UFMG & & & & SUDESTE & & \\
\hline 2002 & ED-058 & UFMG & & & & SUDESTE & & \\
\hline$\frac{2002}{2002}$ & $\begin{array}{ll}E D-050 \\
E D-059\end{array}$ & UNISC & & & & $\frac{S O D E T L}{\text { SUL }}$ & & \\
\hline 2002 & ED-060 & UNICAMP & UFF & & & SUDESTE & & \\
\hline 2002 & ED-061 & UMC & & & & SUDESTE & & \\
\hline 2002 & ED-062 & UEPG & & & & $\overline{\text { SUL }}$ & & \\
\hline 2002 & ED-063 & UFRRJ & & & & SUDESTE & & \\
\hline 2002 & ED-064 & USP & & & & SUDESTE & & \\
\hline 2002 & ED-065 & UFMS & & & & CENTRO-OESTE & & \\
\hline 2002 & ED-065 & $\mathrm{UnB}$ & UNICAMP & DEP. POLÍCIA FEDERAL & & CENTRO-OESTE & SUDESTE & \\
\hline 2002 & ED-067 & USP & & & & SUDESTE & & \\
\hline 2002 & ED-068 & SENAC & & & & SUDESTE & & \\
\hline 2002 & ED-069 & UFMG & & & & SUDESTE & & \\
\hline 2002 & ED-070 & UEL & & & & SUL & & \\
\hline 2002 & ED-071 & UEL & & & & SUL & & \\
\hline 2002 & $\overline{\text { ED-072 }}$ & FAFIG & UFSCAR & & & SUDESTE & & \\
\hline 2002 & 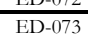 & UEL & C.E.CARLOS DE ALMEIDA & & & SUL & & \\
\hline 2002 & ED-074 & UENF & & & & SUDESTE & & \\
\hline 2002 & ED-075 & UFS & & & & NORDESTE & & \\
\hline 2002 & ED-076 & UFSCAR & & & & SUDESTE & & \\
\hline 2002 & ED-077 & UFMG & C. TEC. PEDAGÓGICO & & & SUDESTE & & \\
\hline 2002 & ED-078 & UFSC & FURB & & & SUL & & PG EM EDUCACC,ÃOXDQ \\
\hline 2002 & ED-079 & UFS & C. SANTOS DUMONT & & & NORDESTE & & \\
\hline 2002 & ED-080 & DCE - UNICAMP & & & & SUDESTE & & \\
\hline 2002 & ED-081 & UFRJ & & & & SUDESTE & & \\
\hline 2002 & ED-082 & UFPR & C.E.DES. CLOTÁRIO PORTUGAL & & & SUL & & \\
\hline 2002 & ED-083 & UFRPE & & & & NORDESTE & & DQXDEXDMEFIS.ANIMAL \\
\hline 2002 & ED-084 & $\mathrm{UCB}$ & & & & CENTRO-OESTE & & \\
\hline 2002 & ED-085 & USP & UERJ & & & SUDESTE & & \\
\hline 2002 & ED-086 & UNICAMP & & & & SUDESTE & & \\
\hline 2002 & $\begin{array}{ll}\text { ED- }-080 \\
\text { ED }\end{array}$ & CEFETEQ-NILÓPOLIS & UNIGRANRIO & & & SUDESTE & & \\
\hline 2002 & ED-088 & $\begin{array}{l}\text { UNICAMP } \\
\end{array}$ & & & & SUDESTE & & \\
\hline 2002 & ED-089 & CEFETEQ-NILÓPOLIS & UNICAMP & & & SUDESTE & & \\
\hline 2002 & ED-090 & UFBA & CENTRO EDUC. IMBUÍ & & & NORDESTE & & \\
\hline 2002 & ED-091 & UNICAMP & & & & SUDESTE & & \\
\hline 2002 & ED-092 & UNICAMP & & & & SUDESTE & & \\
\hline 2002 & ED-093 & FAENQUIL & & & & SUDESTE & & \\
\hline 2002 & ED-094 & UFRN & & & & NORDESTE & & \\
\hline 2002 & ED-095 & UFF & & & & SUDESTE & & PG EM ENS.DE CIĖNCIAS \\
\hline 2002 & ED-096 & UFPE & & & & NORDESTE & & DQFXCE \\
\hline 2002 & ED-097 & CEFETEQ-NILÓPOLIS & & & & SUDESTE & & \\
\hline 2002 & ED-098 & C.E.PADRE ANCHIETA & CEFETEQ-NILÓPOLIS & & & SUDESTE & & \\
\hline 2002 & ED-099 & UERJ & UBM & C. MIL.DO RIO DE JANEIRO & C.E.AGRIPINO GRIECO & SUDESTE & & \\
\hline 2002 & ED-100 & UEPG & & & & SUL & & \\
\hline 2002 & ED-101 & UNICAMP & & & & SUDESTE & & \\
\hline 2002 & ED-102 & EAFUB & UFU & & & SUDESTE & & \\
\hline 2002 & ED-103 & UESB & & & & NORDESTE & & \\
\hline 2002 & ED-104 & UFF & & & & SUDESTE & & \\
\hline 2002 & ED-105 & UFRPE & & & & NORDESTE & & \\
\hline 2002 & ED-106 & UFF & & & & SUDESTE & & \\
\hline
\end{tabular}




\begin{tabular}{|c|c|c|c|c|}
\hline NívEL ESCOLAR1 & NÍVEL ESCOLAR 2 & NÍVEL ESCOLAR 3 & FOCO TEMÁTICO PRINCIPAL & FOCO TEMÁTCO SECUNDÁRIO \\
\hline SUPERIOR & & & CURRÍCULOS E PROGRAMAS & FORMAÇĀAO INICIAL DE PROFESSORES \\
\hline SUPERIOR & & & FORMAÇÃO INICIAL DE PROFESSORES & CARACTERÍSTICAS DOS ALUNOS \\
\hline MÉDIO & & & $\begin{array}{l}\text { CARACTERISTIICAS DO PROFESSOR } \\
\end{array}$ & E FORMAÇÃO CONT. DE PROFESSORES \\
\hline FUNDAMENTAL & & & CURRÍCULOS E PROGRAMAS & FORMAÇÃO CONT. DE PROFESSORES \\
\hline SUPERIOR & & & ORGANIZAÇÃO DA ESCOLA & \\
\hline & & & & \\
\hline SUPERIOR & & & CURRÍCULOS E PROGRAMAS & \\
\hline FUNDAMENTAL & & & CONTEÚDO-MÉTODO & \\
\hline & & & & \\
\hline MÉDIO & & & CARACTERÍSTICAS DO PROFESSOR & \\
\hline MÉDIO & & & CARACTERÍSTICAS DO ALUNO & E ORGANIZAÇÃ̃O DA ESCOLA \\
\hline MÉDIO & & & CURRÍCULOS E PROGRAMAS & FORMACÃO CONT. DE PROFESSORES \\
\hline SUPERIOR & & & FORMAÇÃO INICIAL DE PROFESSORES & \\
\hline & & & & \\
\hline & & & & \\
\hline$\frac{\text { MEDIO }}{\text { MÉDIO }}$ & & & $\begin{array}{l}\text { RECUSSO DIDATICO } \\
\text { CURRICULOS E PROGRAMAS }\end{array}$ & \\
\hline MÉDIO & & & FORMACÃO DE CONCEITOS & \\
\hline & & & & \\
\hline SUPERIOR & & & RECURSO DIDÁTICO & \\
\hline & & & & \\
\hline & & & & \\
\hline SUPERIOR & & & CONTEÚDO-MÉTODO & \\
\hline SUPERIOR & & & CURRÍCULOS E PROGRMAS & \\
\hline SUPERIOR & & & RECURSO DIDÁTICO & \\
\hline SUPERIOR & & & RECURSO DIDÁTICO & E CONTEÚDO-MÉTODO \\
\hline & & & BECLUSO DIDŚTTCO & \\
\hline SUPERIOR & & & & \\
\hline MÉDIO & & & CONTEÚDO-MÉTODO & \\
\hline MÉDIO & & & CONTEÚDO-MÉTODO & E RECURSO DIDÁTICO \\
\hline MEEDIO & & & RECURSO DIDÁTICO & \\
\hline MÉDIO & & & CONTEÚDO-MÉTODO & \\
\hline MÉDIO & & & CONTEÚDO-MÉTODO & \\
\hline MÉDIO & & & CONTEÚDO-MÉTODO & \\
\hline MÉDIO & & & CONTEÚDO-MÉTODO & \\
\hline MÉDIO & & & CURRÍCULOS E PROGRAMAS & \\
\hline & & & & \\
\hline $\begin{array}{c}\text { MÉDIO } \\
\end{array}$ & & & $\begin{array}{l}\text { CURRÍCULOS E PROGRAMAS } \\
\end{array}$ & \\
\hline TIVP & & & 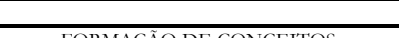 & \\
\hline$\frac{\text { FUNDAMENTAL }}{\text { SUPERIOR }}$ & & & $\begin{array}{l}\text { FORMACAOO DE CONCEITOS } \\
\text { CONTEÚDO-MÉTODO }\end{array}$ & \\
\hline SUPERIOR & & & FORMACČAO DE CONCEITOS & \\
\hline GERAL & & & FORMAÇÃO INICIAL DE PROFESSORES & \\
\hline MÉDIO & & & OUTRO & \\
\hline MÉDIO & & & RECURSO DIDÁTICO & \\
\hline & & & & \\
\hline MÉDIO & SUPERIOR & & RECURSO DIDÁTICO & \\
\hline MÉDIO & SUPERIOR & & RECURSO DIDÁTICO & \\
\hline
\end{tabular}




\begin{tabular}{|c|c|c|c|}
\hline $\begin{array}{l}\text { SUPERIOR } \\
\end{array}$ & & RECURSO DIDÁTICO & \\
\hline GERAL & & & \\
\hline $\begin{array}{c}\text { GERAL } \\
\text { SUPERIOR }\end{array}$ & & RECURSO DIDÁTICO & \\
\hline SUPERIOR & & RECURSO DIDÁTICO & \\
\hline SUPERIOR & & RECURSO DIDÁTICO & \\
\hline $\begin{array}{l}\text { SUPERIOR } \\
\end{array}$ & & CONTEÚDO-MÉTODO & \\
\hline & & & \\
\hline $\begin{array}{l}\text { SUPERIOR } \\
\end{array}$ & & RECURSO DIDÁTICO & \\
\hline MÉDIO & $\begin{array}{l}\text { SUPERIOR } \\
\end{array}$ & CONTEÚDO-MÉTODO & \\
\hline MÉDIO & SUPERIOR & HISTÓRIA DAS CIĖNCIAS & \\
\hline SUPERIOR & & RECURSO DIDÁTICO & \\
\hline SUPERIOR & & CONTEÚDO-MÉTODO & \\
\hline GERAL & & FORMAÇÃO DE CONCEITOS & \\
\hline MÉDIO & & RECURSO DIDÁTICO & \\
\hline MÉDIO & & RECURSO DIDÁTICO & \\
\hline GERAL & & OUTRO & \\
\hline MÉDIO & & CONTEÚDO-MÉTODO & \\
\hline & & & \\
\hline MÉDIO & & $\begin{array}{l}\text { CURRÍCULOS E PROGRAMAS } \\
\end{array}$ & \\
\hline MÉDIO & & RECURSO DIDÁTICO & \\
\hline $\begin{array}{l}\text { MÉDIO } \\
\end{array}$ & & CONTEÚDO-MÉTODO & FORMAÇÃO DE CONCEITOS \\
\hline & & & \\
\hline MÉDIO & SUPERIOR & CONTEÚDO-MÉTODO & \\
\hline SUPERIOR & & CONTEÚDO-MÉTODO & \\
\hline MÉDIO & SUPERIOR & CONTEÚDO-MÉTODO & E FORMAÇÃO INICIAL DE PROFESSORES \\
\hline $\begin{array}{l}\text { MÉDIO } \\
\end{array}$ & & POLÍTICAS PÚBLICAS & \\
\hline MÉDIO & & OUTRO & \\
\hline MÉDIO & & CARACTERÍSTICAS DO ALUNO & \\
\hline & & & \\
\hline SUPERIOR & & RECURSO DIDÁTICO & \\
\hline GERAL & & CONTEÚDO-MÉTODO & \\
\hline MÉDIO & & RECURSO DIDÁTICO & \\
\hline SUPERIOR & & CONTEÚDO-MÉTODO & \\
\hline MEDIO & & CONTEÚDO-MÉTODO & \\
\hline MÉDIO & $\begin{array}{l}\text { SUPERIOR } \\
\end{array}$ & CONTEÚDO-MÉTODO & \\
\hline MÉDIO & & RECURSO DIDÁTICO & \\
\hline & & & \\
\hline SUPERIOR & & RECURSO DIDÁTICO & \\
\hline MÉDIO & & RECURSO DIDÁTICO & \\
\hline MÉDIO & & FORMAÇÃO CONT. DE PROFESSORES & \\
\hline & & & \\
\hline MÉDIO & & CONTEÚDO-MÉTODO & \\
\hline MÉDIO & & ORGANIZAÇÃO DA ESCOLA & \\
\hline $\begin{array}{l}\text { GERAL } \\
\end{array}$ & & FORMAÇÃO DE CONCEITOS & CONTEÚDO-MÉTODO \\
\hline GERAL & & CONTEÚDO-MÉTODO & \\
\hline MÉDIO & & RECURSO DIDÁTICO & \\
\hline MÉDIO & & CONTEÚDO-MÉTODO & FORMAÇÃO DE CONCEITOS \\
\hline MÉDIO & & CONTEÚDO-MÉTODO & \\
\hline $\begin{array}{ll}\text { GERAL } \\
\end{array}$ & & CONTEÚDO-MÉTODO & RECURSO DIDÁTICO \\
\hline & & 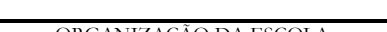 & \\
\hline SUPERIOR & & ORGANIZAÇÃO DA ESCOLA & \\
\hline
\end{tabular}


Planilha de classificação da $26^{a}$ RASBQ - 2003

\begin{tabular}{|c|c|c|c|c|c|c|c|}
\hline ANO & TRABALHO & INSTITUIÇÃÓ 1 & INSTITUIÇÃ̄O 2 & INSTITUIÇÃO 3 & INSTITUIÇÃO 4 & REGIÃO1 & REGIÃO 2 \\
\hline 2003 & ED-001 & UNESP & & & & SUDESTE & \\
\hline 2003 & ED-002 & UFMS & & & & CENTRO-OESTE & \\
\hline 2003 & ED-003 & UFF & UFRJ & & & SUDESTE & \\
\hline 2003 & ED-004 & UNICAMP & CEFETQ-NILÓPOLIS & UFRJ & & SUDESTE & \\
\hline 2003 & ED-005 & UERJ & & & & SUDESTE & \\
\hline 2003 & ED-006 & FURG & & & & SUL & \\
\hline 2003 & ED-007 & NÅO MENCIONA & & & & SUL & \\
\hline 2003 & ED-008 & UFMG & & & & SUDESTE & \\
\hline 2003 & ED-0099 & UFRGS & & & & SUL & \\
\hline 2003 & ED-010 & UFRGS & & & & SUL & \\
\hline 2003 & ED-011 & UFRGS & & & & SUL & \\
\hline 2003 & ED-012 & UFPR & & & & SUL & \\
\hline 2003 & ED-013 & UnB & & & & CENTRO-OESTE & \\
\hline 2003 & ED-014 & UFSJ & UFMG & & & SUDESTE & \\
\hline 2003 & ED-015 & UNICAMP & & & & $\begin{array}{l}\text { SUDESTE } \\
\end{array}$ & \\
\hline 2003 & ED-016 & UNICAMP & & & & SUDESTE & \\
\hline 2003 & ED-017 & $\begin{array}{ll}\text { USP } \\
\end{array}$ & & & & SUDESTE & \\
\hline 2003 & ED-018 & UNICAMP & & & & SUDESTE & \\
\hline 2003 & ED-019 & USP & & & & SUDESTE & \\
\hline 2003 & ED-020 & UNESP & & & & SUDESTE & \\
\hline 2003 & ED-021 & UNESP & & & & SUDESTE & \\
\hline 2003 & ED-022 & UERJ & & & & SUDESTE & \\
\hline 2003 & ED-023 & UERJ & & & & SUDESTE & \\
\hline 2003 & ED-024 & $\mathrm{UnB}$ & $\begin{array}{l}\text { PÄDAGOGISCHE HOCHSCHULE LUDWIGSBURG } \\
\end{array}$ & & & CENTRO-OESTE & EXTERIOR-AL \\
\hline 2003 & ED-025 & $\overline{\text { UENF }}$ & FAC. POLITÉCNICA DE JUNDIAÍ & & & SUDESTE & \\
\hline 2003 & ED-026 & UFF & & & & SUDESTE & \\
\hline 2003 & ED-027 & UNICAMP & & & & SUDESTE & \\
\hline 2003 & ED-028 & USP & & & & SUDESTE & \\
\hline 2003 & ED-029 & UFMG & & & & SUDESTE & \\
\hline 2003 & ED-030 & UFRJ & & & & SUDESTE & \\
\hline 2003 & ED-031 & $\overline{\text { UFBA }}$ & C.E.LUIZ VIANA & C. EDUC.IMBUÍ & & NORDESTE & \\
\hline 2003 & ED-032 & INST. DE EDUCAÇÃO TERRA & & & & SUDESTE & \\
\hline 2003 & ED-033 & UFPE & & & & NORDESTE & \\
\hline 2003 & ED-034 & C. TEC. DA UFMG & & & & SUDESTE & \\
\hline 2003 & ED-035 & UNESP & & & & SUDESTE & \\
\hline 2003 & ED-036 & UFRRJ & & & & SUDESTE & \\
\hline 2003 & ED-037 & $\mathrm{UnB}$ & & & & CENTRO-OESTE & \\
\hline 2003 & ED-038 & PUC-RS & & & & SUL & \\
\hline 2003 & ED-039 & UEL & C.E.MARQUĖS DE CARAVELAS & & & SUL & \\
\hline 2003 & ED-040 & USP & & & & SUDESTE & \\
\hline 2003 & ED-041 & C. COSTA ZAVAGLIA & FAC. DE MEDICINA DO ABC & & & SUDESTE & \\
\hline 2003 & ED-042 & UFS & C. DE APLICAÇÃO & & & NORDESTE & \\
\hline 2003 & ED-043 & UNICAMP & & & & SUDESTE & \\
\hline 2003 & ED-044 & UNIFOR & & & & NORDESTE & \\
\hline 2003 & ED-045 & UNICAMP & & & & SUDESTE & \\
\hline 2003 & ED-046 & UFPR & & & & SUL & \\
\hline 2003 & ED-047 & UENF & & & & SUDESTE & \\
\hline 2003 & ED-048 & $\mathrm{UnB}$ & & & & CENTRO-OESTE & \\
\hline 2003 & ED-049 & UFSC & & & & SUL & \\
\hline 2003 & ED-050 & UFPE & & & & NORDESTE & \\
\hline 2003 & ED-051 & UFRGS & & & & SUL & \\
\hline 2003 & ED-052 & UESB & & & & NORDESTE & \\
\hline 2003 & ED-053 & UFRN & & & & NORDESTE & \\
\hline
\end{tabular}




\begin{tabular}{|c|c|c|c|c|c|c|c|}
\hline 2003 & ED-054 & UFS & C. DE APLICAÇÃO & & & NORDESTE & \\
\hline 2003 & ED-055 & CREUPI & & & & SUDESTE & \\
\hline 2003 & ED-056 & UFRPE & & & & NORDESTE & \\
\hline 2003 & ED-057 & UNEB & & & & NORDESTE & \\
\hline 2003 & ED-058 & UFBA & & & & NORDESTE & \\
\hline 2003 & ED-059 & UFPR & & & & SUL & \\
\hline 2003 & $\mathrm{ED}-060$ & USP & & & & SUDESTE & \\
\hline 2003 & ED-061 & UFRGS & & & & SUL & \\
\hline 2003 & ED-062 & USP & & & & SUDESTE & \\
\hline 2003 & ED-063 & USP & & & & SUDESTE & \\
\hline 2003 & ED-064 & USP & & & & SUDESTE & \\
\hline 2003 & ED-065 & USP & & & & SUDESTE & \\
\hline 2003 & ED-066 & NÃO MENCIONA & & & & SUL & \\
\hline 2003 & ED-067 & UFC & & & & NORDESTE & \\
\hline 2003 & ED-068 & $\begin{array}{l}\text { UNIFOR } \\
\end{array}$ & & & & $\begin{array}{l}\text { NORDESTE } \\
\end{array}$ & \\
\hline 2003 & ED-069 & UFF & & & & SUDESTE & \\
\hline 2003 & ED-070 & $\begin{array}{l}\text { UNISC } \\
\end{array}$ & & & & SUL & \\
\hline 2003 & ED-071 & USP & & & & SUDESTE & \\
\hline 2003 & ED-072 & UNIVATES & & & & SUL & \\
\hline 2003 & ED-073 & UFMS & & & & $\begin{array}{l}\text { CENTRO-OESTE } \\
\end{array}$ & \\
\hline 2003 & ED-074 & CEFETQ-NILÓPOLIS & UNICAMP & UFRJ & & SUDESTE & \\
\hline 2003 & ED-075 & UFF & & & & $\begin{array}{l}\text { SUDESTE } \\
\end{array}$ & \\
\hline 2003 & ED-076 & UFF & & & & SUDESTE & \\
\hline 2003 & ED-077 & UFF & & & & SUDESTE & \\
\hline 2003 & ED-078 & UNILAVRAS & & & & SUDESTE & \\
\hline 2003 & ED-079 & UERJ & & & & SUDESTE & \\
\hline 2003 & ED-080 & USP & UESB & & & SUDESTE & NORDESTE \\
\hline 2003 & ED-081 & UNICAMP & & & & SUDESTE & \\
\hline 2003 & ED-082 & USP & & & & SUDESTE & \\
\hline 2003 & ED-083 & UNICAMP & & & & SUDESTE & \\
\hline 2003 & ED-084 & UNICAMP & & & & SUDESTE & \\
\hline 2003 & ED-085 & UFRN & & & & NORDESTE & \\
\hline 2003 & ED-086 & FAM & & & & SUDESTE & \\
\hline 2003 & ED-087 & UFBA & & & & NORDESTE & \\
\hline 2003 & ED-088 & UNICAMP & & & & SUDESTE & \\
\hline 2003 & ED-089 & $\begin{array}{l}\text { UNICAMP } \\
\end{array}$ & & & & $\begin{array}{l}\text { SUDESTE } \\
\end{array}$ & \\
\hline 2003 & ED-090 & UFSC & & & & SUL & \\
\hline 2003 & ED-091 & UNICEP & USP & & & SUDESTE & \\
\hline 2003 & ED-092 & UBM & UFMG & USS & C. ACAE & SUDESTE & \\
\hline 2003 & ED-093 & UFMS & & & & CENTRO-OESTE & \\
\hline 2003 & ED-094 & UFMS & & & & CENTRO-OESTE & \\
\hline 2003 & ED-095 & IBTA & FMABC & & & SUDESTE & \\
\hline 2003 & ED-096 & IBTA & FMABC & & & SUDESTE & \\
\hline 2003 & ED-097 & UEL & CEAD & & & SUL & \\
\hline 2003 & ED-098 & UEL & C.E.11 DE OUTUBRO & & & SUL & \\
\hline 2003 & ED-099 & UFS & SEC.E DE EDUCAÇÃO & & & NORDESTE & \\
\hline 2003 & ED-100 & UFS & SEC.E. DE EDUCAÇÃO & & & NORDESTE & \\
\hline 2003 & ED-101 & UNISC & & & & SUL & \\
\hline 2003 & ED-102 & UFMG & C. TÉC. PEDAGÓGICO DA UFMG & & & SUDESTE & \\
\hline 2003 & ED-103 & UFPR & & & & SUL & \\
\hline 2003 & ED-104 & UFS & SEC.E DE EDUCAÇÃO & & & NORDESTE & \\
\hline 2003 & ED-105 & UFRJ & & & & SUDESTE & \\
\hline 2003 & ED-106 & UEPG & C.E.POLIVALENTE & C.EST. MENELEU DE ALM.TORRES & & SUL & \\
\hline 2003 & ED-107 & DIR.DE ENS. DE MAUÁ & & & & SUDESTE & \\
\hline 2003 & ED-108 & USP & & & & SUDESTE & \\
\hline 2003 & ED-109 & UFPE & & & & NORDESTE & \\
\hline 2003 & ED-110 & NÃO MENCIONA & & & & SUDESTE & \\
\hline
\end{tabular}




\begin{tabular}{|c|c|c|c|c|c|c|}
\hline 2003 & ED-111 & UnB & UFMG & & $\begin{array}{l}\text { CENTRO-OESTE } \\
\end{array}$ & SUDESTE \\
\hline 2003 & ED-112 & UnB & & & CENTRO-OESTE & \\
\hline 2003 & ED-113 & UNIJUÍ & UNIMEP & & SUL & $\begin{array}{l}\text { SUDESTE } \\
\end{array}$ \\
\hline 2003 & ED-114 & USP & & & SUDESTE & \\
\hline 2003 & ED-115 & UNICAMP & ESC. TÉCNICA DE PAULÍNIA & & SUDESTE & \\
\hline 2003 & ED-116 & FASF & ESC.E COMENDADOR ZICO TOBIAS & & SUDESTE & \\
\hline 2003 & ED-117 & UFRRJ & & & SUDESTE & \\
\hline 2003 & ED-118 & UEM & & & SUL & \\
\hline 2003 & ED-119 & UFSCAR & & & SUDESTE & \\
\hline 2003 & ED-120 & UFBA & & & NORDESTE & \\
\hline 2003 & ED-121 & USP & C. INTEGRADO OBJETIVO & & SUDESTE & \\
\hline 2003 & ED-122 & UFF & & & SUDESTE & \\
\hline 2003 & ED-123 & UFSCAR & & & SUDESTE & \\
\hline 2003 & ED-124 & USP & & & SUDESTE & \\
\hline 2003 & ED-125 & USP & ESC. DE APLICAÇূ̃̃O & & SUDESTE & \\
\hline 2003 & ED-126 & UFSCAR & & & SUDESTE & \\
\hline 2003 & ED-127 & NÃO MENCIONA & & & $\begin{array}{l}\text { CENTRO-OESTE } \\
\end{array}$ & \\
\hline 2003 & ED-128 & UFG & & & CENTRO-OESTE & \\
\hline 2003 & ED-129 & UFG & UFSCAR & USP & CENTRO-OESTE & SUDESTE \\
\hline 2003 & ED-130 & UFMG & & & SUDESTE & \\
\hline 2003 & ED-131 & FURB & ESC. ADOLPHO KONDER & INDÚSTRIA CREMER & SUL & \\
\hline 2003 & ED-132 & UNIFRAN & & & SUDESTE & \\
\hline 2003 & ED-133 & $\mathrm{UCB}$ & & & CENTRO-OESTE & \\
\hline 2003 & ED-134 & UNESP & ESC.E URUBUPUNGÁ & & $\begin{array}{l}\text { SUDESTE } \\
\end{array}$ & \\
\hline 2003 & ED-135 & UERJ & & & $\begin{array}{l}\text { SUDESTE } \\
\end{array}$ & \\
\hline
\end{tabular}




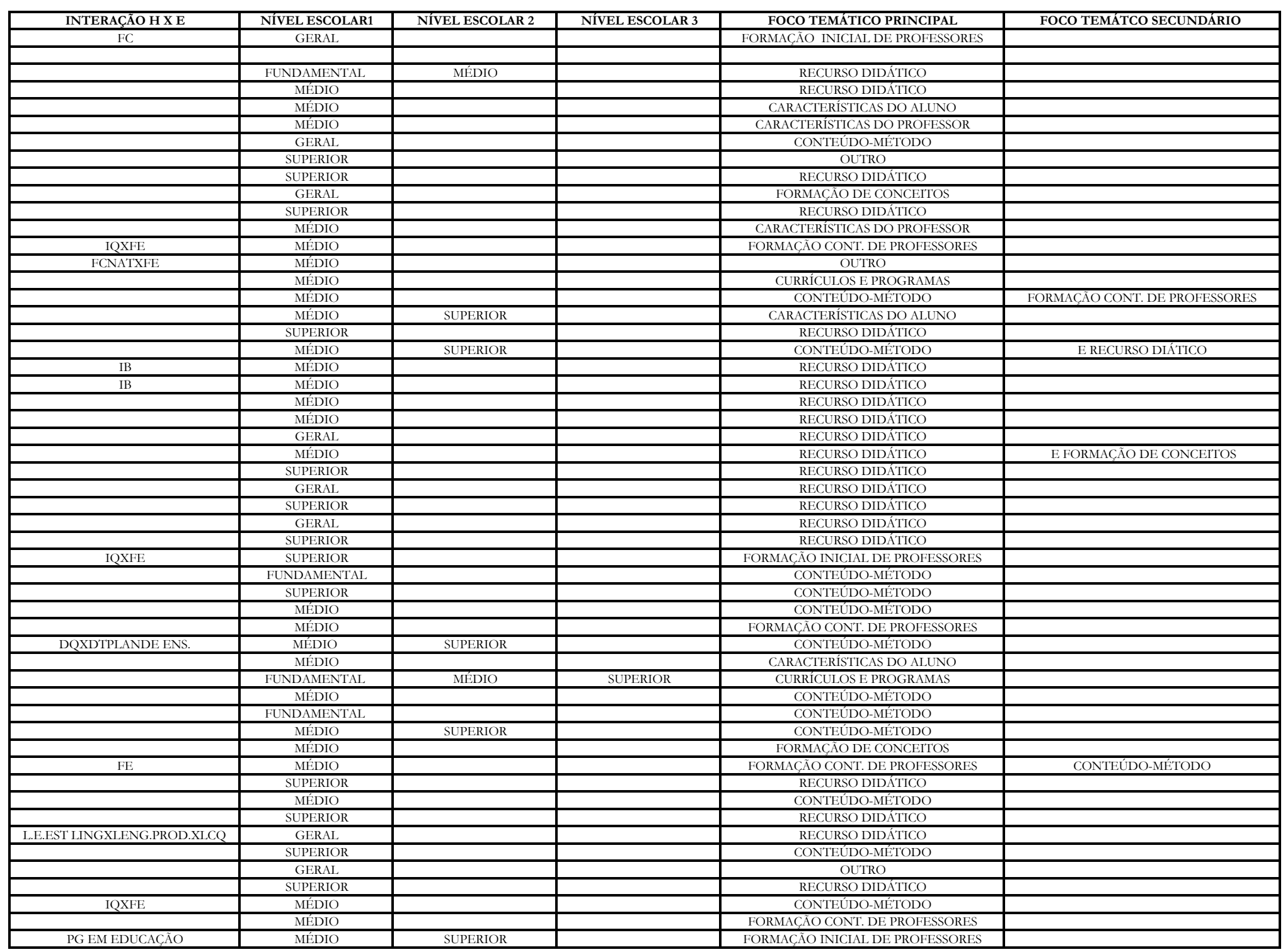




\begin{tabular}{|c|c|c|c|c|c|}
\hline & MÉDIO & & & FORMAÇÃO DE CONCEITOS & \\
\hline & $\begin{array}{l}\text { SUPERIOR } \\
\end{array}$ & & & CONTEÚDO-MÉTODO & \\
\hline \multirow[t]{3}{*}{ DQXDBXDFM } & SUPERIOR & & & FORMAÇÃO DE CONCEITOS & \\
\hline & SUPERIOR & & & ORGANIZAÇÃO DA ESCOLA & \\
\hline & SUPERIOR & & & RECURSO DIDÁTICO & \\
\hline \multirow[t]{2}{*}{ DQXDE } & MÉDIO & & & CARACTERÍSTICAS DO PROFESSOR & \\
\hline & $\begin{array}{l}\text { MÉDIO } \\
\end{array}$ & & & CARACTERÍSTICAS DO ALUNO & \\
\hline \multirow{5}{*}{ DQXDE } & MÉDIO & & & $\begin{array}{c}\text { CARACTERISTICAS DO ALUNO } \\
\text { CONTEÚDO-MÉTODO }\end{array}$ & \\
\hline & MÉDIO & & & CONTEÚDO-MÉTODO & \\
\hline & MÉDIO & & & CONTEÚDO-MÉTODO & \\
\hline & MÉDIO & & & FORMAÇÃO CONT. DE PROFESSORES & \\
\hline & & & & ORGANZACX̃ODA ESCOLA & \\
\hline \multirow{8}{*}{ DCFARMACEÚTICAS } & $\begin{array}{l}\text { SUPERIOR } \\
\text { SUPERIOR }\end{array}$ & & & $\begin{array}{c}\text { ORGANIZAÇAOO DA ESCOLA } \\
\text { ORGANIZAC } \tilde{A} O \text { DA ESCOLA }\end{array}$ & \\
\hline & GERAL & & & RECURSO DIDÁTICO & \\
\hline & SUPERIOR & & & CURRÍCULOS E PROGRAMAS & \\
\hline & SUPERIOR & & & RECURSO DIDÁTICO & \\
\hline & SUPERIOR & & & ORGANIZAÇÃO DA ESCOLA & \\
\hline & & & & & \\
\hline & MÉDIO & & & CONTEÚDO-MÉTODO & \\
\hline & GERAL & & & $\begin{array}{l}\text { PROGRAMA DE ENSINO NÃO ESCOLAR } \\
\end{array}$ & \\
\hline \multirow[t]{5}{*}{ PG EM ENS.DE CIÊNCIAS } & MÉDIO & & & CONTEÚDO-MÉTODO & \\
\hline & SUPERIOR & & & $\begin{array}{l}\text { RECURSO DIDÁTICO } \\
\end{array}$ & \\
\hline & & & & & \\
\hline & SUPERIOR & & & RECURSO DIDÁTICO & \\
\hline & SUPERIOR & & & HISTÓRIA DAS CIÊNCIAS & \\
\hline \multirow[t]{4}{*}{ IQXIB } & SUPERIOR & & & RECURSO DIDÁTICO & \\
\hline & MÉDIO & & & CONTEÚDO-MÉTODO & \\
\hline & GERAL & & & RECURSO DIDÁTICO & \\
\hline & MÉDIO & & & OUTRO & \\
\hline $\begin{array}{l}\text { GEXGQA } \\
\end{array}$ & SUPERIOR & & & CONTEÚDO-MÉTODO & \\
\hline \multirow[t]{8}{*}{ BIOMEDICINA } & SUPERIOR & & & RECURSO DIDÁTICO & \\
\hline & MÉDIO & SUPERIOR & & RECURSO DIDÁTICO & \\
\hline & SUPERIOR & & & CONTEÚDO-MÉTODO & \\
\hline & MÉDIO & $\begin{array}{l}\text { SUPERIOR } \\
\end{array}$ & & CONTEÚDO-MÉTODO & \\
\hline & MÉDIO & & & CONTEÚDO-MÉTODO & \\
\hline & MÉDIO & & & CONTEÚDO-MÉTODO & \\
\hline & MÉDIO & & & CONTEÚDO-MÉTODO & \\
\hline & MÉDIO & & & FORMAÇÃO DE CONCEITOS & \\
\hline \multirow{3}{*}{$\frac{\text { DQXDZOOTECNIA }}{\frac{\text { QXMEDICINA }}{}}$} & SUPERIOR & & & CONTEÚDO-MÉTODO & \\
\hline & GERAL & & & RECURSO DIDÁTICO & \\
\hline & GERAL & & & RECURSO DIDÁTICO & \\
\hline \multirow[t]{5}{*}{ DQXCTO.EDUC. } & MÉDIO & & & CONTEÚDO-MÉTODO & \\
\hline & MÉDIO & & & FORMAÇÃO DE CONCEITOS & \\
\hline & FUNDAMENTAL & & & FORMAÇÃO DE CONCEITOS & \\
\hline & MÉDIO & & & CONTEÚDO-MÉTODO & \\
\hline & SUPERIOR & & & $\begin{array}{l}\text { CURRÍCULOS E PROGRAMAS } \\
\end{array}$ & \\
\hline \multirow[t]{7}{*}{ IQXFE } & MÉDIO & & & CARACTERÍSTICAS DO ALUNO & E RECURSO DIDÁTICO \\
\hline & MÉDIO & & & CARACTERÍSTICAS DO ALUNO & \\
\hline & MÉDIO & & & FORMAÇÃO CONT. DE PROFESSORES & \\
\hline & SUPERIOR & & & FORMAÇÃO INICIAL DE PROFESSORES & E RECURSO DIDÁTICO \\
\hline & MÉDIO & & & CONTEÚDO-MÉTODO & \\
\hline & MÉDIO & & & FORMAÇÃO CONT. DE PROFESSORES & \\
\hline & FUNDAMENTAL & & & FORMAÇÃO DE CONCEITOS & \\
\hline \multirow{2}{*}{ DQXDPSI } & FUNDAMENTAL & MÉDIO & SUPERIOR & CARACTERÍSTICAS DO ALUNO & E CARACTERÍSTICAS DO PROFESSOR \\
\hline & MÉDIO & & & CARACTERÍSTICAS DO PROFESSOR & \\
\hline
\end{tabular}




\begin{tabular}{|c|c|c|c|c|}
\hline IQXFE & $\begin{array}{ll}\frac{\text { MÉDIO }}{\text { MÉIO }} \\
\end{array}$ & & $\begin{array}{c}\text { FORMAC,ÁO INIIIAL DE PROEFSSORES } \\
\text { FORMCIX̃O DE CONCETOS }\end{array}$ & OUTRO \\
\hline & MÉDIO & SUPERIOR & FORMAÇÃO INICIAL DE PROFESSORES & \\
\hline & VÉDIO & & CONTE'IONONII & \\
\hline & MÉDIO & & CONTEÜDO-MËTODO & POLITITCAS PÚBLLICAS \\
\hline & $\begin{array}{l}\text { MÉDIO } \\
\end{array}$ & $\begin{array}{l}\text { SUPERIOR } \\
\end{array}$ & CONTEÚDO-MÉTODO & \\
\hline & MÉDIO & SUPERIOR & CONTEÚDO-MÉTODO & \\
\hline & GERAL & & RECURSO DIDÁTICO & \\
\hline & SUPERIOR & & $\begin{array}{l}\text { RECURSO DIDÁTTCO } \\
\text { COOTEĹDO-MTEDO }\end{array}$ & FORMACÃO DE CONCEITOS \\
\hline & $\frac{\text { SUPERIOR }}{\text { SUPE }}$ & & CONTEÚDO-MÉTODO & \\
\hline & MÉDIO & SUPERIOR & CONTEÚDO-MÉTODO & \\
\hline & SUPERIOR & & 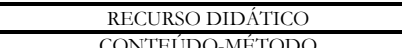 & \\
\hline & $\frac{\text { MENER }}{\text { SUPERIOR }}$ & & $\frac{\text { CONEUDO-METODO }}{\text { RECURSO DIDÁTICO }}$ & CURRICLLOS EPROGRAMAS \\
\hline & MÉDIO & & ORGANIZACČ̃O DA ESCOLA & \\
\hline & & & & \\
\hline & MÉDIO & & RECURSO DIDÁTICO & \\
\hline & SUPERIOR & & CONTEÚDO-MÉTODO & \\
\hline & $\frac{\text { MLDER }}{\text { SUPERIOR }}$ & & $\frac{\text { CONTEÚDO-METODO }}{\text { RECURSO DIDATIICO }}$ & \\
\hline$\overline{D F Q X F E}$ & MÉDIO & & FORMAC & \\
\hline & MEDIO & $\begin{array}{l}\text { SUPERIOR } \\
\end{array}$ & CONTEÚDO-MI & \\
\hline
\end{tabular}


Planilha de classificação da $27^{\mathrm{a}}$ RASBQ - 2004

\begin{tabular}{|c|c|c|c|c|c|c|c|}
\hline ANO & TRABALHO & INSTITUIÇÃO 1 & INSTITUIÇÃO 2 & INSTITUIÇÃO 3 & INSTITUIÇÃO 4 & INSTITUIÇÃO 5 & REGIÃO 1 \\
\hline 2004 & ED-001 & & & & & & \\
\hline 2004 & ED-002 & UNIV. DA AÇ̊̃O EDUCIONAL & & & & & SUDESTE \\
\hline 2004 & ED-003 & & & & & & \\
\hline 2004 & ED-004 & & & & & & \\
\hline 2004 & ED-005 & & & & & & \\
\hline 2004 & ED-006 & & & & & & \\
\hline 2004 & ED-007 & & & & & & \\
\hline 2004 & ED-008 & & & & & & \\
\hline 2004 & ED-009 & & & & & & \\
\hline 2004 & ED-010 & & & & & & \\
\hline 2004 & ED-011 & UNIPAM & ESC.E JOSÉ M. BRANDÃO & & & & SUDESTE \\
\hline 2004 & ED-012 & UNIPÁM & & & & & SUDESTE \\
\hline 2004 & $\mathrm{ED}-013$ & & & & & & \\
\hline 2004 & ED-014 & UFPEL & & & & & SUL \\
\hline 2004 & $\overline{\mathrm{ED}-015}$ & UFRN & & & & & NORDESTE \\
\hline 2004 & ED-016 & & & & & & \\
\hline 2004 & ED-017 & & & & & & \\
\hline 2004 & ED-018 & UNISC & & & & & SUL \\
\hline 2004 & ED-019 & UFF & & & & & SUDESTE \\
\hline 2004 & ED-020 & UFF & & & & & SUDESTE \\
\hline 2004 & ED-021 & UFG & & & & & CENTRO-OESTE \\
\hline 2004 & $\mathrm{ED}-022$ & UFF & & & & & SUDESTE \\
\hline 2004 & ED-023 & UNILESTE & & & & & SUDESTE \\
\hline 2004 & $\mathrm{ED}-024$ & C. RIO BRANCO & & & & & SUDESTE \\
\hline 2004 & ED-025 & FACP & & & & & SUDESTE \\
\hline 2004 & ED-026 & NÃO MENCIONA & & & & & \\
\hline 2004 & ED-027 & NÃO MENCIONA & & & & & \\
\hline 2004 & ED-028 & UFS & & & & & NORDESTE \\
\hline 2004 & ED-029 & & & & & & \\
\hline 2004 & ED-030 & UFS & & & & & NORDESTE \\
\hline 2004 & ED- -031 & UFPE & & & & & NORDESTE \\
\hline 2004 & $\mathrm{ED}-032$ & UNICAMP & & & & & SUDESTE \\
\hline 2004 & ED-033 & UFF & & & & & SUDESTE \\
\hline 2004 & $\mathrm{ED}-034$ & UNICAMP & UNIV. SÃO FRANCISCO & C. LÚDICO & & & SUDESTE \\
\hline 2004 & $\overline{\mathrm{ED}-035}$ & UNICAMP & & & & & SUDESTE \\
\hline 2004 & ED-036 & USP & & & & & SUDESTE \\
\hline 2004 & ED-037 & & CEFETQ-NILÓPOLIS & UNIGRANRIO & & & SUDESTE \\
\hline 2004 & ED-038 & $\overline{\mathrm{UCLV}}$ & CEFET CELSO SUCKOW DA FONSECA & & & & EXTERIOR-CUBA \\
\hline 2004 & $\mathrm{ED}-039$ & UFC & & & & & NORDESTE \\
\hline 2004 & ED-040 & UEL & $\begin{array}{l}\text { C.E.PRINCESA ISABEL } \\
\end{array}$ & & & & SUL \\
\hline 2004 & ED-041 & NÃO MENCIONA & & & & & SUL \\
\hline 2004 & ED-042 & UNESP & ESC.E URUBUPUNGÁ & & & & SUDESTE \\
\hline 2004 & ED-043 & & & & & & \\
\hline 2004 & 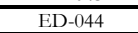 & CEFETQ-NILÓPOLIS & $\begin{array}{l}\text { C.E.PADRE ANCHIETA } \\
\end{array}$ & & & & SUDESTE \\
\hline 2004 & ED-045 & NÃO MENCIONA & & & & & SUDESTE \\
\hline 2004 & ED-046 & UNESP & ESC.E PROF. ADAHIR G. FOGACAA & & & & SUDESTE \\
\hline 2004 & ED-047 & NÃO MENCIONA & & & & & NÃO MENCIONA \\
\hline 2004 & ED-048 & UFG & & & & & CENTRO-OESTE \\
\hline 2004 & $\overline{\mathrm{ED}-049}$ & $\mathrm{UnB}$ & & & & & CENTRO-OESTE \\
\hline 2004 & $\frac{D D-549}{E D-050}$ & UNICAMP & & & & & SUDESTE \\
\hline 2004 & ED-051 & $\mathrm{UCB}$ & & & & & CENTRO-OESTE \\
\hline 2004 & ED-052 & FACITE & & & & & NORDESTE \\
\hline 2004 & ED-053 & MACKENZIE & & & & & $\begin{array}{l}\text { SUDESTE } \\
-1\end{array}$ \\
\hline
\end{tabular}




\begin{tabular}{|c|c|c|c|c|c|c|}
\hline 2004 & ED-054 & UFG & & & & CENTRO-OESTE \\
\hline 2004 & $\mathrm{ED}-055$ & \begin{tabular}{|l|l} 
UFG \\
\end{tabular} & UCG & COOP. DE REC. DE GOIÁNIA & SEMA CONSTRUTORA & CENTRO-OESTE \\
\hline 2004 & ED-056 & USP & & & & $\begin{array}{l}\text { SUDESTE } \\
\end{array}$ \\
\hline 2004 & ED-057 & UNICAMP & & & & SUDESTE \\
\hline 2004 & $\mathrm{ED}-058$ & UNOESTE & & & & $\begin{array}{ll}\text { SUL } \\
\end{array}$ \\
\hline 2004 & ED-059 & UNOESTE & & & & SUL \\
\hline 2004 & ED-060 & UNIMONTES & & & & SUDESTE \\
\hline 2004 & ED-061 & UEFS & & & & NORDESTE \\
\hline 2004 & ED-062 & UFMG & & & & SUDESTE \\
\hline 2004 & ED-063 & UFRPE & & & & NORDESTE \\
\hline 2004 & ED-064 & UFBA & & & & NORDESTE \\
\hline 2004 & ED-065 & $\begin{array}{l}\text { USP } \\
\end{array}$ & & & & SUDESTE \\
\hline 2004 & ED-066 & UFRPE & & & & NORDESTE \\
\hline 2004 & ED-067 & UFRPE & & & & NORDESTE \\
\hline 2004 & ED-068 & UFRPE & & & & NORDESTE \\
\hline 2004 & ED-069 & UEM & & & & SUL \\
\hline 2004 & ED-070 & & & & & \\
\hline 2004 & ED-071 & UFU & & & & SUDESTE \\
\hline 2004 & ED-072 & & & & & \\
\hline 2004 & ED-073 & UNIJUí & & & & SUL \\
\hline 2004 & ED-074 & & & & & \\
\hline 2004 & ED-075 & $\begin{array}{l}\text { UFPI } \\
\end{array}$ & & & & NORDESTE \\
\hline 2004 & ED-076 & UFPI & & & & NORDESTE \\
\hline 2004 & ED-077 & $\begin{array}{l}\text { UNICAMP } \\
\end{array}$ & & & & SUDESTE \\
\hline 2004 & ED-078 & URI & UNISINOS & & & SUL \\
\hline 2004 & ED-079 & UFRJ & & & & $\begin{array}{l}\text { SUDESTE } \\
\end{array}$ \\
\hline 2004 & ED-080 & & & & & \\
\hline 2004 & ED-081 & C.E.LUIZ VIANA FILHO & $\overline{\mathrm{UESB}}$ & & & NORDESTE \\
\hline 2004 & ED-082 & UESB & & & & NORDESTE \\
\hline 2004 & ED-083 & URI & UNISINOS & & & SUL \\
\hline 2004 & ED-084 & & & & & \\
\hline 2004 & ED-085 & UESB & & & & NORDESTE \\
\hline 2004 & ED-086 & UFF & & & & SUDESTE \\
\hline 2004 & ED-087 & UFF & & & & SUDESTE \\
\hline 2004 & ED-088 & USP & & & & SUDESTE \\
\hline 2004 & ED-089 & USP & & & & $\begin{array}{l}\text { SUDESTE } \\
\end{array}$ \\
\hline 2004 & ED-090 & UFG & & & & CENTRO-OESTE \\
\hline 2004 & ED-091 & & & & & \\
\hline 2004 & ED-092 & UERJ & & & & SUDESTE \\
\hline 2004 & ED-093 & $\begin{array}{ll}\text { USP } \\
\end{array}$ & & & & SUDESTE \\
\hline 2004 & ED-094 & ESC.E ANÍBAL DE FREITAS & UNICAMP & & & SUDESTE \\
\hline 2004 & ED-095 & UFS & & & & NORDESTE \\
\hline 2004 & ED-096 & UNISC & & & & SUL \\
\hline 2004 & ED-097 & UFF & & & & SUDESTE \\
\hline 2004 & ED-098 & UFF & & & & SUDESTE \\
\hline 2004 & ED-099 & UFPE & & & & NORDESTE \\
\hline 2004 & ED-100 & UFRPE & UNICAP & & & NORDESTE \\
\hline 2004 & ED-101 & UFRPE & UNICAP & & & NORDESTE \\
\hline 2004 & ED-102 & FEB & & & & SUDESTE \\
\hline 2004 & ED-103 & & & & & \\
\hline 2004 & ED-104 & NÃO MENCIONA & & & & \\
\hline 2004 & ED-105 & NÃO MENCIONA & & & & SUL \\
\hline 2004 & ED-106 & NÃO MENCIONA & & & & SUL \\
\hline 2004 & ED-107 & UERJ & & & & SUDESTE \\
\hline 2004 & ED-108 & UFF & & & & SUDESTE \\
\hline 2004 & ED-109 & UFF & & & & SUDESTE \\
\hline 2004 & ED-110 & UFS & & & & NORDESTE \\
\hline
\end{tabular}




\begin{tabular}{|c|c|c|c|c|c|c|c|}
\hline 2004 & ED-111 & UFSCAR & & & & & SUDESTE \\
\hline 2004 & ED-112 & UFSCAR & & & & & SUDESTE \\
\hline 2004 & ED-113 & UFRJ & FIOCRUZ & & & & SUDESTE \\
\hline 2004 & ED-114 & UFRJ & & & & & SUDESTE \\
\hline 2004 & ED-115 & IMAPES & & & & & SUDESTE \\
\hline$\frac{2004}{2004}$ & $\frac{{ }^{2}-115}{\mathrm{ED}-116}$ & $\frac{1 \mathrm{~N} A \mathrm{PES}}{\mathrm{UFS}}$ & SEC. DE EDUCAÇÃO & $\begin{array}{l}\text { C.E.SANTOS DUMONT } \\
\end{array}$ & & & $\frac{\text { SUDESIE }}{\text { NORDESTE }}$ \\
\hline 2004 & ED-117 & & & & & & \\
\hline$\frac{2004}{2004}$ & $\frac{\mathrm{ED}-118}{\mathrm{ED}-118}$ & & & & & & \\
\hline 2004 & ED-119 & & & & & & \\
\hline 2004 & ED-120 & & & & & & \\
\hline 2004 & ED-121 & & & & & & \\
\hline 2004 & ED-122 & & & & & & \\
\hline 2004 & ED-123 & & & & & & \\
\hline 2004 & ED-124 & NÃO MENCIONA & & & & & \\
\hline 2004 & ED-125 & NÃO MENCIONA & & & & & \\
\hline 2004 & ED-126 & & & & & & \\
\hline 2004 & ED-127 & NÃO MENCIONA & & & & & \\
\hline 2004 & ED-128 & & & & & & \\
\hline 2004 & ED-129 & & & & & & \\
\hline 2004 & $\frac{\mathrm{ED}^{2}-137}{\mathrm{ED}-130}$ & & & & & & \\
\hline 2004 & ED-131 & & & & & & \\
\hline 2004 & ED-132 & & & & & & \\
\hline 2004 & ED-133 & & & & & & \\
\hline 2004 & ED-134 & & & & & & \\
\hline$\frac{2004}{2004}$ & $\frac{\mathrm{ED}-1 \mathrm{T4}}{\mathrm{ED}-135}$ & & & & & & \\
\hline 2004 & ED-136 & & & & & & \\
\hline 2004 & $\frac{{ }^{2}-150}{\mathrm{ED}-137}$ & UEM & & & & & $\overline{\text { SUL }}$ \\
\hline 2004 & ED-138 & UNICAMP & & & & & SUDESTE \\
\hline 2004 & ED-139 & UESC & & & & & NORDESTE \\
\hline 2004 & ED-140 & UESC & & & & & NORDESTE \\
\hline 2004 & ED-141 & & & & & & \\
\hline 2004 & ED-142 & UNIVERSO & & & & & SUDESTE \\
\hline 2004 & ED-143 & UEM & C. EST.FRANCISCO ZARDO & & & & SUL \\
\hline 2004 & ED-144 & UFRR & ESC. DE APLICACCÃO & & & & NORTE \\
\hline 2004 & ED-145 & $\mathrm{UnB}$ & & & & & CENTRO-OESTE \\
\hline 2004 & ED-146 & UFRPE & & & & & NORDESTE \\
\hline 2004 & ED-147 & UFRPE & & & & & NORDESTE \\
\hline 2004 & ED-148 & FASF & UNINCOR & CEFET DE BAMBUÍ & COOP. DE ENS. DE BAMBUII & ESC.E ZICO TOBIAS & SUDESTE \\
\hline 2004 & ED-149 & FASF & UNINCOR & CEFET DE BAMBUÍ & COOP. DE ENS. DE BAMBUÍ & ESC.E ZICO TOBIAS & SUDESTE \\
\hline 2004 & ED-150 & UFS & C. DE APLICAÇ̃̃O & & & & NORDESTE \\
\hline 2004 & ED-151 & UFS & C. DE APLICACCÃO & & & & NORDESTE \\
\hline 2004 & ED-152 & UNICENTRO & NÚCLEO REG. DE EDUCAÇÃO & & & & SUL \\
\hline 2004 & ED-153 & UFPE & & & & & NORDESTE \\
\hline$\frac{2004}{2004}$ & $\frac{\mathrm{ED}-1.13}{\mathrm{ED}-154}$ & $\frac{\text { UTFE }}{\text { UFRPE }}$ & & & & & NORDESTE \\
\hline 2004 & ED-155 & $\mathrm{UnB}$ & & & & & CENTRO-OESTE \\
\hline$\frac{2004}{2004}$ & 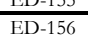 & UFRRJ & & & & & SUDESTE \\
\hline 2004 & ED-157 & $\mathrm{UnB}$ & & & & & $\begin{array}{l}\text { CENTRO-OESTE } \\
\end{array}$ \\
\hline 2004 & ED-158 & UNEB & & & & & NORDESTE \\
\hline 2004 & ED-159 & $\mathrm{UnB}$ & & & & & CENTRO-OESTE \\
\hline 2004 & ED-160 & $\mathrm{UnB}$ & & & & & CENTRO-OESTE \\
\hline 2004 & ED-161 & UCB & & & & & CENTRO-OESTE \\
\hline 2004 & ED-162 & FAC. DE MINAS & UNINCOR & UFMG & UFV & REDE PITÁGORAS & SUDESTE \\
\hline 2004 & $\begin{array}{ll}\mathrm{ED}-102 \\
\mathrm{ED}-163\end{array}$ & UFPI & & & & & $\frac{\text { NORDESTE }}{\text { NORD }}$ \\
\hline 2004 & ED-164 & USP & & & & & SUDESTE \\
\hline 2004 & ED-165 & UESB & & & & & NORDESTE \\
\hline 2004 & ED-166 & FASF & & & & & SUDESTE \\
\hline 2004 & ED-167 & C. TÉC. DA UFMG & & & & & SUDESTE \\
\hline
\end{tabular}




\begin{tabular}{|c|c|c|c|c|c|c|c|}
\hline 2004 & ED-168 & UFMG & C. TÉC. DA UFMG & & & & SUDESTE \\
\hline 2004 & ED-169 & SEC. EDUC. DO DF & & & & & $\begin{array}{l}\text { CENTRO-OESTE } \\
\end{array}$ \\
\hline 2004 & ED-170 & UNOESTE & & & & & SUL \\
\hline 2004 & ED-171 & UNOESTE & & & & & SUL \\
\hline 2004 & ED-172 & USP & & & & & SUDESTE \\
\hline 2004 & ED-173 & UNOESTE & & & & & SUL \\
\hline 2004 & ED-174 & FACITE & & & & & NORDESTE \\
\hline 2004 & ED-175 & UFRPE & & & & & NORDESTE \\
\hline 2004 & ED-176 & & & & & & \\
\hline 2004 & ED-177 & C. SANTA MÓNICA & UFRJ & & & & SUDESTE \\
\hline 2004 & ED-178 & UFRJ & & & & & SUDESTE \\
\hline 2004 & ED-179 & & & & & & \\
\hline 2004 & ED-180 & UFRRJ & & & & & SUDESTE \\
\hline 2004 & ED-181 & USP & & & & & SUDESTE \\
\hline 2004 & ED-182 & NÃO MENCIONA & & & & & SUDESTE \\
\hline 2004 & ED-183 & NÃO MENCIONA & & & & & NORDESTE \\
\hline 2004 & ED-184 & $\begin{array}{ll}\text { USP } \\
\end{array}$ & & & & & $\begin{array}{l}\text { SUDESTE } \\
\end{array}$ \\
\hline 2004 & ED-185 & & & & & & \\
\hline 2004 & ED-186 & & & & & & \\
\hline 2004 & ED-187 & $\mathrm{UFBA}$ & SENAI & & & & NORDESTE \\
\hline 2004 & ED-188 & & & & & & \\
\hline 2004 & ED-189 & USP & & & & & SUDESTE \\
\hline 2004 & ED-190 & UnB & & & & & CENTRO-OESTE \\
\hline 2004 & ED-191 & & & & & & \\
\hline 2004 & ED-192 & CREUPI & & & & & SUDESTE \\
\hline 2004 & ED-193 & FAMINAS & UNINCOR & UFMG & $\overline{\mathrm{UFV}}$ & REDE PITÁGORAS & SUDESTE \\
\hline 2004 & ED-194 & & & & & & \\
\hline
\end{tabular}




\begin{tabular}{|c|c|c|c|c|c|c|}
\hline $\begin{array}{l}\text { REGIÃO 2 } \\
\end{array}$ & INTERAÇÃO H X E & NÍVEL ESCOLAR1 & NÍVEL ESCOLAR 2 & NÍVEL ESCOLAR 3 & FOCO TEMÁTICO PRINCIPAL & FOCO TEMÁTCO SECUNDÁRIO \\
\hline & & SUPERIOR & & & CONTEÚDO-MÉTODO & \\
\hline & & & & & & \\
\hline & & & & & & \\
\hline & & & & & & \\
\hline & & & & & & \\
\hline & & & & & & \\
\hline & & & & & & \\
\hline & & & & & & \\
\hline & & & & & & \\
\hline & & SUPERIOR & & & FILOSOFIA DA CIÉNCIA & CARACTERÍSTICAS DO ALUNO \\
\hline & & SUPERIOR & & & FORMAÇÅ̄O INICIAL DE PROFESSORES & $\begin{array}{l}\text { CARACTERÍSTICAS DO ALUNO } \\
\end{array}$ \\
\hline & & & & & 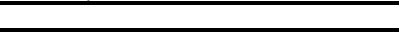 & \\
\hline & & $\overline{\text { SUPERIOR }}$ & & & $\overline{\text { RECURSO DIDÁTICO }}$ & \\
\hline & & SUPERIOR & & & CONTEÚDO-MÉTODO & \\
\hline & & SUPERIOR & & & CONTEÚDO-MÉTODO & \\
\hline & & MÉDIO & SUPERIOR & & CARACTERIŚSTICAS DO ALUNO & E FORMAÇÃO INICIAL DE PROFESSORES \\
\hline & & GERAL & & & RECURSO DIDÁTICO & \\
\hline & & SUPERIOR & & & CURRÍCULOS E PROGRAMAS & \\
\hline & & MÉDIO & & & CONTEÚDO-MÉTODO & \\
\hline & & GERAL & & & OUTRO & \\
\hline & & & & & & \\
\hline & & MÉDIO & & & CONTEÚDO-MÉTODO & FORMAÇÃO DE CONCEITOS \\
\hline & & & & & & \\
\hline & & FUNDAMENTAL & MÉDIO & SUPERIOR & FORMAČ̃O DE CONCEITOS & \\
\hline & & MEDIO & SUPERIOR & & CURRÍCULOS E PROGRAMAS & \\
\hline & & MÉDIO & & & RECURSO DIDÁTICO & \\
\hline & $\mathrm{FE}$ & MÉDIO & SUPERIOR & & RECURSO DIDÁTICO & \\
\hline & FEXIQ & SUPERIOR & & & CARACTERIŚSTICAS DO PROFESSOR & \\
\hline & & SUPERIOR & & & CURRÍCULOS E PROGRAMAS & \\
\hline & & MÉDIO & & & RECURSO DIDÁTICO & \\
\hline SUDESTE & & MÉDIO & SUPERIOR & & CURRÍCULOS E PROGRAMAS & \\
\hline & & MÉDIO & & & $\begin{array}{l}\text { CARACTERÍSTICAS DO ALUNO } \\
\end{array}$ & \\
\hline & & MÉDIO & & & CONTEÚDO-MÉTODO & \\
\hline & & FUNDAMENTAL & SUPERIOR & & CONTEÚDO-MÉTODO & \\
\hline & DFQXFE & MEDIO & SUPERIOR & & FORMAÇÃO CONT. DE PROFESSORES & \\
\hline & & SUPERIOR & & & CURRÍCULOS E PROGRAYAS & \\
\hline & & $\begin{array}{l}\text { SUPEIOR } \\
\text { MEDIO }\end{array}$ & & & $\begin{array}{l}\text { CURRICLOS E PROGRAMAS } \\
\text { FORMACÃO DE CONCEITOS }\end{array}$ & \\
\hline & & MÉDIO & & & ORGANIZACCÃO DA ESCOLA & \\
\hline & & MÉDIO & & & RECURSO DIDÁTICO & \\
\hline & & SUPERIOR & & & RECURSO DIDÁTICO & \\
\hline & & $\begin{array}{l}\text { SUPERIOR } \\
\end{array}$ & & & CARACTERÍSTICAS DO ALUNO & \\
\hline & IQXFE & & & & & \\
\hline & & SUPERIOR & & & RECURSO DIDÁTICO & \\
\hline & & SUPERIOR & & & CONTEÚDO-MÉTODO & \\
\hline & & SUPERIOR & & & ORGANIZAÇÃO DA ESCOLA & \\
\hline
\end{tabular}




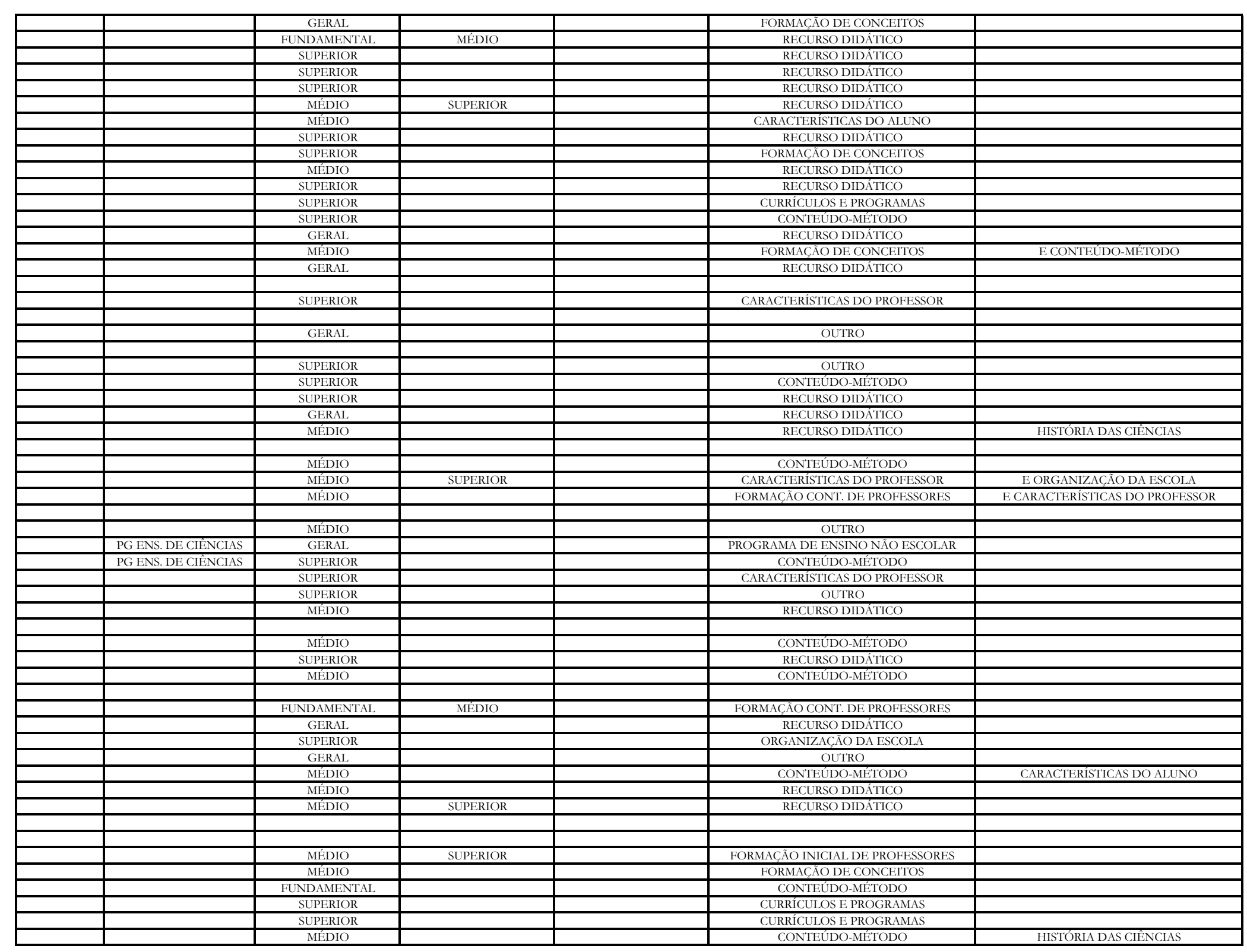




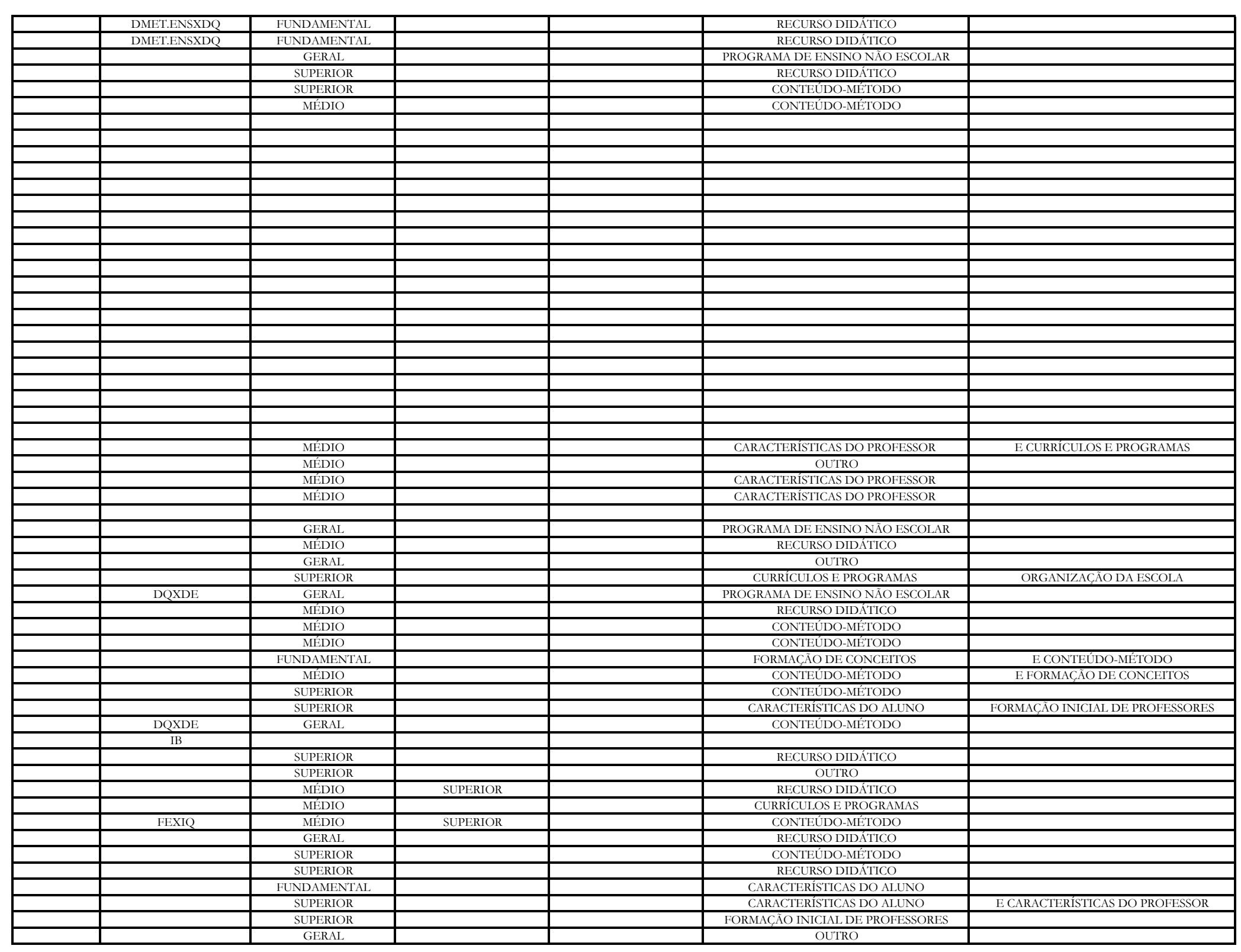




\begin{tabular}{|c|c|c|c|c|c|c|}
\hline & & GERAL & & & RECURSO DIDÁTICO & $\begin{array}{l}\text { PROGRAMA DE ENSINO NÃO ESCOLAR } \\
\end{array}$ \\
\hline & & MÉDIO & & & CURRÍCULOS E PROGRAMAS & \\
\hline & & FUNDAMENTAL & $\overline{M E ́ D I O}$ & & CONTEÚDO-MÉTODO & \\
\hline & & MÉDIO & SUPERIOR & & CONTEÚDO-MËTODO & \\
\hline & & MÉDIO & & & FORMACĆAO DE CONCEITOS & \\
\hline & & $\frac{M E D I O}{M E ́ D I O}$ & & & RECURSO DIDÁTICO & \\
\hline & & $\begin{array}{l}\text { SUPERIOR } \\
\end{array}$ & & & CONTEÚDO-MÉTODO & \\
\hline & & GERAL & & & RECURSO DIDÁTICO & \\
\hline & & & & & & \\
\hline & & $\overline{M E ́ D I O}$ & & & RECURSO DIDÁTICO & \\
\hline & FEXIQ & FUNDAMENTAL & & & CONTEÚDO-MÉTODO & \\
\hline & & & & & & \\
\hline & & SUPERIOR & & & ORGANIZAÇ̃̃O DA ESCOLA & \\
\hline & & MÉDIO & & & OUTRO & \\
\hline & & MÉDIO & & & CONTEÚDO-MÉTODO & \\
\hline & & MÉDIO & & & CONTEÚDO-MÉTODO & \\
\hline & & MÉDIO & & & FORMAÇÃO CONT. DE PROFESSORES & \\
\hline & & & & & & \\
\hline & & & & & & \\
\hline & & SUPERIOR & & & RECURSO DIDÁTICO & \\
\hline & & & & & & 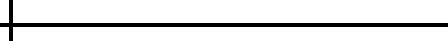 \\
\hline & $\mathrm{FE}$ & $\begin{array}{l}\text { GERAL } \\
\text { MÉDIO }\end{array}$ & $\begin{array}{l}\text { SUPERIOR } \\
\end{array}$ & & $\begin{array}{c}\text { OUTRO } \\
\text { CONTEÚDO-MÉTODO }\end{array}$ & FORMAÇÃO INICIAL DE PROFESSORES \\
\hline & & & & & 2 & \\
\hline & & SUPERIOR & & & CONTEÚDO-MÉTODO & \\
\hline & & $\begin{array}{l}\text { GERAL } \\
\end{array}$ & & & CONTEÚDO-MÉTODO & \\
\hline & & & & & & \\
\hline
\end{tabular}


Planilha de classificação da $28^{a}$ RASBQ - 2005

\begin{tabular}{|c|c|c|c|c|c|c|c|c|}
\hline ANO & TRABALHO & INSTITUIÇÁOO 1 & INSTITUIÇÁAO 2 & $\begin{array}{l}\text { INSTITUIÇÁO } 3 \\
\end{array}$ & INSTITUIÇÃO 4 & REGIÁOO 1 & REGIÁO 2 2 & INTERAÇÁOO H X E \\
\hline 2005 & ED-001 & UnB & & & & CENTRO-OESTE & & \\
\hline 2005 & ED-002 & UNESP & & & & $\begin{array}{l}\text { SUDESTE } \\
\end{array}$ & & \\
\hline 2005 & ED-003 & UNESP & & & & SUDESTE & & \\
\hline 2005 & ED-004 & UENF & & & & $\begin{array}{l}\text { SUDESTE } \\
\end{array}$ & & \\
\hline 2005 & ED-005 & UNESP & & & & SUDESTE & & \\
\hline 2005 & ED-006 & UFMG & & & & SUDESTE & & \\
\hline 2005 & ED-007 & UnB & & & & CENTRO-OESTE & & IQXFE \\
\hline 2005 & ED-008 & UnB & & & & $\begin{array}{l}\text { CENTRO-OESTE } \\
\end{array}$ & & \\
\hline 2005 & ED-009 & $\overline{\mathrm{UFMG}}$ & & & & SUDESTE & & \\
\hline 2005 & ED-010 & UEM & & & & SUL & & \\
\hline 2005 & ED-011 & FACP & & & & SUDESTE & & \\
\hline 2005 & ED-012 & FEB & & & & SUDESTE & & \\
\hline 2005 & ED-013 & UFRR & ESC.E AYRTON SENA & & & NORTE & & \\
\hline 2005 & ED-014 & UFRR & ESC. MONTEIRO LOBATO & & & NORTE & & \\
\hline 2005 & ED-015 & UFRRJ & & & & SUDESTE & & \\
\hline 2005 & ED-016 & NÃO MENCIONA & & & & NÃO MENCIONA & & \\
\hline 2005 & ED-017 & UNESP & ESC.E DE URUBUPUNGÁ & & & SUDESTE & & \\
\hline 2005 & ED-018 & UEM & & & & $\begin{array}{l}\text { SUL } \\
\end{array}$ & & \\
\hline 2005 & ED-019 & UEM & & & & SUL & & \\
\hline 2005 & ED-020 & UFS & & & & NORDESTE & & \\
\hline 2005 & ED-021 & USP & & & & SUDESTE & & \\
\hline 2005 & ED-022 & $\overline{\text { UFSCAR }}$ & & & & SUDESTE & & \\
\hline 2005 & ED-023 & UFF & & & & SUDESTE & & \\
\hline 2005 & ED-024 & USP & ESC. VERA CRUZ & & & SUDESTE & & \\
\hline 2005 & ED-025 & UNICAMP & & & & SUDESTE & & $\mathrm{FE}$ \\
\hline 2005 & ED-026 & UnB & & & & $\begin{array}{l}\text { CENTRO-OESTE } \\
\end{array}$ & & PG EM ENS.DE CIËNCIAS \\
\hline 2005 & ED-027 & USP & & & & SUDESTE & & \\
\hline 2005 & ED-028 & UnB & & & & CENTRO-OESTE & & \\
\hline 2005 & ED-029 & NÃO MENCIONA & & & & $\begin{array}{l}\text { SUL } \\
\end{array}$ & & \\
\hline 2005 & ED-030 & UNIJUí & & & & SUL & & \\
\hline 2005 & ED-031 & NÃO MENCIONA & & & & $\begin{array}{l}\text { SUL } \\
\end{array}$ & & \\
\hline 2005 & ED-032 & UNIJUí & & & & SUL & & \\
\hline 2005 & ED-033 & $\begin{array}{l}\text { USP } \\
\end{array}$ & & & & SUDESTE & & \\
\hline 2005 & ED-034 & UFMG & & & & SUDESTE & & \\
\hline 2005 & ED-035 & USP & & & & SUDESTE & & FE \\
\hline 2005 & ED-036 & UFRJ & & & & SUDESTE & & \\
\hline 2005 & ED-037 & UFRJ & UFF & & & SUDESTE & & \\
\hline 2005 & ED-038 & USP & & & & SUDESTE & & \\
\hline 2005 & ED-039 & USP & & & & SUDESTE & & \\
\hline 2005 & ED- 040 & UFG & & & & $\begin{array}{l}\text { CENTRO-OESTE } \\
\end{array}$ & & \\
\hline 2005 & ED-041 & USP & DP UNION & & & SUDESTE & & \\
\hline 2005 & ED-042 & UFRJ & & & & SUDESTE & & \\
\hline 2005 & ED-043 & NÃO MENCIONA & & & & SUL & & \\
\hline 2005 & ED-044 & $\mathrm{UnB}$ & & & & CENTRO-OESTE & & \\
\hline 2005 & ED-045 & CEFETQ-NILÓPOLIS & & & & SUDESTE & & \\
\hline 2005 & ED-046 & UFF & & & & SUDESTE & & \\
\hline 2005 & ED-047 & UESB & & & & NORDESTE & & \\
\hline 2005 & ED-048 & UNICAMP & & & & SUDESTE & & \\
\hline 2005 & ED-049 & NÃO MENCIONA & & & & SUL & & \\
\hline 2005 & ED-050 & UESB & & & & NORDESTE & & \\
\hline 2005 & ED-051 & USP & & & & SUDESTE & & \\
\hline 2005 & ED-052 & USP & & & & SUDESTE & & \\
\hline 2005 & ED-053 & \begin{tabular}{l|l} 
USP \\
\end{tabular} & & & & $\begin{array}{l}\text { SUDESTE }\end{array}$ & & \\
\hline
\end{tabular}




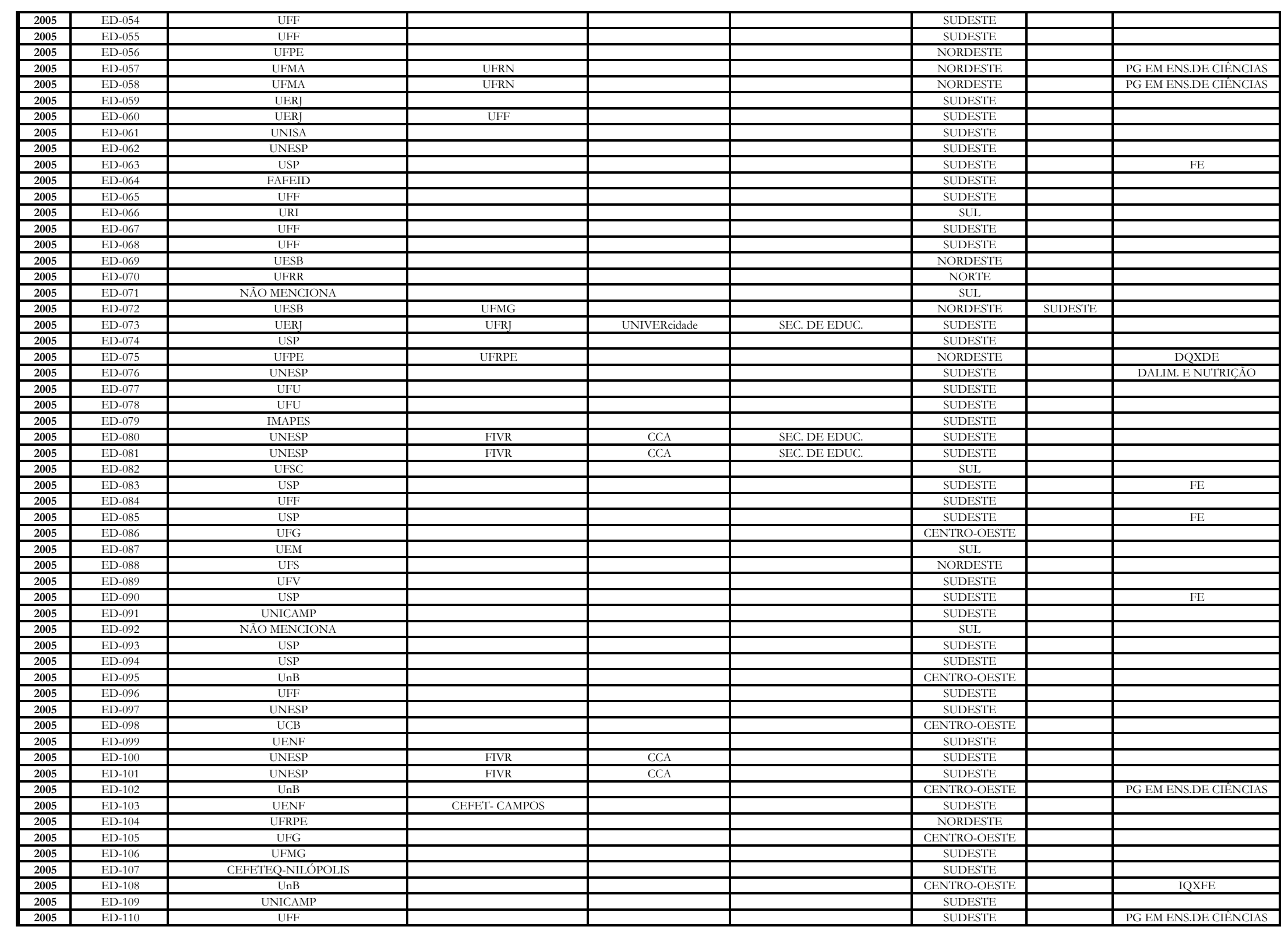




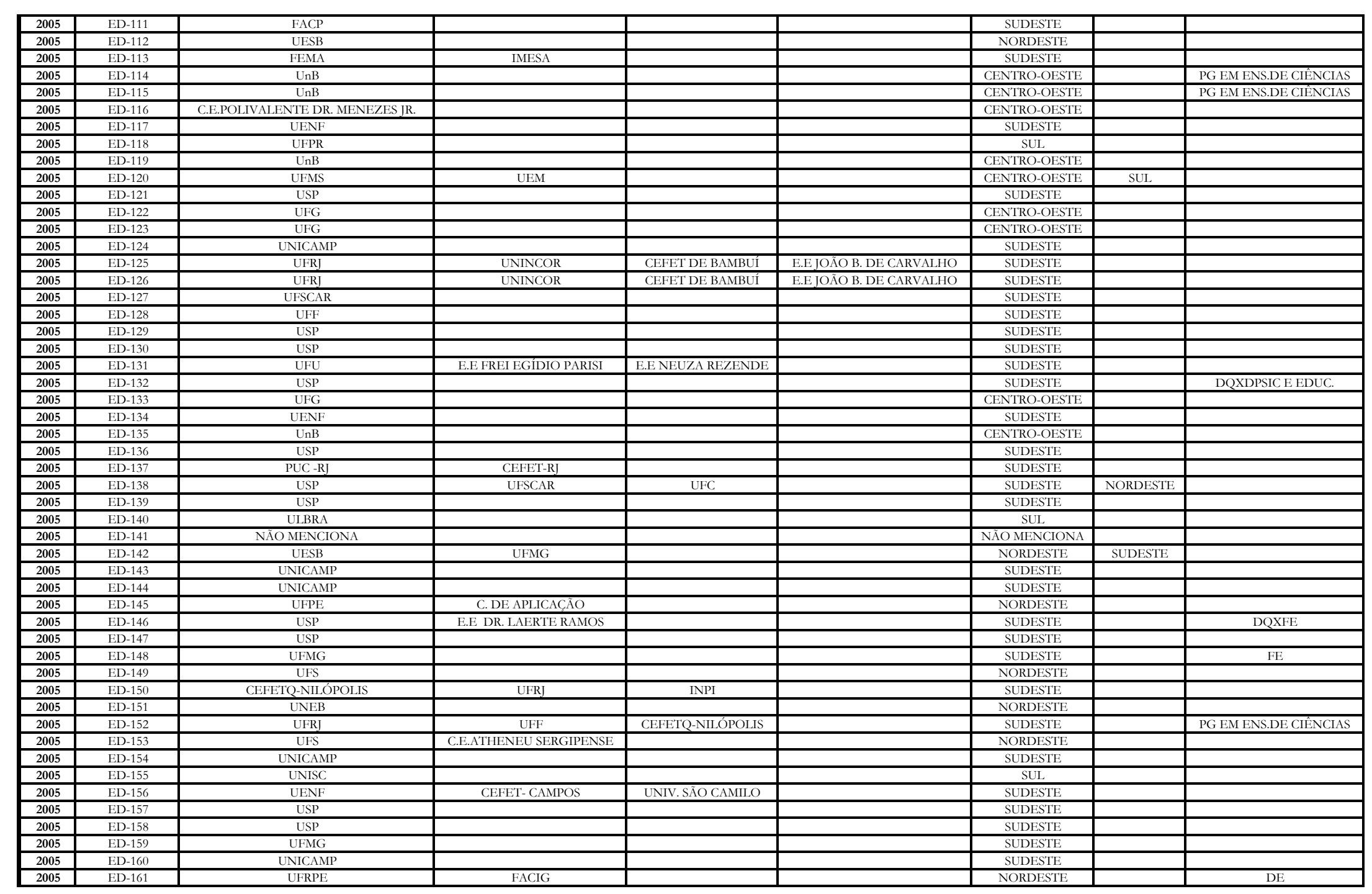




\begin{tabular}{|c|c|c|c|c|c|}
\hline NIVEL ESCOLAR1 & NIVEL ESCOLAR 2 & NIVEL ESCOLAR 3 & FOCO TEMÁTICO PRINCIPAL & FOCO TEMATTCO SECUNDARIO & FOCO TEMATCO TERCIARIO \\
\hline MÉDIO & SUPERIOR & & RECURSO DIDÁTICO & & \\
\hline MÉDIO & & & CONTEÚDO-MÉTODO & & \\
\hline FUNDAMENTAL & & & FORMAÇÃO CONT. DE PROFESSORES & & \\
\hline SUPERIOR & & & RECURSO DIDÁTICO & & \\
\hline SUPERIOR & & & CURRÍCULOS E PROGRAMAS & & \\
\hline SUPERIOR & & & CONTEÚDO-MÉTODO & & \\
\hline MÉDIO & & & RECURSO DIDÁTICO & $\begin{array}{l}\text { E CARACTERÍSTICAS DO ALUNO } \\
\end{array}$ & E CARACTERÍSTICAS DO PROFESSOR \\
\hline MÉDIO & & & RECURSO DIDÁTICO & & \\
\hline SUPERIOR & & & RECURSO DIDÁTICO & & \\
\hline MÉDIO & & & CARACTERÍSTICAS DO ALUNO & & \\
\hline SUPERIOR & & & CONTEÚDO-MÉTODO & & \\
\hline GERAL & & & RECURSO DIDÁTICO & & \\
\hline MÉDIO & & & CURRÍCULOS E PROGRAMAS & & \\
\hline MÉDIO & & & CONTEÚDO-MÉTODO & & \\
\hline MÉDIO & SUPERIOR & & RECURSO DIDÁTICO & & \\
\hline MÉDIO & SUPERIOR & & FORMAÇÃO CONT. DE PROFESSORES & & \\
\hline MÉDIO & & & FORMAÇÃO CONT. DE PROFESSORES & & \\
\hline MÉDIO & SUPERIOR & & CARACTERÍSTICAS DO ALUNO & E CARACTERÍSTICAS DO PROFESSOR & \\
\hline SUPERIOR & & & RECURSO DIDÁTICO & & \\
\hline FUNDAMENTAL & & & CONTEÚDO-MÉTODO & & \\
\hline SUPERIOR & & & RECURSO DIDÁTICO & & \\
\hline MÉDIO & SUPERIOR & & CONTEÚDO-MÉTODO & & \\
\hline MÉDIO & & & CONTEÚDO-METTODO & E CARACTERÍSTICAS DO ALUNO & \\
\hline MÉDIO & & & RECURSO DIDÁTICO & & \\
\hline MÉDIO & SUPERIOR & & FORMAÇÃO INICIAL DE PROFESSORES & E CARACTERÍSTICAS DO ALUNO & \\
\hline MÉDIO & & & CARACTERÍSTICAS DO PROFESSOR & & \\
\hline SUPERIOR & & & CONTEÚDO-MÉTODO & & \\
\hline MÉDIO & SUPERIOR & & RECURSO DIDATICO & & \\
\hline MÉDIO & & & CONTEÚDO-MÉTODO & & \\
\hline SUPERIOR & & & FORMAÇÃO DE CONCEITOS & E CONTEÚDO-MÉTODO & \\
\hline MÉDIO & & & FORMAÇÃO DE CONCEITOS & E CONTEÚDO-MÉTODO & \\
\hline FUNDAMENTAL & & & FORMAÇÃO CONT. DE PROFESSORES & & \\
\hline MEDIO & & & FORMAÇÃO DE CONCEITOS & & \\
\hline SUPERIOR & & & CARACTERÍSTICAS DO ALUNO & E FORMAÇ̊̃O INICIAL DE PROFESSORES & \\
\hline MÉDIO & & & CONTEÚDO-MÉTODO & & \\
\hline SUPERIOR & & & FORMAÇÃO INICIAL DE PROFESSORES & CARACTERÍSTICAS DO ALUNO & \\
\hline SUPERIOR & & & OUTRO & CURRICULOS E PROGRAMAS & \\
\hline SUPERIOR & & & CONTEÚDO-MÉTODO & & \\
\hline SUPERIOR & & & CURRÍCULOS E PROGRAMAS & & \\
\hline GERAL & & & POLÍTICAS PÚBLICAS & & \\
\hline SUPERIOR & & & RECURSO DIDÁTICO & & \\
\hline MÉDIO & SUPERIOR & & HISTÓRIA DO ENSINO DE CIĖNCIAS & RECURSO DIDÁTICO & \\
\hline MÉDIO & SUPERIOR & & FORMAÇÃO INICIAL DE PROFESSORES & & \\
\hline $\begin{array}{l}\text { SUPERIOR } \\
\end{array}$ & & & $\begin{array}{l}\text { CARACTERISTICAS DO ALUNO } \\
\end{array}$ & E FORMAÇĀO INICIAL DE PROFESSORES & \\
\hline MÉDIO & & & RECURSO DIDÁTICO & & \\
\hline MÉDIO & & & RECURSO DIDÁTICO & & \\
\hline MÉDIO & & & CARACTERIŚSTICAS DO PROFESSOR & & \\
\hline SUPERIOR & & & CURRÍCULOS E PROGRAMAS & E CARACTERÍSTICAS DO ALUNO & E CARACTERÍSTICAS DO PROFESSOR \\
\hline MÉDIO & & & CURRÍCULOS E PROGRAMAS & & \\
\hline MÉDIO & & & $\begin{array}{l}\text { CARACTERÍSTICAS DO PROFESSOR } \\
\end{array}$ & & \\
\hline SUPERIOR & & & CONTEÚDO-MÉTODO & & \\
\hline SUPERIOR & & & CARACTERISTICAS DO PROFESSOR & & \\
\hline SUPERIOR & & & RECURSO DIDÁTICO & & \\
\hline
\end{tabular}




\begin{tabular}{|c|c|c|c|c|}
\hline SUPERIOR & & RECURSO DIDÁTICO & & \\
\hline SUPERIOR & & CONTEÚDO-MÉTODO & & \\
\hline FUNDAMENTAL & MÉDIO & FORMAÇÃO DE CONCEITOS & & \\
\hline MËDIO & & RECURSO DIDÁTICO & & \\
\hline MÉDIO & & CARACTERÍSTICAS DO ALUNO & E CARACTERÍSTICAS DO PROFESSOR & \\
\hline MÉDIO & & CONTEÚDO-MÉTODO & & \\
\hline GERAL & & CONTEÚDO-MÉTODO & & \\
\hline GERAL & & PROGRAMA DE ENSINO NÃO ESCOLAR & FORMAÇÃO INICIAL DE PROFESSORES & \\
\hline MÉDIO & & RECURSO DIDÁTICO & & \\
\hline MÉDIO & & RECURSO DIDÁTICO & & \\
\hline $\begin{array}{l}\text { SUPERIOR } \\
\end{array}$ & & CONTEÚDO-MÉTODO & & \\
\hline $\begin{array}{l}\text { SUPERIOR } \\
\end{array}$ & & RECURSO DIDÁTICO & & \\
\hline GERAL & & CURRÍCULOS E PROGRAMAS & & \\
\hline SUPERIOR & & CONTEÚDO-MÉTODO & $\begin{array}{l}\text { FORMAÇÃO INICIAL DE PROFESSORES } \\
\end{array}$ & \\
\hline $\begin{array}{l}\text { SUPERIOR } \\
\end{array}$ & & ORGANIZAÇÃO DA ESCOLA & & \\
\hline $\begin{array}{l}\text { SUPERIOR } \\
\end{array}$ & & $\begin{array}{l}\text { RECURSO DIDÁTICO } \\
\end{array}$ & & \\
\hline MÉDIO & SUPERIOR & RECURSO DIDÁTICO & & \\
\hline MÉDIO & SUPERIOR & FORMAÇÃO INICIAL DE PROFESSORES & E FORMAÇÃO CONT. DE PROFESSORES & \\
\hline MÉDIO & & FORMAÇÃO CONT. DE PROFESSORES & & \\
\hline FUNDAMENTAL & MÉDIO & CONTEÚDO-MÉTODO & & \\
\hline MÉDIO & & CONTEÚDO-MÉTODO & & \\
\hline MÉDIO & & CONTEÚDO-MÉTODO & & \\
\hline MÉDIO & SUPERIOR & RECURSO DIDÁTICO & & \\
\hline MÉDIO & & RECURSO DIDÁTICO & & \\
\hline MÉDIO & & FORMAÇÃO CONT. DE PROFESSORES & & \\
\hline SUPERIOR & & RECURSO DIDÁTICO & & \\
\hline MÉDIO & & CONTEÚDO-MÉTODO & & \\
\hline MÉDIO & & FORMAÇÃO CONT. DE PROFESSORES & & \\
\hline MÉDIO & SUPERIOR & CONTEÚDO-MÉTODO & & \\
\hline $\begin{array}{l}\text { FUNDAMENTAL } \\
\end{array}$ & MÉDIO & FORMAÇÃO CONT. DE PROFESSORES & & \\
\hline SUPERIOR & & CONTEÚDO-MÉTODO & & \\
\hline MÉDIO & & RECURSO DIDÁTICO & & \\
\hline $\begin{array}{l}\text { FUNDAMENTAL } \\
\end{array}$ & MÉDIO & FORMAÇÃO DE CONCEITOS & & \\
\hline SUPERIOR & & ORGANIZAÇÃO DA ESCOLA & & \\
\hline MÉDIO & & CARACTERÍSTICAS DO PROFESSOR & & \\
\hline SUPERIOR & & CURRÍCULOS E PROGRAMAS & & \\
\hline GERAL & & RECURSO DIDÁTICO & & \\
\hline SUPERIOR & & $\begin{array}{l}\text { CARACTERÍSTICAS DO ALUNO } \\
\end{array}$ & & \\
\hline MÉDIO & & CURRÍCULOS E PROGRAMAS & E CARACTERÍSTICAS DO PROFESSOR & \\
\hline SUPERIOR & & $\begin{array}{l}\text { CARACTERÍSTICAS DO ALUNO } \\
\end{array}$ & & \\
\hline MÉDIO & & CURRÍCULOS E PROGRAMAS & & \\
\hline SUPERIOR & & RECURSO DIDÁTICO & & \\
\hline SUPERIOR & & RECURSO DIDÁTICO & & \\
\hline MÉDIO & & FORMACCÃO DE CONCEITOS & & \\
\hline SUPERIOR & & $\begin{array}{l}\text { RECURSO DIDÁTICO } \\
\end{array}$ & & \\
\hline MÉDIO & & CONTEÚDO-MÉTODO & & \\
\hline $\begin{array}{l}\text { FUNDAMENTAL } \\
\end{array}$ & MÉDIO & CARACTERÍSTICAS DO PROFESSOR & & \\
\hline MÉDIO & & CARACTERÍSTICAS DO PROFESSOR & & \\
\hline MÉDIO & SUPERIOR & RECURSO DIDÁTICO & & \\
\hline MÉDIO & & CONTEÚDO-MÉTODO & & \\
\hline MÉDIO & & CONTEÚDO-MÉTODO & & \\
\hline MÉDIO & & CARACTERÍSTICAS DO ALUNO & & \\
\hline SUPERIOR & & RECURSO DIDÁTICO & & \\
\hline MÉDIO & & CONTEÚDO-MÉTODO & & \\
\hline MÉDIO & SUPERIOR & CONTEÚDO-MÉTODO & CARACTERÍSTICAS DO ALUNO & \\
\hline FUNDAMENTAL & & RECURSO DIDÁTICO & & \\
\hline MÉDIO & SUPERIOR & RECURSO DIDÁTICO & & \\
\hline
\end{tabular}




\begin{tabular}{|c|c|c|c|c|c|}
\hline $\begin{array}{l}\text { SUPERIOR } \\
\end{array}$ & & & CONTEÚDO-MÉTODO & & \\
\hline FUNDAMENTAL & MÉDIO & SUPERIOR & FORMAÇÃO INICIAL DE PROFESSORES & E FORMAÇÃO CONT. DE PROFESSORES & \\
\hline MÉDIO & & & $\begin{array}{l}\text { CARACTERÍSTICAS DO ALUNO } \\
\end{array}$ & $\begin{array}{l}\text { E CARACTERÍSTICAS DO PROFESSOR } \\
\end{array}$ & \\
\hline MÉDIO & & & FORMAÇÃO CONT. DE PROFESSORES & & \\
\hline MÉDIO & & & FORMAÇÃO CONT. DE PROFESSORES & & \\
\hline GERAL & & & CONTEÚDO-MÉTODO & & \\
\hline MÉDIO & & & CONTEÚDO-MÉTODO & & \\
\hline SUPERIOR & & & CARACTERÍSTICAS DO ALUNO & & \\
\hline SUPERIOR & & & RECURSO DIDÁTICO & & \\
\hline MÉDIO & & & CONTEÚDO-MÉTODO & & \\
\hline MÉDIO & & & CONTEÚDO-MÉTODO & FORMACCÃO DE CONCEITOS & \\
\hline SUPERIOR & & & CONTEÚDO-MÉTODO & & \\
\hline SUPERIOR & & & RECURSO DIDÁTICO & & \\
\hline SUPERIOR & & & RECURSO DIDÁTICO & & \\
\hline MÉDIO & & & CONTEÚDO-MÉTODO & & \\
\hline MÉDIO & & & CONTEÚDO-MÉTODO & & \\
\hline MÉDIO & & & RECURSO DIDÁTICO & & \\
\hline SUPERIOR & & & RECURSO DIDÁTICO & & \\
\hline SUPERIOR & & & OUTRO & & \\
\hline GERAL & & & OUTRO & & \\
\hline MÉDIO & & & CARACTERÍSTICAS DO ALUNO & & \\
\hline MÉDIO & & & $\begin{array}{l}\text { PROGRAMA DE ENSINO NÃO ESCOLAR } \\
\end{array}$ & & \\
\hline MÉDIO & & & $\begin{array}{l}\text { CARACTERISTICAS DO PROFESSOR } \\
\end{array}$ & & \\
\hline SUPERIOR & & & CARACTERÍSTICAS DO ALUNO & & \\
\hline MÉDIO & & & CARACTERÍSTICAS DO PROFESSOR & & \\
\hline SUPERIOR & & & CURRÍCULOS E PROGRAMAS & E CARACTERÍSTICAS DO ALUNO & \\
\hline GERAL & & & HISTÓRIA DO ENSINO DE CIÊNCIAS & & \\
\hline SUPERIOR & & & RECURSO DIDÁTICO & & \\
\hline MÉDIO & & & FORMAÇÃO DE CONCEITOS & E PROGRAMA DE ENSINO NÃO ESCOLAR & \\
\hline SUPERIOR & & & CARACTERÍSTICAS DO ALUNO & & \\
\hline GERAL & & & HISTÓRIA DAS CIÊNCIAS & & \\
\hline MÉDIO & & & CONTEÚDO-MÉTODO & & \\
\hline MÉDIO & & & RECURSO DIDÁTICO & & \\
\hline MÉDIO & & & RECURSO DIDÁTICO & & \\
\hline MÉDIO & & & CARACTERIŚSTICAS DO PROFESSOR & & \\
\hline MÉDIO & SUPERIOR & & CONTEÚDO-MÉTODO & & \\
\hline GERAL & & & CURRÍCULOS E PROGRAMAS & & \\
\hline GERAL & & & CARACTERÍSTICAS DO PROFESSOR & & \\
\hline MÉDIO & & & CONTEÚDO-MÉTODO & & \\
\hline MÉDIO & & & OUTRO & & \\
\hline MÉDIO & SUPERIOR & & RECURSO DIDÁTICO & & \\
\hline MÉDIO & SUPERIOR & & CONTEÚDO-MÉTODO & & \\
\hline MÉDIO & & & FORMAÇÃO DE CONCEITOS & E CONTEÚDO-MÉTODO & \\
\hline MÉDIO & SUPERIOR & & RECURSO DIDÁTICO & & \\
\hline MÉDIO & & & CARACTERÍSTICAS DO ALUNO & E CARACTERÍSTICAS DO PROFESSOR & \\
\hline MÉDIO & SUPERIOR & & RECURSO DIDÁTICO & & \\
\hline GERAL & & & RECURSO DIDÁTICO & & \\
\hline SUPERIOR & & & $\begin{array}{l}\text { PROGRAMA DE ENSINO NÃO ESCOLAR } \\
\end{array}$ & & \\
\hline GERAL & & & CONTEÚDO-MÉTODO & & \\
\hline MÉDIO & & & OUTRO & & \\
\hline GERAL & & & RECURSO DIDÁTICO & & \\
\hline
\end{tabular}


Lista das IES identificadas nos trabalhos por ordem decrescente de produção

UNIVERSIDADE DE SÃO PAULO - USP

UNIVERSIDADE ESTADUAL DE CAMPINAS - UNICAMP

UNIVERSIDADE FEDERAL FLUMINENSE - UFF

UNIVERSIDADE FEDERAL DE MINAS GERAIS - UFMG

UNIVERSIDADE FEDERAL RURAL DE PERNAMBUCO - UFRPE

UNIVERSIDADE DE BRASÍLIA - UnB

UNIVERSIDADE ESTADUAL DO RIO DE JANEIRO - UERJ

UNIVERSIDADE FEDERAL DO RIO DE JANEIRO - UFRJ

UNIVERSIDADE ESTADUAL PAULISTA JÚLIO DE MESQUITA - UNESP

UNIVERSIDADE FEDERAL DE SERGIPE - UFS

UNIVERSIDADE FEDERAL DE GOIÁS - UFG

CENTRO FEDERAL DE EDUCAÇÃO TECNOLÓGICA DE QUÍMICA : CEFETQ -NILÓPOLIS UNIVERSIDADE FEDERAL DE SÃO CARLOS - UFSCAR

UNIVERSIDADE FEDERAL VIÇOSA - UFV

UNIVERSIDADE FEDERAL DE PERNAMBUCO - UFPE

UNIVERSIDADE ESTADUAL DE LONDRINA - UEL

UNIVERSIDADE ESTADUAL DO SUDOESTE DA BAHIA - UESB

UNIVERSIDADE CATÓLICA DE BRASÍLIA - UCB

UNIVERSIDADE FEDERAL DE UBERLÂNDIA - UFU

UNIVERSIDADE FEDERAL DA BAHIA - UFBA

UNIVERSIDADE ESTADUAL DO NORTE FLUMINENSE - UENF

UNIVERSIDADE DE SANTA CRUZ DO SUL - UNISC

UNIVERSIDADE FEDERAL RURAL DO RIO DE JANEIRO - UFRRJ

UNIVERSIDADE FEDERAL DO RIO GRANDE DO SUL - UFRGS

UNIVERSIDADE FEDERAL DO RIO GRANDE DO NORTE - UFRN

UNIVERSIDADE FEDERAL DO PARANÁ - UFPR

UNIVERSIDADE FEDERAL DO MATO GROSSO DO SUL - UFMS

UNIVERSIDADE ESTADUAL DE MARINGÁ - UEM

UNIVERSIDADE FEDERAL DE SANTA CATARINA - UFSC

PONTIFÍCIA UNIVERSIDADE CATÓLICA: PUC - RJ

UNIVERSIDADE REGIONAL DO NOROESTE DO ESTADO DO R. GRANDE DO SUL - UNIJUÍ

UNIVERSIDADE METODISTA DE PIRACICABA - UNIMEP

UNIVERSIDADE FEDERAL DO CEARÁ - UFC

UNIVERSIDADE DO VALE DO RIO VERDE - UNINCOR

FUNDAÇÃO DE ENSINO SUPERIOR DE SÃO JOÃO DEL REI - FUNREI

UNIVERSIDADE FEDERAL PIAUÍ - UFPI

UNIVERSIDADE ESTADUAL DO OESTE DO PARANÁ - UNIOESTE

UNIVERSIDADE FEDERAL DE RORAIMA - UFRR

UNIVERSIDADE ESTADUAL DO CENTRO-OESTE DO PARANÁ - UNICENTRO

FUNDAÇÃO UNIVERSIDADE FEDERAL DO RIO GRANDE - FURG

FACULDADES INTEGRADAS DO VALE DO RIBEIRA - FIVR

FACULDADE DE FILOSOFIA, CIÊNCIAS E LETRAS DO ALTO SÃO FRANCISCO - FASF

CENTRO FEDERAL DE EDUCAÇÃO TECNOLÓGICA DE BAMBUÍ - CEFET-BAMBUÍ

UNIVERSIDADE REGIONAL INTEGRADA - URI

UNIVERSIDADE REGIONAL DE BLUMENAU - FURB

UNIVERSIDADE FEDERAL DO MARANHÃO - UFMA

UNIVERSIDADE ESTADUAL DE PONTA GROSSA - UEPG

UNIVERSIDADE DO SUL DE SANTA CATARINA - UNISUL

UNIVERSIDADE DO NORTE DO PARANÁ - UNOPAR

UNIVERSIDADE DO ESTADO DA BAHIA - UNEB

UNIVERSIDADE DE MOGI DAS CRUZES - UMC

FACULDADE DE PAULÍNIA - FACP 
FACULDADE DE MEDICINA DO ABC - FMABC

UNIVERSIDADE SÃO FRANCISCO - USF 2

UNIVERSIDADE PARA O DESENVOLVIMENTO DO ESTADO E REGIÃO DO PANTANAL UNIDERP

UNIVERSIDADE METROPOLITANA DE SANTOS - UNIMES 2

UNIVERSIDADE FEDERAL DE SANTA MARIA - UFSM 2

UNIVERSIDADE ESTADUAL DE SANTA CRUZ - UESC 2

UNIVERSIDADE DO VALE DO RIO DOS SINOS - UNISINOS 2

UNIVERSIDADE DO SAGRADO CORAÇÃO - USC 2

UNIVERSIDADE DO GRANDE RIO - UNIGRANRIO 2

UNIVERSIDADE DE FORTALEZA - UNIFOR 2

UNIVERSIDADE CATÓLICA DE PERNAMBUCO - UNICAP 2

UNIVERSIDADE CATÓLICA DE GOIÁS - UCG 2

INSTITUTO MANCHESTER PAULISTA DE ENSINO SUPERIOR - IMAPES 2

FUNDAÇÃO EDUCACIONAL DE BARRETOS - FEB 2

FACULDADES INTEGRADAS MARIA IMACULADA - FIMI 2

FACULDADE DE TECNOLOGIA E CIÊNCIAS - FACITE 2

FACULDADE DE MINAS - FAMINAS 2

CENTRO UNIVERSITÁRIO DE PATOS DE MINAS - UNIPAM 2

CENTRO REGIONAL UNIVERSITÁRIO DE ESPIRÍTO SANTO DO PINHAL - CREUPI 2

CENTRO FEDERAL DE EDUCAÇÃO TECNOLÓGICA DE CAMPOS - CEFET-CAMPOS 2 CENTRO FEDERAL DE EDUCAÇÃO TECNOLÓGICA CELSO SUCKOW DA FONSECA: CEFETRJ

UNIVERSIDADE SEVERINO SOMBRA - USS

UNIVERSIDADE SÃO JUDAS TADEU - USJT

UNIVERSIDADE SÃO CAMILO - ES: FAFI

UNIVERSIDADE SALGADO DE OLIVEIRA - UNIVERSO

UNIVERSIDADE PRESBITERIANA MACKENZIE - MACKENZIE

UNIVERSIDADE PAULISTA - UNIP

UNIVERSIDADE LUTERANA DO BRASIL - ULBRA

UNIVERSIDADE FEDERAL DO PARÁ - UFPA

UNIVERSIDADE FEDERAL DE SÃO JOÃO DEL REI - UFSJ

UNIVERSIDADE FEDERAL DE PELOTAS - UNIPEL

UNIVERSIDADE FEDERAL DE JUIZ DE FORA - UFJF

UNIVERSIDADE ESTADUAL DE MONTES CLAROS - UNIMONTES

UNIVERSIDADE ESTADUAL DE FEIRA DE SANTANA - UEFS

UNIVERSIDADE ESTÁCIO DE SÁ - UNESA

UNIVERSIDADE DO ESTADO DE MINAS GERAIS - UEMG

UNIVERSIDADE DE PERNAMBUCO - UPE

UNIVERSIDADE DE MARÍLIA - UNIMAR

UNIVERSIDADE DE FRANCA - UNIFRAN

UNIVERSIDADE DE BARRA MANSA - UBM

UNIVERSIDADE DA AÇÃO EDUCACIONAL DO PROGRAMA BRASILEIRO DE METROLOGIA

EM QUÍMICA

UNIVERSIDADE CENTRAL PAULISTA - UNICEP

PONTIFÍCIA UNIVERSIDADE CATÓLICA : PUC - RS

INSTITUTO MUNICIPAL DE ENSINO SUPERIOR DE ASSIS - IMESA

FUNDAÇÃO EDUCACIONAL DE CARATINGA - FUNEC

FACULDADE SANTA LÚCIA

FACULDADE POLITÉCNICA DE JUNDIAÍ - FPJ

FACULDADES FEDERAIS INTEGRADAS DE DIAMANTINA - FAFEID

FACULDADE DE FORMAÇÃO DE PROFESSORES DE NAZARÉ DA MATA - FFPNM

FACULDADE DE FILOSOFIA, CIÊNCIAS E LETRAS DE PATOS DE MINAS - FAFIPA 1

FACULDADE DE FILOSOFIA, CIÊNCIAS E LETRAS DE GUAXUPÉ -FAFIG 1

FACULDADE DE FILOSOFIA, CIÊNCIAS E LETRAS DE FORMIGA - FAFI 1 
FACULDADE DE ENGENHARIA QUÍMICA DE LORENA - FAENQUIL 1

FACULDADE DE CIÊNCIAS HUMANAS E SOCIAIS DE IGARASSU - FACIG 1

FACULDADE DE AMERICANA - FAM 1

ESCOLA DE FARMÁCIA E ODONTOLOGIA DE ALFENAS - UNIFAL 1

CENTRO UNIVERSITÁRIO UNIVATES - UNIVATES 1

CENTRO UNIVERSITÁRIO DO LESTE DE MINAS GERAIS $\quad 1$

CENTRO UNIVERSITÁRIO DE LAVRAS - UNILAVRAS 1

CENTRO UNIVERSITÁRIO DE BARRA MANSA - UBM 1

CENTRO UNIVERSITÁRIO DA CIDADE - UNIVERcidade 1

CENTRO FEDERAL DE EDUCAÇÃO TECNOLÓGICA DO PARANÁ - CEFET- PR 1

não menciona $\quad 31$ 